\title{
Design, Construction, and Qualificataion of the West Virginia University Environmental Wind Tunnel
}

\author{
Stephen N. Rotruck
}

Follow this and additional works at: https://researchrepository.wvu.edu/etd

\section{Recommended Citation}

Rotruck, Stephen N., "Design, Construction, and Qualificataion of the West Virginia University Environmental Wind Tunnel" (2016). Graduate Theses, Dissertations, and Problem Reports. 6534. https://researchrepository.wvu.edu/etd/6534

This Thesis is protected by copyright and/or related rights. It has been brought to you by the The Research Repository @ WVU with permission from the rights-holder(s). You are free to use this Thesis in any way that is permitted by the copyright and related rights legislation that applies to your use. For other uses you must obtain permission from the rights-holder(s) directly, unless additional rights are indicated by a Creative Commons license in the record and/ or on the work itself. This Thesis has been accepted for inclusion in WVU Graduate Theses, Dissertations, and Problem Reports collection by an authorized administrator of The Research Repository @ WVU. For more information, please contact researchrepository@mail.wvu.edu. 


\title{
Design, Construction, and Qualification of the West Virginia University Environmental Wind Tunnel
}

\author{
Stephen N. Rotruck
}

Thesis submitted

to the Benjamin Statler College of Engineering and Mineral Resources at West Virginia University

In partial fulfillment of the requirements for the degree of

Master of Science in

Mechanical Engineering

Patrick H. Browning, Ph.D., Chair

Wade Huebsch, Ph.D.

John Kuhlman, Ph.D.

Department of Mechanical and Aerospace Engineering

Morgantown, West Virginia

2016

Keywords: Environmental Wind Tunnel, Boundary Layer Wind Tunnel Copyright 2016 Stephen N. Rotruck 


\title{
Abstract \\ Design, Construction, and Qualification of the West Virginia University Environmental Wind Tunnel
}

\author{
Stephen N. Rotruck
}

The interaction with the planetary atmosphere is an unavoidable fact when dealing with problems related to aerodynamic studies within the confines of the planet. These include flow effects on bridges, buildings, and various terrain types. Researchers look for more realistic approaches to modeling the complex behavior of the turbulent atmosphere. Environmental wind tunnels (EWTs) were specifically developed to meet this need.

Using parts donated by Cornell University to West Virginia University, a new EWT was built to allow researchers at West Virginia University to begin studying interactions with flow phenomena present in Earth's atmosphere. Problems in the original design required sections of the EWT to the be redesigned, including irregular flow in the contraction, separation of flow in the wide angle diffuser, and a lack of adequately reliable methods of flow control.

Each tunnel section was individually examined and redesigned for optimal performance using a variety of tools. Contraction shapes were compared using computational fluid dynamics to obtain optimal flow entering the fetch. Analytical methods were deployed using techniques developed over the past decades to design a fetch that can accurately simulate planetary boundary layer growth. New controls were added to allow more diverse conditions and increased customization, such as the addition of variable frequency drives to vary test section velocity. Once construction was complete qualification of the EWT was required to model characteristics of the tunnel for future user benefits. This thesis presents an exhaustive qualification method for the newly constructed EWT. 


\section{Dedication}

This thesis dedicated to my mother and father, who never stopped believing in me and encouraged me to pursue my goals without hesitation. 


\section{Acknowledgments}

I would like to acknowledge;

My advisor and committee chair, Dr. Patrick Browning, for his willingness to go to bat for me. His hours spent working with me to make this project come to fruition.

My committee members, Dr. Wade Huebsch and Dr. John Kuhlman, for their input and guidance.

The Department of Mechanical and Aerospace Engineering, for giving me the resources to allow my ideas to become reality.

My mentor, Ian Raun, who spent hours teaching me the way around a toolbox and anything mechanical. Also, for inspiring me to pursue a career in engineering.

Lastly, I would like to thank all my friends and family. 


\section{Contents}

$\begin{array}{ll}\text { Abstract } & \text { i }\end{array}$

$\begin{array}{ll}\text { Dedication } & \text { iii }\end{array}$

Acknowledgments $\quad$ iv

Table of Contents $\quad$ v

List of Figures $\quad$ ix

List of Tables $\quad$ xii

Nomenclature $\quad$ xiii

1 Introduction $\quad 1$

1.1 Problem Statement . . . . . . . . . . . . . . . . . 4

1.2 Thesis Organization . . . . . . . . . . . . . . . . 5

2 Review of Relevant Literature $\quad 6$

2.1 Planetary Boundary Layers . . . . . . . . . . . . . . . . . . . 6

2.1 .1 Thermal Interaction . . . . . . . . . . . . . . . . 8

2.1.2 Surface Friction Interaction _. . . . . . . . . . . . . . . . 9

2.1.3 Power Law Estimation . . . . . . . . . . . . . . . . 12

2.1.4 Turbulence Characteristics . . . . . . . . . . . . . . . 13 
2.2 Applications to Environmental Wind Tunnels . . . . . . . . . . . . . 15

2.3 Current Research using EWTs . . . . . . . . . . . . . . . . . . . . . 18

$\begin{array}{llr}3 & \text { Design } & 20\end{array}$

3.1 Settling Chamber . . . . . . . . . . . . . . . . . . . 21

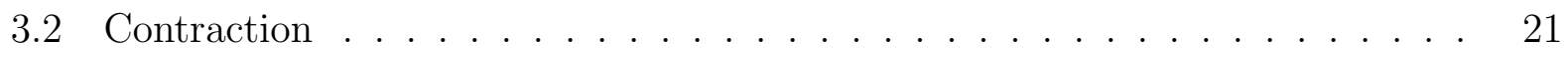

3.2 .1 Contraction Ratio . . . . . . . . . . . . . . . . . . . . 22

3.2 .2 Wall Shape . . . . . . . . . . . . . . . . . . . . 23

3.3 Fetch . . . . . . . . . . . . . . . . . . . . . . . 29

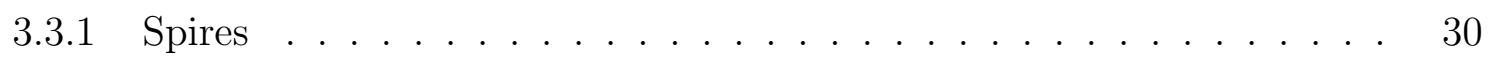

3.3 .2 Roughness Elements . . . . . . . . . . . . . . . . . . . . 32

3.3 .3 Adjustable Roof . . . . . . . . . . . . . . . . . . . . . 35

3.3 .4 Windows . . . . . . . . . . . . . . . . . . 36

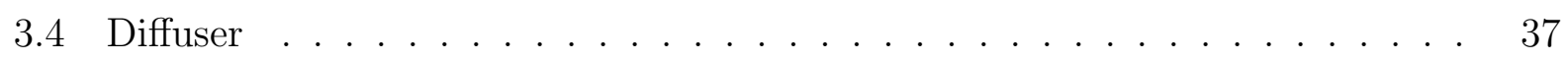

$3.4 .1 \quad$ Diffuser Inlet $\ldots \ldots \ldots \ldots$

3.4 .2 Low Divergence Angle Diffuser . . . . . . . . . . . . . . . . . . 41

3.5 Drive System . . . . . . . . . . . . . . . . . . . . . . . 44

3.6 Complete Tunnel . . . . . . . . . . . . . . . . . . . . 44

4 Performance Estimations $\quad 46$

4.1 Pressure Loss per Section $\ldots \ldots \ldots$. . . . . . . . . . . . 46

4.1 .1 Settling Chamber . . . . . . . . . . . . . . . . 46

4.1 .2 Contraction . . . . . . . . . . . . . . . 47

$4.1 .3 \quad$ Fetch . . . . . . . . . . . . . . . . . . . . . . . 49

4.1 .4 Test Section . . . . . . . . . . . . . . . . . . . . 49

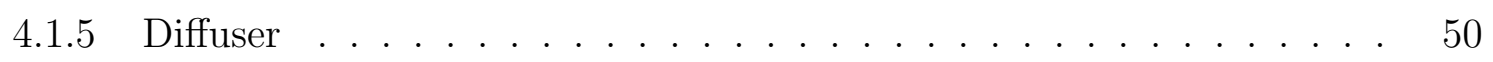

4.2 EWT Total Pressure Loss _ . . . . . . . . . . . . . . . . . . . . 52

4.2.1 Fan Power Required for Steady Operation . . . . . . . . . . . . 53 
4.2.2 Variation of Test Section Velocity . . . . . . . . . . . . 54

5 WVU EWT Construction $\quad 55$

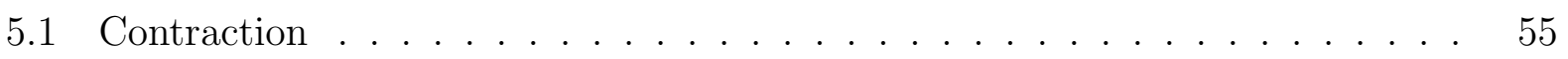

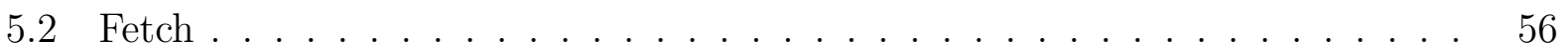

5.3 Testing Room . . . . . . . . . . . . . . . . . . . . . 59

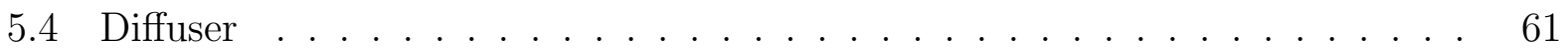

5.5 Drive System . . . . . . . . . . . . . . . . . . . . . . 62

6 Qualification Methods $\quad 65$

6.1 Measured Parameters for Qualification ................ 65

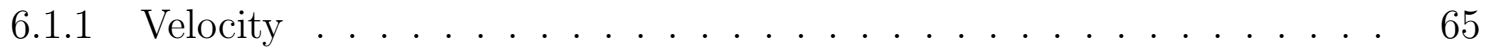

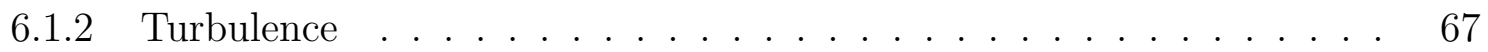

6.2 Recommendations for Qualification of WVU EWT . . . . . . . . . . 68

6.2 .1 Measuring Velocity . . . . . . . . . . . . . . . 69

6.2.2 Measuring Turbulence .................... 71

6.2.3 Interpreting Hot-Film Probe Signal . . . . . . . . . . . . . . . 71

6.2.4 Calibration of Probes . . . . . . . . . . . . . . . 72

6.2.5 Traverse System . . . . . . . . . . . . . . . . 73

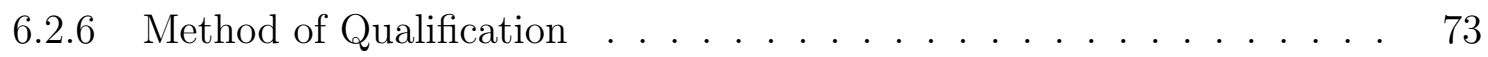

7 Conclusions and Recommendations $\quad 77$

7.1 Future of EWT . . . . . . . . . . . . . . . . 78

$\begin{array}{ll}\text { Bibliography } & 80\end{array}$

Appendix A: Ceiling Displacement for Zero Pressure Gradient 92

Appendix B: Example Ceiling Displacement $\quad 92$

$\begin{array}{ll}\text { Appendix C: Moody Chart } & 92\end{array}$ 
Appendix E: IGV Data Reported by Buffalo Forge 


\section{List of Figures}

1.1 Top view of original Cornell EWT, including labels of each section [1] . . . . 2

1.2 Open jet similar to the test section of the EWT $[2] \ldots \ldots$

2.1 Parts of atmospheric boundary layer, adapted from $[8] \ldots \ldots$

2.2 Boundary layer evolution over a day-night cycle $[6] \ldots \ldots$. . . . . . . . . . . 8

2.3 Data collected by Wei and Willmarth [13], with line fitted by logarithmic law 10

2.4 Mean wind profiles over uniform terrains of differing roughness $[20]$. . . . 12

2.5 Turbulence energy spectrum $[8] \ldots \ldots$. . . . . . . . . . . . 14

2.6 Spire and floor roughness layout $[30] \ldots \ldots$. . . . . . . . . . 18

3.1 Isometric view rendering of complete EWT . . . . . . . . . . . . . . 20

3.2 Original Cornell EWT contraction [1] . . . . . . . . . . . . . . . 22

3.3 Example S-Shape contraction $[44] \ldots \ldots$. . . . . . . . . . . . . 24

3.4 Cornell elliptical contraction mesh . . . . . . . . . . . . . . . . . 25

3.5 WVU s-shape contraction mesh . . . . . . . . . . . . . . 25

3.6 Cornell contraction outlet velocity profile . . . . . . . . . . . . . . 26

3.7 WVU contraction outlet velocity profile . . . . . . . . . . . 26

3.8 Development of the velocity profile through Cornell contraction . . . . . . . 27

3.9 Isometric view of redesigned "S-shape" contraction . . . . . . . . . . . . 28

3.10 Top view of redesigned "S-shape" contraction . . . . . . . . . . . . . . 28

3.11 Side view of redesigned "S-shape" contraction . . . . . . . . . . . . . . 29 
3.12 Spire and roughness element configuration $[30] \ldots \ldots$. . . . . . . . . 30

3.13 Graphical representation of estimated spire height (in inches) . . . . . . . . . 31

3.14 Graphical representation of estimated base width (in inches) . . . . . . . . 32

3.15 Spire Design (all dimensions in inches) . . . . . . . . . . . . . . . 33

3.16 Graphical representation of the Wooding formula with elements 6 inches apart (all dimensions in inches $) \ldots \ldots \ldots 34$

3.17 Fetch floor layout (all dimensions in inches) $\ldots \ldots . \ldots . . \ldots 34$

3.18 Adjustable ceiling render; the nuts on threaded rods can be tightened and loosened to raise and lower each section independently to achieve zero pressure gradient. The nuts are held in place by additional lock nuts above and below each cross-support . . . . . . . . . . . . . . . . . . 35

3.19 Example fetch ceiling adjustment $\ldots \ldots \ldots \ldots$

3.20 Side view of the fetch . . . . . . . . . . . . . . . . 37

3.21 Isometric view of the fetch . . . . . . . . . . . . . . . . 37

3.22 Open jet similar to the test section of the EWT $[2] \ldots \ldots . \ldots . \ldots 39$

3.23 Open jet mass core expansion through the test section of the EWT (in inches) 40

3.24 Original wide angle diffuser design $[1] \ldots \ldots 4 \ldots$

3.25 WVU low angle diffuser core . . . . . . . . . . . . . . . . . 42

3.26 Side view rendering of WVU low angle diffuser $\ldots \ldots \ldots$. . . . . . . 43

3.27 Top view rendering of WVU low angle diffuser $\ldots \ldots$. . . . . . . . . 43

3.28 Isometric view rendering of WVU low angle diffuser, viewed from outlet . . 43

3.29 Isometric view rendering of complete EWT . . . . . . . . . . . . 45

3.30 Side view rendering of complete EWT $\ldots \ldots \ldots . \ldots \ldots$

5.1 One side of the contraction; four were created and attached to each other to create the shape of the contraction $\ldots \ldots \ldots \ldots \ldots$

5.2 Contraction side placed at location on the EWT before installation $\ldots \ldots 56$

5.3 First three main supports for the fetch section of the nine total are placed . 56 
5.4 All main fetch supports in place, with one interior wall installed . . . . . . . 57

5.5 Both side walls were installed with the first removable floor section placed inside for sizing verification . . . . . . . . . . . . . . . 57

5.6 Areas where window assembly will be placed cut into wall. Removable floor completed and installed . . . . . . . . . . . . . . . 58

5.7 Areas where window assembly will be placed cut into wall. Removable floor

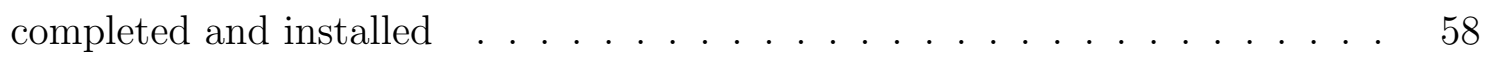

5.8 First short wall in testing room before being stood vertical . . . . . . . . . . 59

5.9 Long wall and location of diffuser inlet being constructed . . . . . . . . . . 59

5.10 Main testing room walls complete . . . . . . . . . . . . . 60

5.11 Completed main testing room, ceiling now constructed. Electrical and drywall were next step at this point . . . . . . . . . . . . . . . . 60

5.12 Main support for diffuser installed . . . . . . . . . . . . . . . . . 61

5.13 Diffuser shell being installed . . . . . . . . . . . . . . . . . . 62

5.14 Diffuser walls installed and corners reinforced . . . . . . . . . . . . 62

5.15 When the frame that hold the motors was transported it was cut in half. Welding the frame back together was required before motors could be placed back in it. . . . . . . . . . . . . . . . . . . . 63

5.16 The frame as attached the floor using anchors that were implanted into the

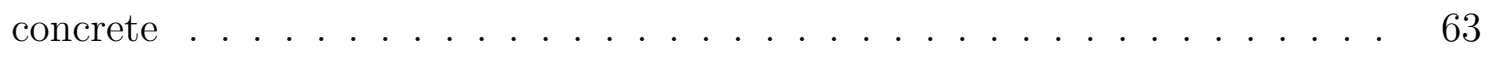

5.17 All motors installed and secured to the frame . . . . . . . . . . . . 64

6.1 Example hot-wire anemometer calibration curve . . . . . . . . . . . 66

6.2 Bridge and amplifier circuit used in CTA systems to measure velocity [55] . . 69

6.3 Example traverse system setup, the vertical arm can be removed when not in

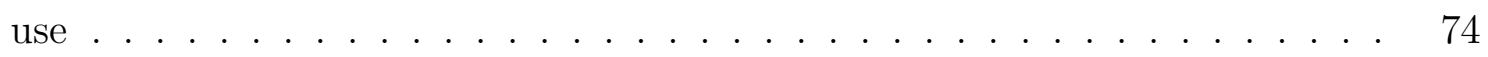

6.4 Example average center line profile reported for suburban setting . . . . . 76 


\section{List of Tables}

2.1 Roughness height for various terrain types (in meters) [17] . . . . . . . 11

4.1 Pressure coefficient of the contraction at various velocities . . . . . . . . 49

4.2 Pressure coefficient of the diffuser at various velocities . . . . . . . . . . . 51

4.3 Total Pressure coefficients and pressure losses for sections with test section velocity equal to $30 \frac{m}{s} \ldots \ldots \ldots \ldots$

6.1 Recommended settings used for qualification . . . . . . . . . . . . . 74 


\title{
Nomenclature
}

\author{
Abbreviations \\ $A B L$ Atmospheric Boundary Layer \\ $B L \quad$ Boundary Layer \\ EWT Environmental Wind Tunnel \\ $I G V$ Inlet Guide Vanes \\ PBL Planetary Boundary Layer \\ PIV Particle image velocimetry \\ TI Turbulence Intensity \\ $V F D$ Variable frequency drive \\ Symbols \\ $\alpha \quad$ Hellman Exponent \\ $\alpha_{1} \quad$ Expansion angle of constant velcity core region \\ $\alpha_{2} \quad$ Expansion angle of open jet \\ $\bar{U} \quad$ Mean velocity \\ $\beta \quad$ Constant used in spire calculation \\ $\delta \quad$ Boundary layer height in fetch \\ $\eta \quad$ Combined motor and fan efficiency \\ $\kappa \quad$ von Kármán constant \\ $\mu \quad$ Dynamic Viscosity \\ $\Omega \quad$ Angular frequency of planetary rotation \\ $\phi \quad$ Latitude
}




\begin{tabular}{|c|c|}
\hline$\Psi$ & Constant used in spire calculation \\
\hline$\Psi$ & Stability term \\
\hline$\rho$ & Density \\
\hline$\sigma$ & Standard deviation \\
\hline$\tau_{w}$ & Wall shear stress \\
\hline$h$ & Boundary layer height \\
\hline$N$ & Power law Terrain type \\
\hline$\theta$ & Diffuser divergence angle \\
\hline$A_{R}$ & Area ratio \\
\hline$b$ & Base width of spires \\
\hline$c$ & Contraction ratio \\
\hline$C_{f}$ & Skin friction coefficient \\
\hline$D$ & Center-to-center distance \\
\hline$f$ & Coriolis frequency \\
\hline$f$ & Friction Factor \\
\hline$f t$. & feet \\
\hline$g_{c}$ & Conversion factor between mass and lbs, in pound units \\
\hline$h$ & Spire height \\
\hline$k$ & Cube edge dimension \\
\hline$K_{i}$ & Pressue coefficient for each section \\
\hline$L$ & Characteristic length \\
\hline$L$ & Obukhov length \\
\hline$L_{u}$ & Integral Length Scale \\
\hline$P_{s}$ & Static pressure \\
\hline$P_{t}$ & Total pressure \\
\hline$q_{i}$ & Dynamic pressure of section \\
\hline$R(\tau)$ & Autocorrelation between single point seperated by time \\
\hline
\end{tabular}


$R_{u_{1} u_{2}}$ Autocorrelation between two spatially seperate points

Re Reynolds number

$R F \quad$ Reserve Factor

$U \quad$ Characteristic velocity

$u^{\prime}, v^{\prime}, w^{\prime}$ Direction fluctuating velocity

$u_{*} \quad$ Friction velocity

$x_{O H}$ Distance of virtual origin from fetch outlet

$y_{1} \quad$ Expansion distance of constant velcity core region

$y_{2} \quad$ Expansion distance of open jet

$y_{R} \quad$ Expansion distance of mass core of open jet

$z \quad$ Elevation

$z_{0} \quad$ Roughness height

$z_{d} \quad$ Zero-plane displacement

TF Turbulence Factor

\section{Subscripts}

$\begin{array}{ll}A V & \text { Average } \\ C & \text { Contraction } \\ D & \text { Diffuser } \\ e x & \text { Expansion } \\ F & \text { Fetch } \\ f & \text { Frictional } \\ H & \text { Hydraulic diameter } \\ I & \text { Inlet } \\ O & \text { Outlet } \\ S C & \text { Settling Chamber } \\ T S & \text { Testing section } \\ \text { eff } & \text { Effective }\end{array}$




\section{Chapter 1}

\section{Introduction}

Engineers have always searched for better ways to experimentally test theories and hypotheses. Wind tunnels have emerged over the past century as a key tool for engineers to study fluid flow phenomena. As fluid experiments became even more focused on specialized fields, the need to build different types of wind tunnels for these types of studies became necessary. Vertical tunnels, water tunnels, smoke tunnels, and other specialized tunnels emerged and became common.

The general goal of a standard wind tunnel, is to have the most uniform flow possible for experiments. Designers try to create a tunnel that has low turbulence and little mean flow variation throughout the cross section of the test section. This consistency presents a problem for engineers who wish to test theories that require unsteady and/or non-uniform flow conditions. The use of artificial techniques to create unsteady conditions for testing in normal wind tunnels have been developed over the past decades; however, the wind tunnels were originally designed for a different purpose and accurate simulations were hard to create, even with these new techniques.

An environmental wind tunnel (EWT), or boundary layer tunnel, is specifically designed to simulate boundary layers for testing. The main feature that separates an EWT from a normal tunnel is the inclusion of a fetch. This fetch is a long, enclosed area that allows 
for boundary layers to form and grow as air flows over the surfaces, interacting with floor roughness and other devices placed within the flow. When the air has reached a test section model it has developed into the desired boundary layer profile for the engineer to provide accurate testing.

In 1974, Dr. Robert Ribando wrote a thesis on the design and construction of an EWT at Cornell University in Ithaca, NY. The EWT was developed by Cornell University's Department of Architecture of the College of Architecture, Art, and Planning. It later included participants from Sage Action, Inc. of Dryden, NY, and Sibley School of Mechanical and Aerospace Engineering. The original design goal was to study the interaction between highrise buildings and the local wind environment. Interest outside the Department of Architecture led to participation of the other groups as they recognized the potential of the tunnel as an important research tool [1].

The major components of the Cornell tunnel were a contraction, fetch, test section, diffuser, and fan section, shown in Figure 1.1. The fetch measured 32 feet in length. As the air traveled through this section it developed a turbulent boundary layer. The ceiling height was designed to be adjustable. This served two purposes: it allowed for the zero pressure gradient conditions found in nature, and it also minimized blockage. The neutral setting of the fetch had a cross sectional area of $12 \mathrm{ft}^{2}$. The width was set at 4 feet, and the height at 3 feet.

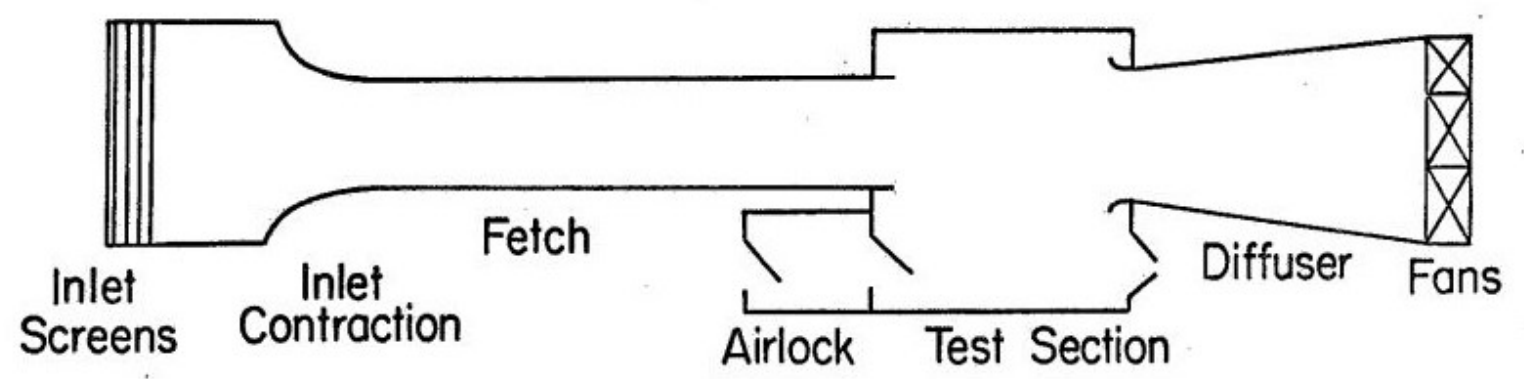

Figure 1.1: Top view of original Cornell EWT, including labels of each section [1]

The test section of the EWT was considered an open jet design, shown in Figure 1.2. 
The air exiting the fetch would be allowed to naturally expand. The flow would then enter a diffuser. This diffuser allowed for smooth transition from the test section to the fans/inlet vanes.

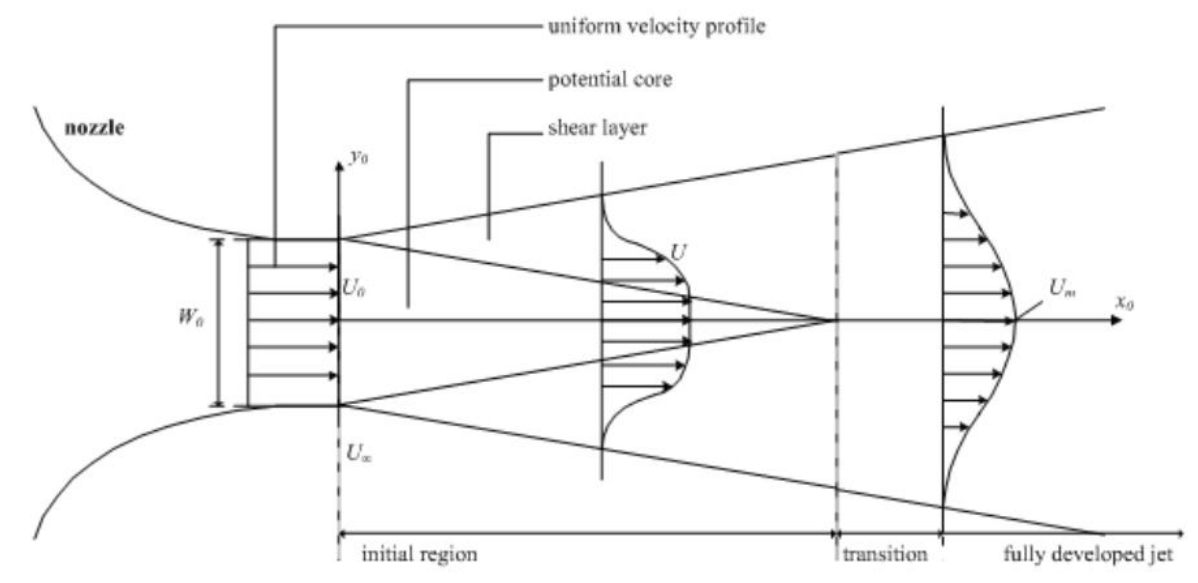

Figure 1.2: Open jet similar to the test section of the EWT [2]

The EWT was powered by six 2-Speed 15hp 3-Phase motors arranged in a $2 \times 3$ matrix. Each motor was fitted with a Buffalo Forge Type S Adustax, Arrangement 4, Vane axial fans. Additionally, each fan had independent inlet guide vanes (IGV) installed that would allow for further tuning of the flow. It was estimated that at a low speed (1700 RPM) with the IGVs fully opened, the maximum wind speed was $2.0 \mathrm{in} . \mathrm{H}_{2} \mathrm{O}$, and at high speed (3500 $\mathrm{RPM}$ ), the maximum wind speed could be 2.8 in. $\mathrm{H}_{2} \mathrm{O}$

The tunnel was in service until August 2012. During its service, the EWT was used in diverse areas of research, from small-scale soil surface evaporative loses [3] to wind loading on off-shore platforms [4]. The EWT was also used for projects that would normally not be associated with an EWT; for example, the last project the tunnel was used for was a BMW motorcycle engine air cooling test. When the time came for the tunnel to be decommissioned, the useable parts, such as the contraction, and motor assembly, were donated to West Virginia University. 


\section{$1.1 \quad$ Problem Statement}

In Fall 2012, Cornell University donated parts from their decommissioned environmental wind tunnel (EWT) to West Virginia University (WVU). Plans were set into motion to rebuild the EWT with updated technology. Unfortunately, from the original tunnel, few parts were salvageable due to the nature of the building materials, which contained hazardous materials. Only the drive system was able to be recovered in working form for reconstruction in Morgantown, WV. Therefore, the rest of the EWT, including the contraction, fetch, and diffuser, needed to be rebuilt from scratch. The original design of the EWT was constrained by size and as a result the tunnel had flow anomalies that needed to be addressed. These included, but were not limited to, flow separation in the exit diffuser, improper performance of the contraction, and limited speeds of the EWT. This required a redesign of these key components from the original EWT's design, for optimal performance. Once construction was completed the EWT then needed to be qualified so that important characteristics could be documented for future use of the EWT, such as velocity profile and turbulence in the test section. This data will allow for users to recreate accurate boundary layers for their testing needs. 


\subsection{Thesis Organization}

Chapter 2 deals with relevant literature that is related to the theories and methods behind the design of an EWT. This section includes atmospheric boundary layer theory, how turbulence plays a role in the environment, and techniques developed for simulating boundary layers.

Chapter 3 gives a summary of the design of the improved tunnel. Included in this section is reasoning behind redesign and any relevant analytical calculations needed to simulate an accurate boundary layer.

Chapter 4 gives a summary of the tunnel performance. This section also provides analytical calculations on certain measurements of the tunnel's performance, such as pressure loss and whether certain key components of the Cornell EWT are suitable for use on the new EWT after its redesign.

Chapter 5 includes summary of construction. Figures of construction progress are shown and techniques used to construct the EWT are outlined for each of the sections.

Chapter 6 includes data collection and analysis techniques for qualification of the EWT. Qualification is needed to allow the users of the tunnel to understand important characteristics for future experimentation, such as turbulence intensity and boundary layer velocity profiles.

Chapter 7 offers conclusions of the thesis in regards to qualifications and redesign of the EWT. The chapter also includes a summary relevant data, design features, and recommendations for further research that may stem from the construction of this EWT. 


\section{Chapter 2}

\section{Review of Relevant Literature}

\subsection{Planetary Boundary Layers}

Boundary layers (BL) have been studied at length throughout the $20^{\text {th }}$ Century. Ludwig Prandtl presented an important paper [5] in which he recognized the Navier-Stokes equations could be simplified. He reasoned that inside a boundary layer forces were dominated by viscous effects. The interaction with the boundary body created drag force due to a shear stress that diffused from the surface of the body outward, into the flowing fluid. Meanwhile, in a second flow region outside the boundary layer, the viscosity could be neglected. This ability to neglect the area outside of the boundary layer could be used to create a simple closed form solution of the Navier-Stokes equations for laminar BLs.

There exists a body of research that discusses a specialized type of boundary layer: planetary boundary layer (PBL), or an atmospheric boundary layer (ABL). Entire books have been written on the complex nature of these boundary layers [6], [7], [8], [9].

Figure 2.1 demonstrates the layers of an atmospheric boundary layer. An ABL is divided into two major sections. This division is done to produce more accurate results. In the outer layer or an Ekman layer, first mathematically described by Ekman [10], a force balance is present between turbulent drag, Coriolis force, and pressure gradient force. The inner layer 
or surface layer is the primary region where the flow is affected by a solid structure in which the flow is moving over it. In the case of an ABL, the solid surface would be the planet.

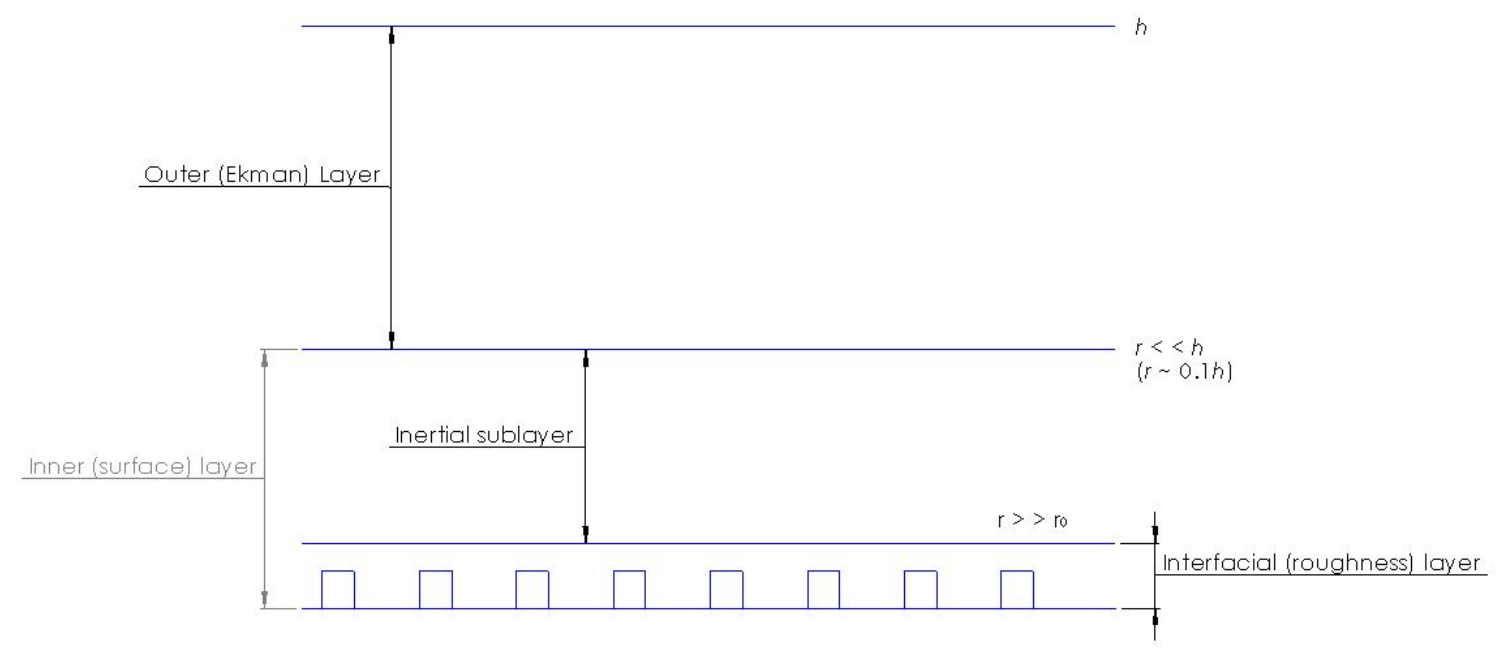

Figure 2.1: Parts of atmospheric boundary layer, adapted from [8]

The surface layer is additionally subdivided into two sections. The inertial sublayer is the larger area within the inner layer; if the distance from the wall is great enough, the flow is not affected by viscosity and can be neglected. The area of the inner layer closest to the surface is the roughness sublayer. In this region opposite of the inertial sublayer, viscosity is a dominating force [11].

At the surface, due to no slip condition, the velocity is zero. As the height increases, the velocity increases to the freestream velocity. When the freestream velocity is reached, it denotes the end of the boundary layer. A common definition of boundary layer thickness is the height at which the velocity is $99 \%$ of the freestream velocity.

An ABL is found in the lowest layer of the Earth's atmosphere, the troposphere, with a BL height of 1-2 km above the surface of the Earth. Within the troposphere, two main forms of surface-to-air interactions occur, which are thermal and mechanical. The combination of these two complex interactions govern how the ABL behaves [11]. 


\subsubsection{Thermal Interaction}

The thermal interaction is a result of the heating and cooling of the Earth's surface. Heat is added to the PBL through sensible heating, radiative flux divergence, horizontal advection, and entrainment. Throughout the day the Earth's surface heats up and emits this heat into the atmosphere. Figure 2.2 shows the evolution of the ABL over a day in local time $[6]$.

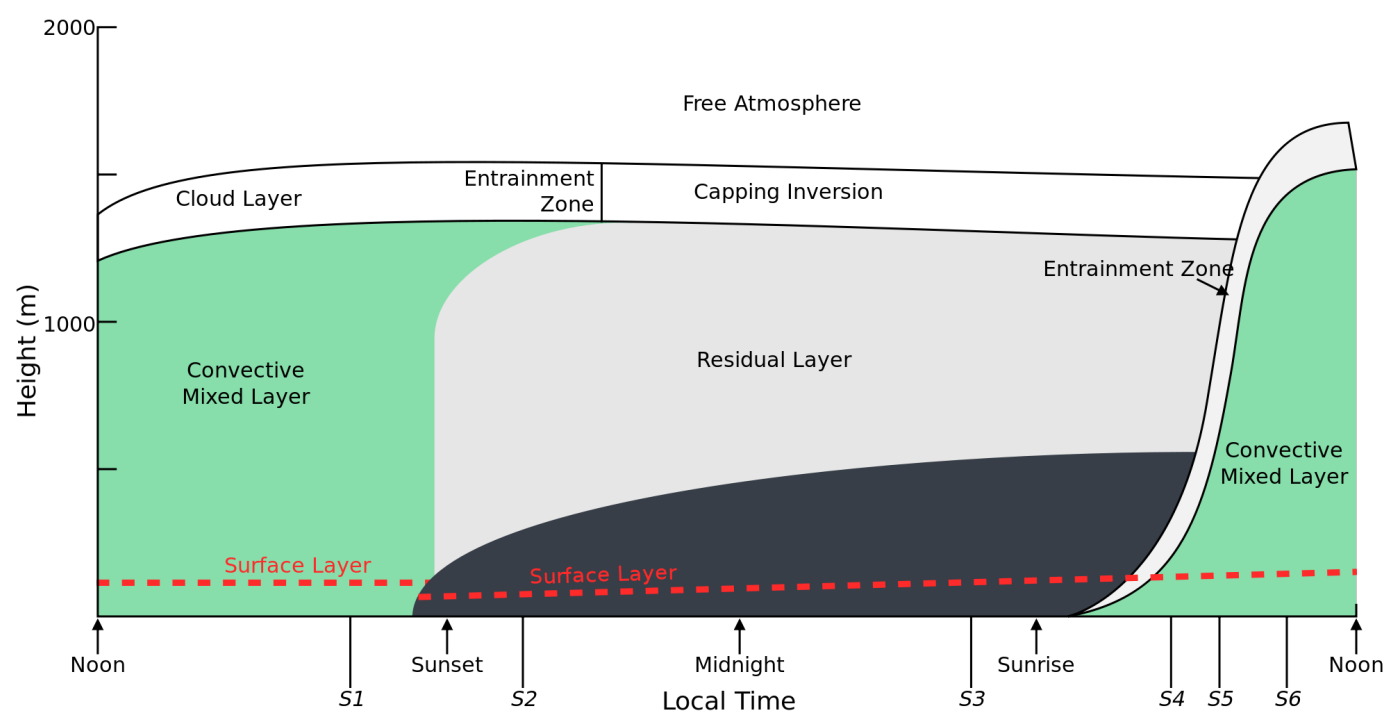

Figure 2.2: Boundary layer evolution over a day-night cycle [6]

Beginning at around sunrise, surface heating creates turbulent eddies, producing a convective mixed layer. The mixed layer continues to grow until late morning. After sunset, the cooling creates a stable, cool BL shown in black in the figure. Above the stable BL is the residual layer, which is the leftovers of the mixed layer developed during the day. During the entire day the thin surface layers' vertical fluxes are nearly constant. The process is called the diurnal cycle.

Under strong wind conditions, the ABL can be treated as neutrally stable and adiabatic with most thermal effects being suppressed. The wind speeds are also considerably lower than the speed of sound and hence the entire flow is considered incompressible [12]. This is further justified by the fact that the mean motion is (mainly) confined to the horizontal 
planes while the mean density is mainly only dependent on elevation.

\subsubsection{Surface Friction Interaction}

The mechanical interaction comes from the air passing over the surface and creating friction. This friction causes shearing of the wind and creates turbulence. With the thermal interaction absent, the $\mathrm{ABL}$ is considered to be neutral. If the $\mathrm{ABL}$ is neutral, a logarithmic law velocity profile $\bar{U}(z)$ using the friction velocity, $u_{*}$, and height, $z$, can describe the profile of the boundary layer.

$$
u_{*}=\sqrt{\frac{\tau_{w}}{\rho}}
$$

And the wall at the ground shear stress, $\tau_{w}$, shown below

$$
\tau_{w}=\mu\left(\frac{d \bar{U}}{d y}\right)_{y=0}
$$

At the zero plane displacement, the Reynolds Stress is at its maximum, and the surface shear stress is transferred through the surface layer. Therefore, the friction velocity can be extended to the Equation 2.3:

$$
u_{*}=\sqrt{-\overline{\left(u^{\prime} v^{\prime}\right)}}
$$

Data for the profile of the boundary layer has been experimentally found numerous times. Figure 2.3 shows example data collected from Wei and Willmarth [13]. The log-linear line

describes the logarithmic law given by Equation 2.4 below. When $\frac{\bar{U}}{u_{*}}$ is plotted versus Reynolds number (Re), the points fall on a single curve, a straight line over a range of two orders of magnitude in $z$.

$$
\frac{\bar{U}(z)}{u_{*}}=A \ln \frac{u_{*} z}{\nu}+B
$$




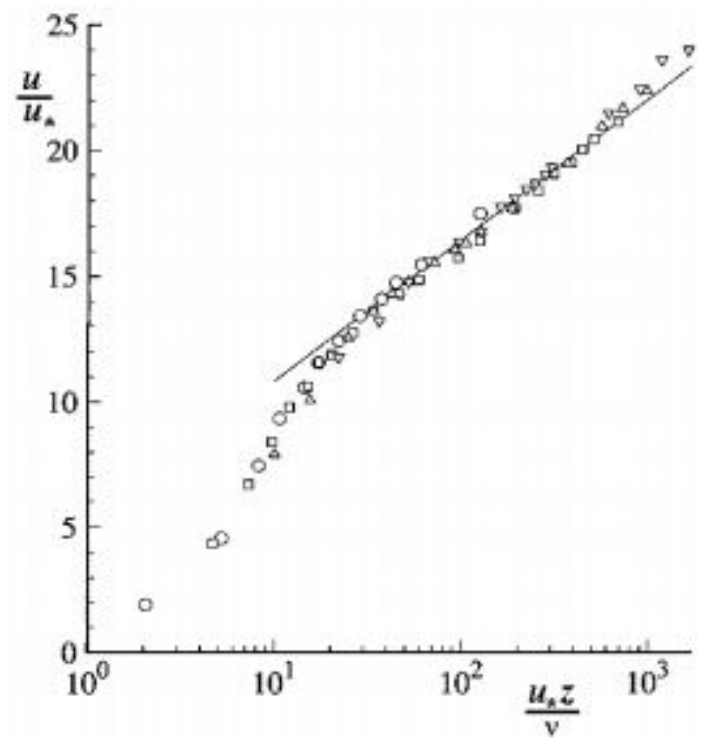

Figure 2.3: Data collected by Wei and Willmarth [13], with line fitted by logarithmic law

The variables $\mathrm{A}$ and $\mathrm{B}$ were determined through experimental means. It has been established that $\mathrm{A}=2.44$ and $\mathrm{B}=5.2$ within a $5 \%$ error for smooth walls [14]. Equation 2.5 includes these terms as with $\frac{1}{A}=\kappa=0.41$, which is known as the Von Kármán constant. The value of the Von Kármán constant was first experimentally found by Theodore von Kármán's student J. Nikurade to be 0.40. Later Coles [15] discovered it was closer to 0.41. Over the years the value is still debated and reported between 0.32 to 0.65 and is still accepted to be about 0.40 [16]. For this thesis, the value is considered to be 0.41 .

When the logarithmic law is written with dimensions, the velocity profile takes the form shown in Equation 2.5. This equation is the most commonly used form that can be found in textbooks dedicated to ABL study and meteorology.

$$
\bar{U}(z)=\frac{u_{*}}{\kappa} \ln \frac{z-z_{d}}{z_{0}}
$$

Referring to the previous equation, $\mathrm{z}_{d}$ is the zero-plane displacement, or the height at which wind speed is zero. If the velocity at the bottom of the ABL is at the surface, then $z_{d}$ becomes zero and the log law can be simplified to the following equation. 


$$
\bar{U}(z)=\frac{u_{*}}{\kappa} \ln \frac{z}{z_{0}}
$$

This roughness height, $\mathrm{z}_{0}$, is not the average height of the bumps on the surface of the wall, but is a fraction of them. The value of $z_{0}$ is around one-tenth of the height of the bumps [8]. Table 2.1 contains some examples of roughness heights for certain surfaces types, based on various sources.

Table 2.1: Roughness height for various terrain types (in meters) [17]

\begin{tabular}{|c|c|c|c|}
\hline Class & Surface & Description & Roughness height \\
\hline 1 & Sea & Open Sea & 0.0002 \\
2 & Smooth & Mud Flats, snow, little vegetation, no obstacles & 0.005 \\
3 & Open & Flat terrain: few isolated obstacles & 0.03 \\
4 & Roughly Open & Low Crops: occasional large obstacles & 0.1 \\
5 & Rough & High crops: scattered obstacles & 0.25 \\
6 & Very Rough & Orchards, bushes: numerous obstacles & 0.5 \\
7 & Closed & Regular large obstacle coverage (suburban area) & 1.0 \\
8 & Chaotic & City center with high and low rise buildings & $<2$ \\
\hline
\end{tabular}

A term that can be introduced into the logarithmic profile is the stability term, $\Psi$. The stability term is a function of $z, z_{0}$, and $L . L$ is considered to be the Obukhov Length, a length parameter found in the surface layer of the ABL and expressed by using Richardson's criterion for dynamic stability [18]. This length describes how buoyancy affects the turbulent flow later used to develop Monin-Obukhov similarity theory [19]. This term can be added to the logarithmic law to account for this buoyancy, shown in Equation 2.7.

$$
\bar{U}(z)=\frac{u_{*}}{\kappa}\left[\ln \frac{z}{z_{0}}+\Psi\left(z, z_{0}, L\right)\right]
$$

Under neutrally stable conditions, the stability term $\Psi$ drops out and matches the simple logarithmic law in Equation 2.6. This thesis will deal with neutrally stable conditions. 


\subsubsection{Power Law Estimation}

A power law may also be used to model the boundary layer velocity profile. This model was developed in the 1960s, and is usually associated with A.G. Davenport [20]. The model consists of fitting an empirical power law to the velocity profile over the entire thickness, $h$, of the boundary layer. The form of this law can be found in Equation 2.8.

$$
\frac{\bar{U}(z)}{U_{\infty}}=\left(\frac{z}{h}\right)^{\frac{1}{N}}
$$

This equation models the velocity profile up to the gradient height of the boundary layer when it increases monotonically. Like the logarithmic law, the shape of this function is determined by the terrain type or the surface roughness of the body which the flow is passing over. The $N$ value can vary from about 3 for urban areas to 7 for open flat country. Figure 2.4 illustrates the differences between terrain types. Note that in urban terrain the velocity is proportional to $z$ to the power of $\frac{1}{N}$, with $N=2.5$. The inverse of the $N$ value is called the Hellman exponent, $\alpha$.

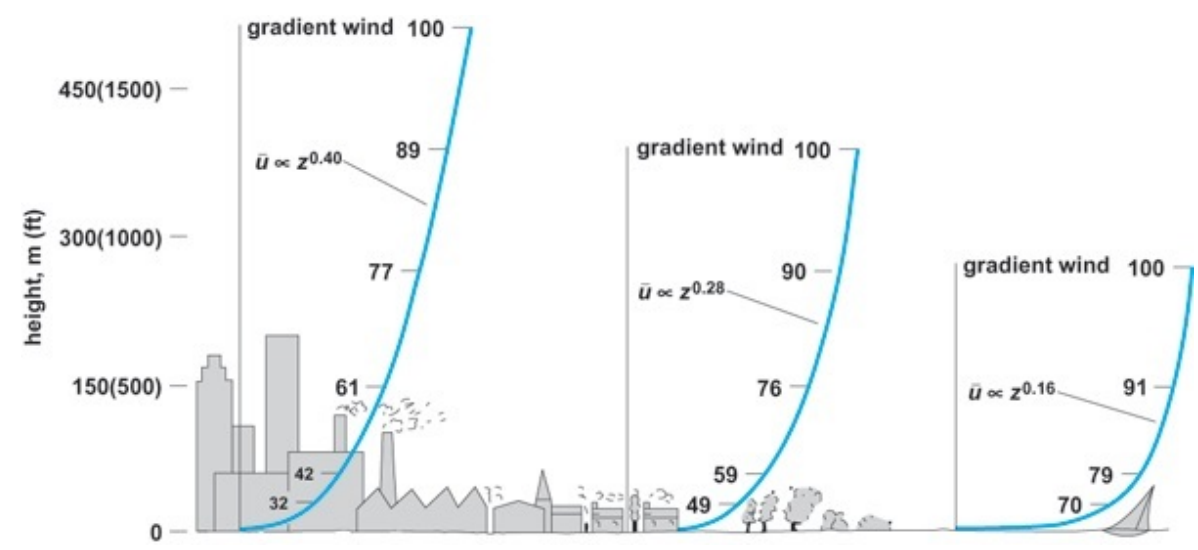

Figure 2.4: Mean wind profiles over uniform terrains of differing roughness [20]

This power law method provides good estimations of wind profiles, and is used in building designs for its accuracy above 10 meters in height. Since most buildings are higher than 10 meters, engineers often use a simpler approach by using a power law estimation over a logarithmic law. It should also be pointed out that neither the power law or logarithmic law 
can be differentiated to evaluate the wall shear stress

\subsubsection{Turbulence Characteristics}

Atmospheric boundary layers are turbulent in nature, exhibiting both temporal and spatial variations. The Reynolds decomposition, shown in Equation 2.9, is frequently used to divide the flow field into mean and fluctuating components. $\bar{U}$ is the time averaged component and $u$ ' the fluctuating component. Equation 2.10 is the ratio of the standard deviation and the mean flow velocity, also known as turbulence intensity, TI.

$$
\begin{gathered}
U=\overline{U(x, y, z)}+u^{\prime}(x, y, z) \\
T I=\frac{\sigma}{U_{\infty}}
\end{gathered}
$$

Problems related to diffusion and the scale and spectrum of turbulence were studied by Taylor [21]. Taylor noted that velocities vary both spatially and temporally. Gusts and eddies could be indicated through correlation measurements. Taylor presented the following hypothesis:

$$
L_{u}=\int_{0}^{\infty} R_{u_{1} u_{2}}(x) d x
$$

$\mathrm{L}_{u}$ is the turbulence length scale in the $\mathrm{u}$ direction and $R_{u_{1} u_{2}}$ is considered a crosscovariance of the fluctuating longitudinal velocity components separated at a spatial distance. Flow disturbances travel with the mean velocity, so Equation 2.11 can be written in the form of Equation 2.12, with $R(\tau)$ being an autocorrelation of the fluctuating longitudinal velocity and the time lag, $\tau$ between measured velocities.

$$
L_{u}=\bar{U} \int_{0}^{\infty} R(\tau) d \tau
$$


Komogorov is most closely tied to the understanding of small scale turbulence, or Komogorov scale turbulence. Komogorov noted that the energy transfer process goes from large to small scales using his similarity theory of turbulence. His hypothesis showed that small scale eddies appear at the high frequency of the spectrum with independent properties and are nearly isotropic, especially at high Re [22]. Conunihan later divided the spectrum into three categories [23], shown in Figure 2.5:

1. Low frequency range, where energy is transferred by inertial forces to higher frequencies. Most turbulent energy is at this range.

2. Intermediate range, or vertical subrange, which follows Kolmogorov $-5 / 3$ law.

3. High frequency range, where viscous forces dominate and dissipation occurs.

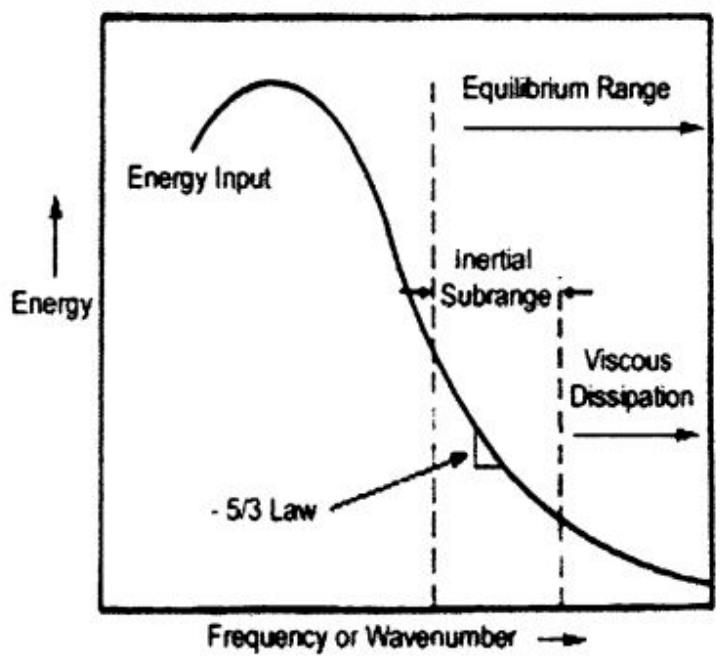

Figure 2.5: Turbulence energy spectrum $[8]$

Turbulence intensity is the most common form of turbulence measure. Turbulence intensity is considered in all three directions, longitudinal $(u)$, lateral $(v)$, and vertical $(w)$. The following equations define turbulence intensity in the $u, v$, and $w$ direction, respectively, in which $\sigma_{u}, \sigma_{v}$, and $\sigma_{w}$ are the standard deviations in their respective direction. 


$$
\begin{gathered}
T I_{u}=\frac{\sigma_{u}}{\bar{U}}=\frac{1}{\bar{U}} \sqrt{\frac{1}{N} \sum_{i=1}^{N}\left(u_{i}-\bar{u}\right)^{2}} \\
T I_{v}=\frac{\sigma_{v}}{\bar{V}}=\frac{1}{\bar{V}} \sqrt{\frac{1}{N} \sum_{i=1}^{N}\left(v_{i}-\bar{v}\right)^{2}} \\
T I_{w}=\frac{\sigma_{w}}{\bar{W}}=\frac{1}{\bar{W}} \sqrt{\frac{1}{N} \sum_{i=1}^{N}\left(w_{i}-\bar{w}\right)^{2}}
\end{gathered}
$$

Note $\mathrm{N}$ is not the terrain types used in boundary layer power law profile. It is the total number of measurements.

\subsection{Applications to Environmental Wind Tunnels}

ABL experiments were first performed in general purpose wind tunnels. Significant effort was devoted to developing appropriate simulation boundary layers in the shortest flow distance. Eventually the methods became very complex and required more specialized focus. From this requirement, the subject of wind engineering was created. Wind engineering combines meteorology, fluid dynamics, structural mechanics and statistical analysis. Generally, these areas of study are separated into four areas [24]

1. Wind Forces of Buildings and Structures, which focuses on forces, moments, deflection, local pressures and velocities,

2. Dynamics of Structures, that includes buffet, flutter, swaying, and breathing,

3. Local Winds, including problems that require measuring mean wind velocities, turbulence, and turbulence energy and scales, and

4. Mass Transport by Winds, which covers soil erosion, pollution, blowing soil, efflux from smokestacks, and diffusion. 
The design of experiment in an EWT tunnel is important to get the most accurate simulation of the interaction with an ABL. Cermak and Plate [25], [26], [27] described five requirements for experiments in EWTs:

1. Proper scaling of buildings and topographic features,

2. Matching Reynolds numbers,

3. Matching Rossby numbers,

4. Kinematic simulation of air flow, boundary layer velocity distribution, and turbulence, and

5. Matching zero pressure gradient.

The Reynolds number usually has a small effect due to the sharp edges of the objects that are being studied. If a problem arises, the Reynolds number can be corrected with the use of tools, such as trip strips. When working with buildings, the Reynolds number is usually based on the characteristic width, as seen by the oncoming flow.

The Rossby number is used to describe the effects of the Earth's rotation on its wind. It is the ratio of inertial to Coriolis force. A small Rossby number indicates a system which is strongly affected by Coriolis forces. A large number is present when inertial forces dominate the system. Matching Rossby numbers are very hard to simulate in a tunnel, but often this has a very small effect. The Rossby number accounts for wind direction change, which is around 5 degrees in 600 feet, and is defined in Equation 2.16:

$$
R o=\frac{U}{L f}
$$

where $U$ and $L$ are characteristic velocity and length scales, respectively, $f$ is the Coriolis frequency $f=2 \Omega \sin (\phi), \Omega$ is the angular frequency of planetary rotation and $\phi$ the latitude.

The most important component of an EWT is the ability to accurately simulate the velocity distribution within the boundary layer. Counihan's goal was to artificially produce a simulation of the Earth's boundary layer in a distance of two to three BL heights. The simulation included important characteristics in each problem to be studied. For instance, 
plume dispersal problems required correct modeling of lateral and vertical turbulence intensity and the spectrum of each component, particularly at the low frequency end. Counihan stated that a grid of horizontal rods and screens produced the desired profiles. However, turbulence properties were not at ideal levels. Most notable was turbulence intensity [28].

To help simulate proper condition, Counihan used a low wall followed by vortex generators that were placed the length of the fetch. These vortex generators were simple 45 degree deltas. The results from this study were unsatisfactory for his goal. Spanwise, the homogeneity was poor, and excessive turbulence intensity was measured close to the wall. He also observed unnatural variation in the Reynolds stress with height at the more upstream positions. He concluded that the vortices being produced by the vortex generators rolled up into the concentrated vortices high above the growing boundary layer. This result caused inefficient mixing. He proposed that a redesign of the generators could yield better results.

Counihan managed to grow a simulated rural boundary layer in a distance of four to five boundary layer heights. The final scheme included a low barrier followed by a set of "elliptic wedge" vortex generators followed by a length of rough ground [28]. Counihan [29] was able to produce an urban simulation with the desired velocity profile. Turbulence properties seemed to be fairly well simulated. Counihan used LEGO bricks fitted to a LEGO baseboard in the wind tunnel to simulate an urban environment. It was considered an adequate representation of an urban boundary layer.

Irwin then developed a method using spires, shown in Figure 2.6 to stimulate boundary layer growth, instead of the elliptical wedge vortex generators. The installation of spires at the beginning of the fetch could be used to create proper mean velocity distribution and turbulence intensity levels. Irwin developed a formula for flat plate spires that taper and could be used to calculate boundary layer created in an EWT fetch section. Using this formula, researchers can calculate the design measurements of the spires to accurately simulate an ABL [30].

Along with spires, roughness elements could be installed on the floor of the fetch to aid 


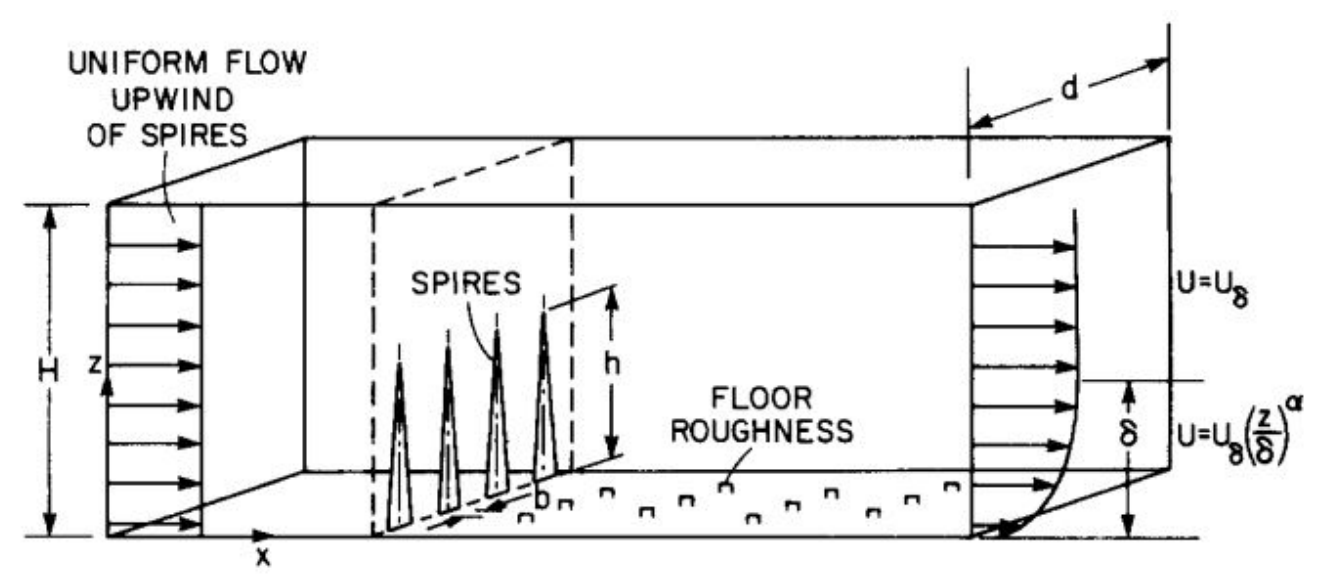

Figure 2.6: Spire and floor roughness layout [30]

in growth of the boundary layer, shown in Figure 2.6. The roughness elements usually are in the form of cubes, but other methods have been used. Irwin also created a method for calculating the dimensions needed for floor roughness elements to attain required boundary layer velocity profile. More on the design of spires will be detailed in Chapter 3 in the fetch design section

The longitudinal pressure gradient usually found in wind tunnels is made worse in the presence of a thick boundary layer. To combat this, an EWT is usually installed with adjustable roof panels in the fetch. This design allows the user to create the zero pressure gradient which is found in the real world, by adjusting the height of the roof through the length of the fetch.

\subsection{Current Research using EWTs}

EWTs provide researchers with an opportunity for use in a vast number of areas that are being studied today:

- Particle Emissions and Transport: particles such as sand moving over distance can be modeled within a EWT. The movement patterns can be studied as particles move over areas, towards residential areas or interactions with the local ecosystem. See: [31], [32] 
- Plume Studies: commercial exhaust from stacks are directly affected by the ABL. Dispersions of pollutants can be modeled from a source, such as a model factory or power plant. This observation also can be extended to the dispersion of hazardous and radioactive exhaust. See: [33], [34], [35]

- Wind Loads on Structures: one of the main reasons behind the creation of EWTs was the study of wind loading on building, bridges, and other structures. Buildings and bridges have increased in height over the years, but EWTs can also be used on smaller buildings for pressure distribution studies. See: [36], [37], [38]

- City Planning:: urban areas are expanding and also increasing in height. Scale models of urban areas can be made and wind currents can be recorded through these urban canyons at a macro level. See: [39]

- Alternative Energy: the need for alternative energy is an ever growing area of research. One type of alternative energy being utilized is wind power. EWTs allow for scale models of these wind farms to be constructed and tested for validation of the design of the wind farm. See: [40] 


\section{Chapter 3}

\section{Design}

In this chapter, the different components of the new West Virginia University EWT will be reviewed. The description of each section of the EWT will include any changes to the original Cornell tunnel that have been modified for improved performance. Any design techniques that are used in the redesign will be include, such as analytic and numerical techniques. An overall schematic of the wind tunnel is can be seen in Figure 3.1.

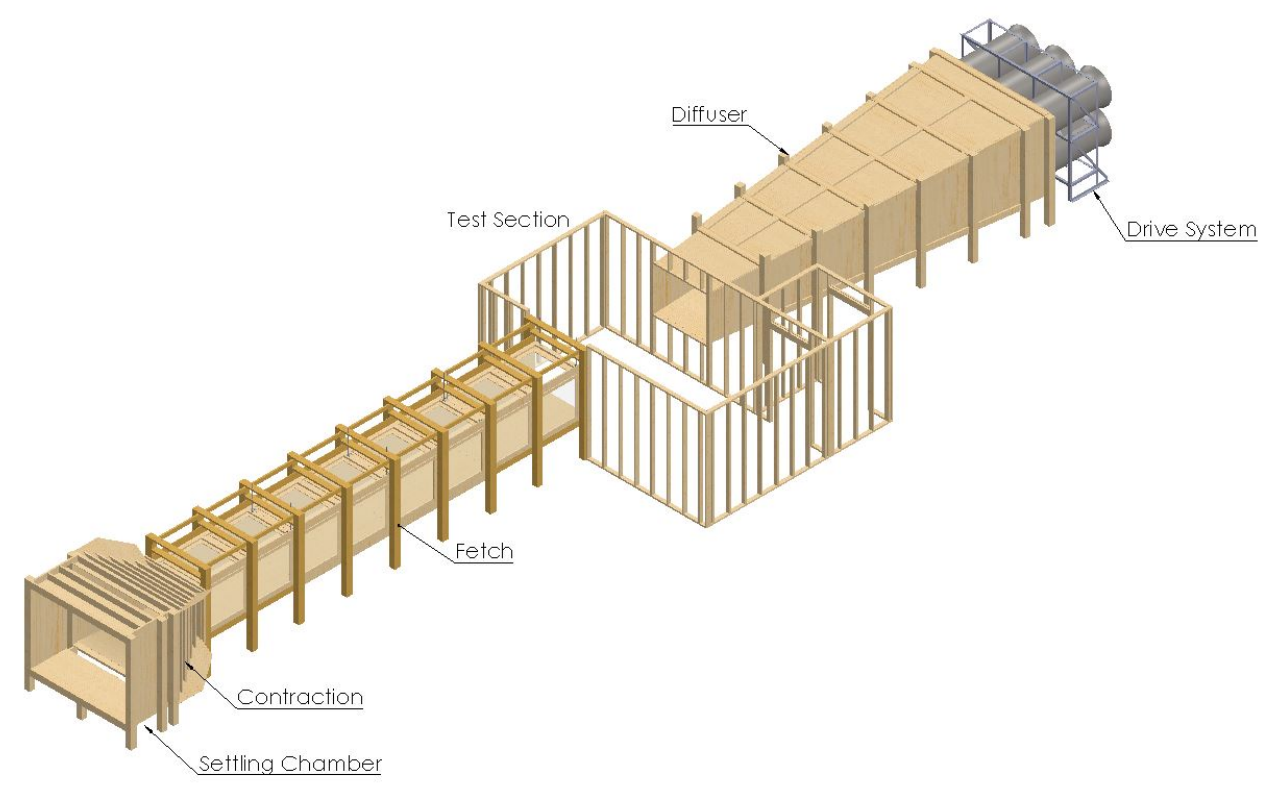

Figure 3.1: Isometric view rendering of complete EWT 


\subsection{Settling Chamber}

The smallest of the sections of the EWT can have a large impact on the performance of the tunnel. The settling chamber has localized devices that help control flow. These devices include screens and honeycombs. The combination of the two types of devices assist the flow in being more steady and uniform. Flow passes through small grids of the screens and honeycombs and reduces the size of the turbulence eddies and helps straighten the flow directionality. The nearly uniform flow resistance normal to the desired flow directional also helps to make the flow more uniform.

While turbulence is something that the EWT is designed to simulate, a clean starting point in the quality of the flow is needed. By using various techniques, the flow can be manipulated to the desired velocity profile and turbulence levels further upstream. Without inlet screens and honeycombs, the non-uniform flow of the air will cause unpredictable and unwanted velocity gusts and changes in profile that will affect data collection within the tunnel. In addition to suppressing turbulence, the screens also act as a physical barrier. Any foreign objects that are sucked into the tunnel should be stopped by the screens.

The Cornell tunnel had a package of screens and honeycombs installed in it. Since the screens and honeycombs were in good working condition, they were installed in the new EWT to reduce cost of the construction. They are easily replaceable in the future because they are an independent unit that can be removed from the settling chamber.

\subsection{Contraction}

As described in Mehta-Bradshaw [41], a contraction:

1. Increases the mean velocity which allows the honeycomb and screens to be placed in a low speed region, thus reducing pressure losses and ultimately the power required to attain desired test section speeds. 
2. Reduces both mean and fluctuating velocity variations to a smaller fraction of the average velocity.

\subsubsection{Contraction Ratio}

The contraction ratio, $\mathrm{c}$, is the most important design parameter when designing a contraction. Generally, contraction ratios that range between 6-10 are found to be acceptable for use in low speed tunnels. It is common for contraction ratios to be higher or lower. The larger the contraction ratio the better performance in terms of speed and efficiency, but it comes with increased cost of materials used in the tunnel walls and screens and straightener sections, assuming a fixed test section size.

One limitation that is placed on the design of the contraction for the WVU EWT is the inlet and outlet size. The original sizes, as seen in Figure 3.2, are to be used again. The rationale of this design decision is explained in the settling chamber section. The tunnel's contraction ratio is 4.0, which is lower than described in Bell-Mehta [42]. As previously stated, a lower contraction ratio may be used but performance may suffer as a result. However, this contraction ratio clearly will result in a small, and less costly tunnel than a larger contraction ratio would yield.
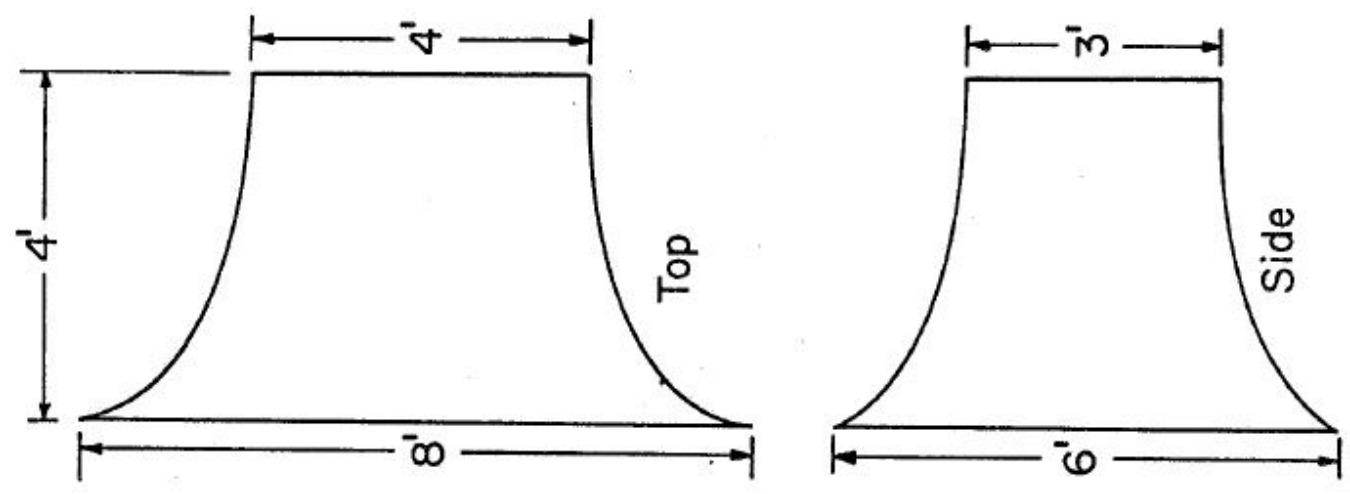

Figure 3.2: Original Cornell EWT contraction [1] 
Separation in the contraction is something that must avoided. Separation occurs when the contraction is too short. Designing a longer contraction is a way to avoid separation. However, this modification does increase the total tunnel length, cost, and exit boundary layer thickness.

The cross-sectional shape must also be considered. Non-circular cross-sections tend to have flow near the wall that migrate laterally. This can lead to separation in corners. Mehta's investigation showed that this does not cause a problem in a well-designed square contraction. He also noted that adding small $45^{\circ}$ corner fillets can lead to a reduction in the need for boundary layer mitigation [43]. The cross-sectional shapes are set by existing design requirements. The inlet on the contraction is measured 8 feet by 6 feet to accommodate the existing honeycomb and screen panels. The outlet will be the original 3 feet by 4 foot, which is being used as the inlet size of the fetch. The outlet size in similar to the WVU closed loop subsonic wind tunnel.

\subsubsection{Wall Shape}

Both elliptical and S-shape designs were considered while designing the original tunnel at Cornell. The decision was made to use a simple elliptical quadrant design because it allows for ease of construction, and the original designer thought the performance would be acceptable for use in the environmental wind tunnel.

The abruptness of the transition from the settling chamber to the contraction could cause flow to behave in undesired ways. The sharp transition of the wall shape raised questions, specifically regarding whether flow stagnation would be a problem. Ribando ran a simple test

with bubbles as flow visualization in Cornell's Bio-Thermal tunnel. The study confirmed the recirculation zone existed. It was noted that the downstream flow was not adversely affected [1]. However, during decommissioning of the tunnel, it was apparent that subsequent work had been done on the tunnel's contraction in which plates were installed that made the shape less abrupt. While there is no data to back up why the plates were installed, the author 
assumes that the shape was not performing as it was originally designed.

For the redesign, a change in the shape of the contour of the contraction was desired to get optimal performance out of the tunnel. As stated, Ribando went with the elliptical quadrant design due to the ease of construction and the lack of noticeable decrease in performance. Considering the later modifications that were made, the redesign resembled the commonly used S-shape, as shown in Figure 3.3.

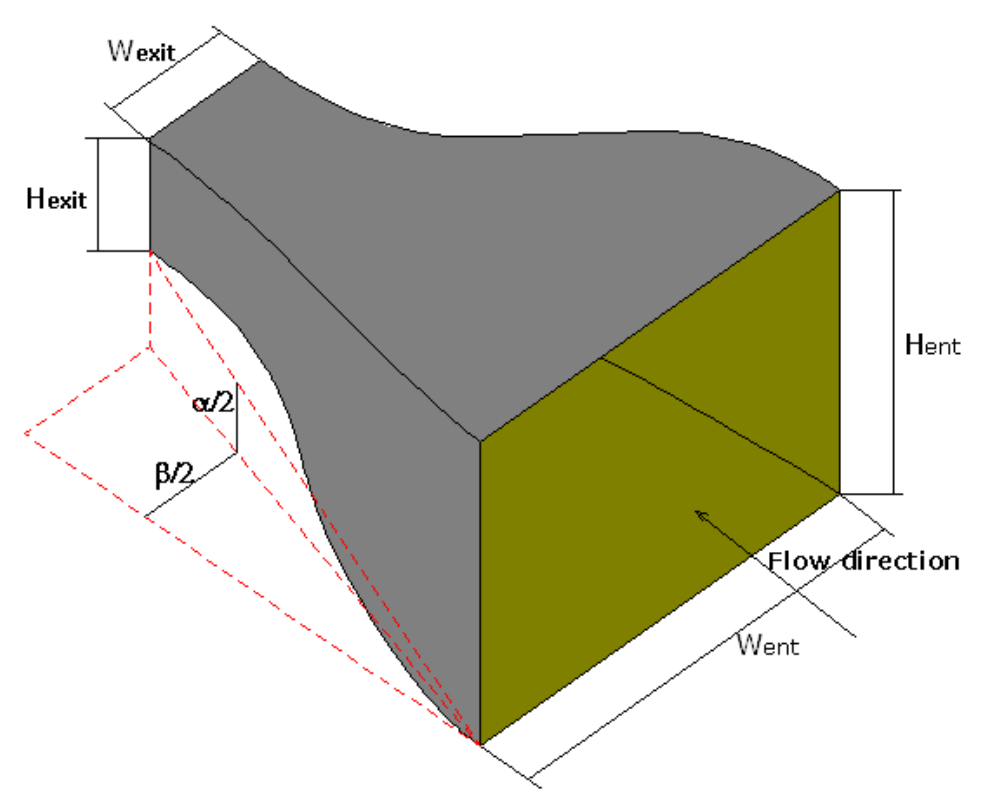

Figure 3.3: Example S-Shape contraction [44]

The two general ways to design a contraction are by using a polynomial to estimate the optimal shape for the walls, or a "design by eye" method, where the designer uses their best judgement based on the appearance of the curvature. Both methods have been used in the design and construction of major wind tunnels. The shear layer tunnel at NASA's Ames Research Center used a design by eye method; while the mixing layer tunnel at the same complex, used a 5th order polynomial to describe the wall shape for the contraction [42].

Using the same inlet and outlet area dimensions and length of the contraction, such types of contraction wall shapes were analyzed, using the ANSYS Fluent CFD program to compare the outlet velocity profiles. The maximum fetch velocity that is required for the tunnel has been set at $30 \mathrm{~m} / \mathrm{s}$. Using volumetric flow rate equal in inlet and outlet, the inlet velocity 
is calculated. Setting the inlet boundary condition for both contractions at a uniform inlet speed of $6.7 \mathrm{~m} / \mathrm{s}$, two contour plots of the outlets were obtained. Views of the Fluent models meshes for the original Cornell contraction and the finalized WVU contraction are shown in Figure 3.4 and 3.5, respectively.

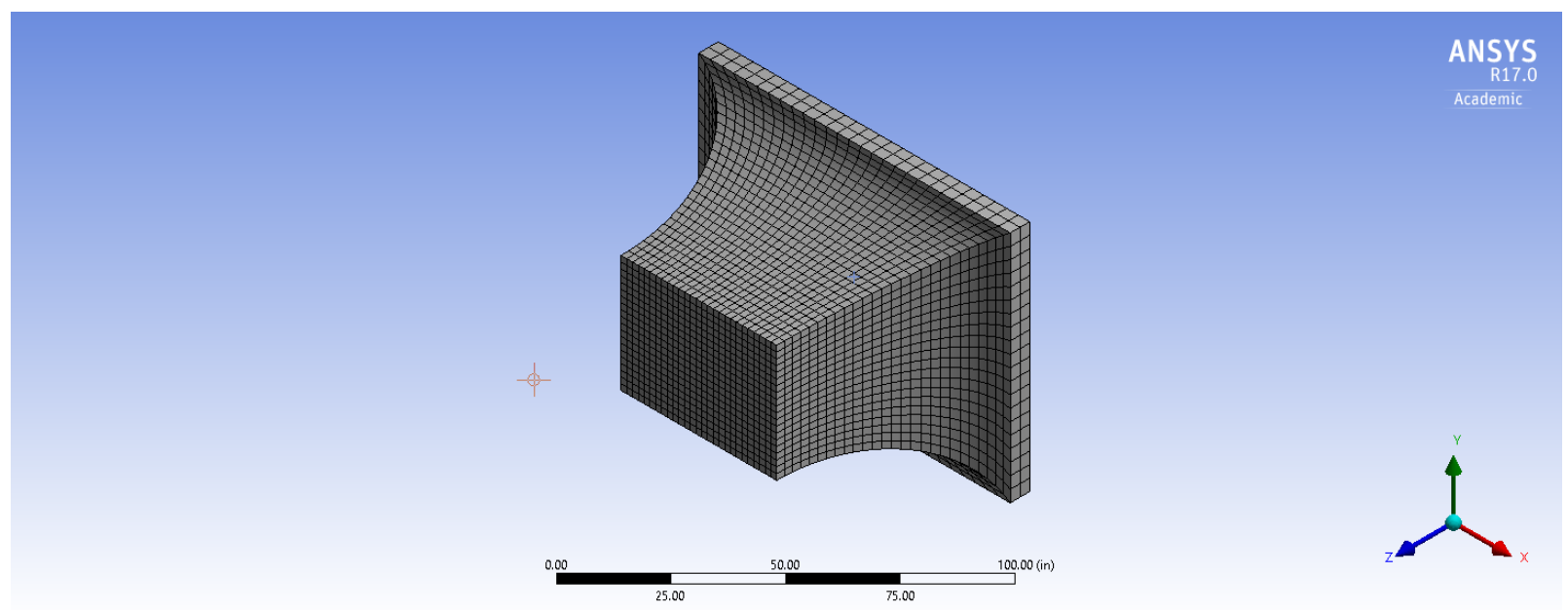

Figure 3.4: Cornell elliptical contraction mesh

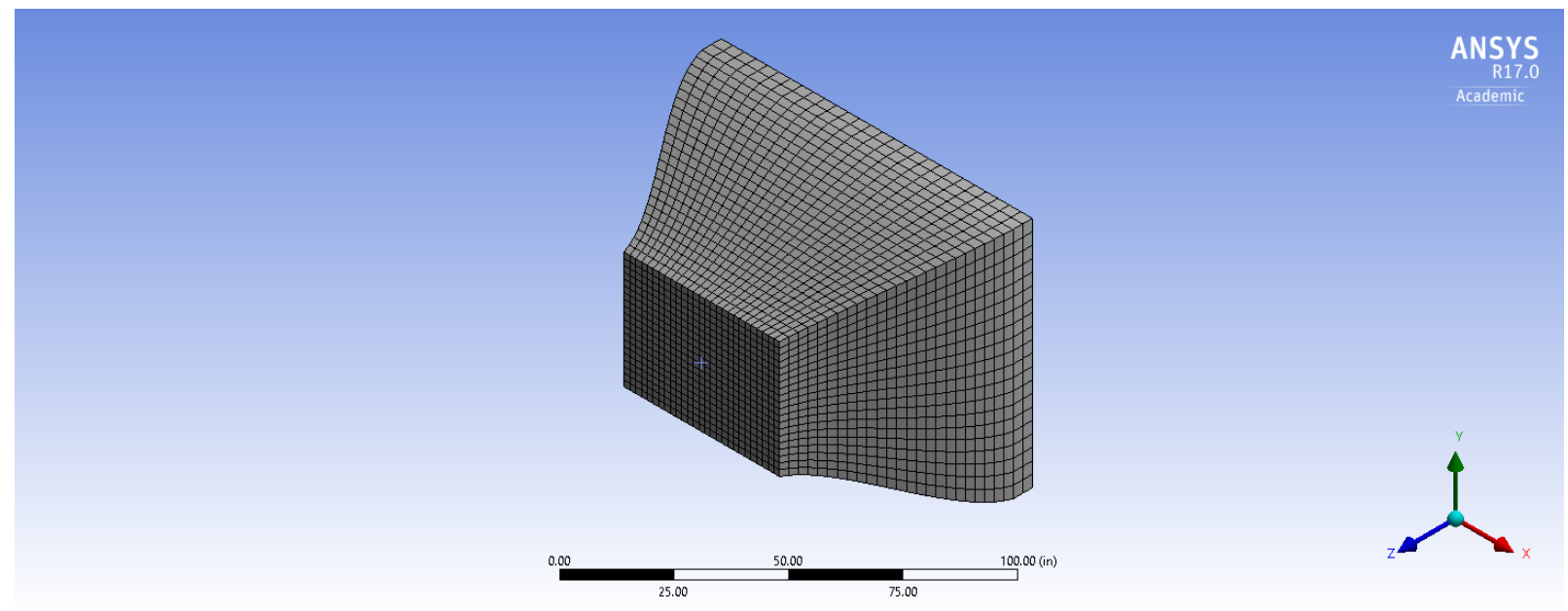

Figure 3.5: WVU s-shape contraction mesh

The outlet velocity contour map in Figure 3.6 shows that the original Cornell tunnel elliptical design appears to have, in all four corners, flow velocity that is higher then what is desired. This non-uniformity is not ideal for flow entering the fetch. The flow entering the fetch should be as even as possible so flow altering devices can be used inside the fetch section 
to condition the flow to the desired shape. In Figure 3.7, the computed outlet velocity profile is shown for an s-shape wall that used a design by eye method. The flow is more uniform then the elliptical contraction. The flow behaves in a predictable manner with a velocity across the area of about $30 \mathrm{~m} / \mathrm{s}$.

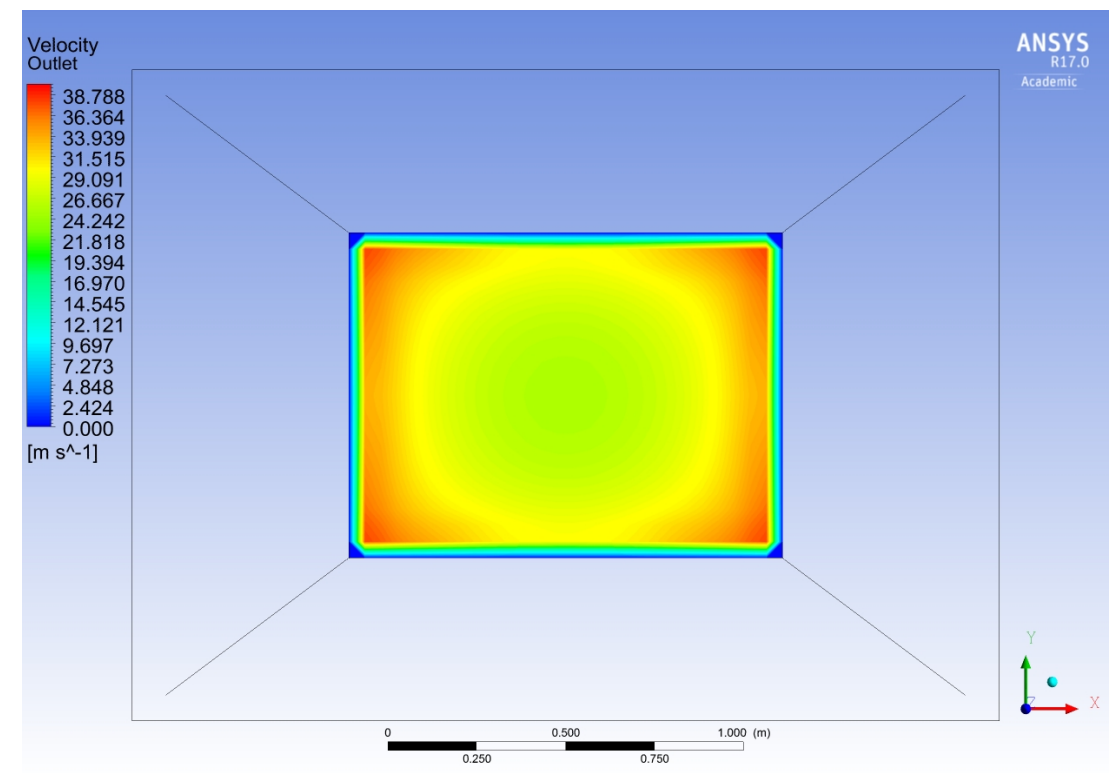

Figure 3.6: Cornell contraction outlet velocity profile

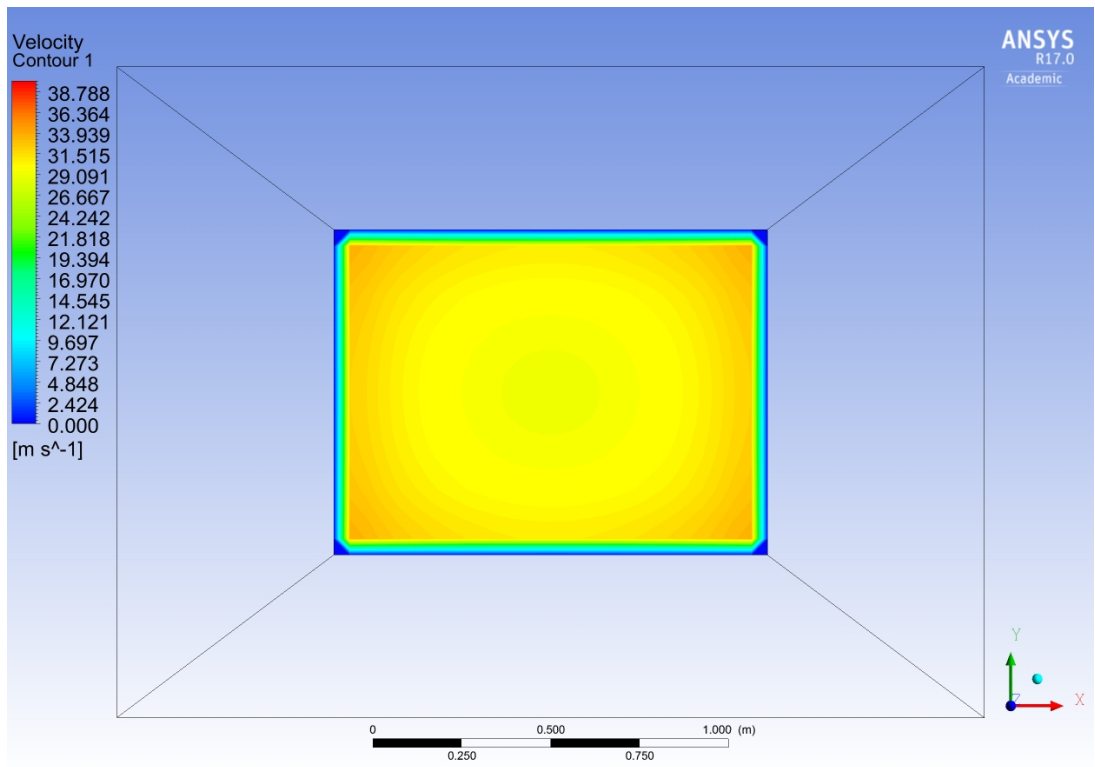

Figure 3.7: WVU contraction outlet velocity profile

Figure 3.8 shows the development of the flow through the Cornell contraction as an 


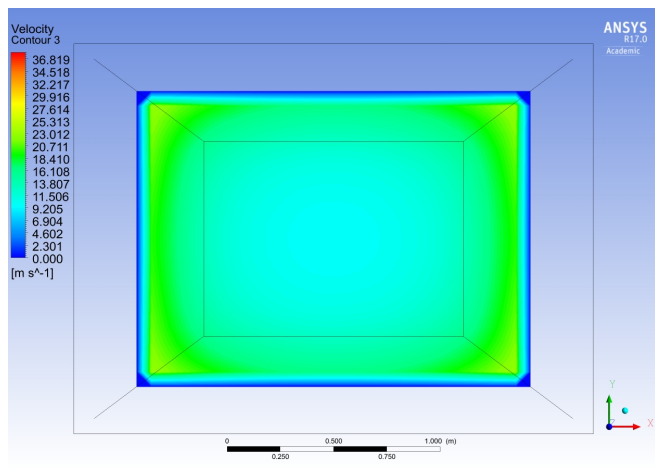

(a) 6 inches from inlet

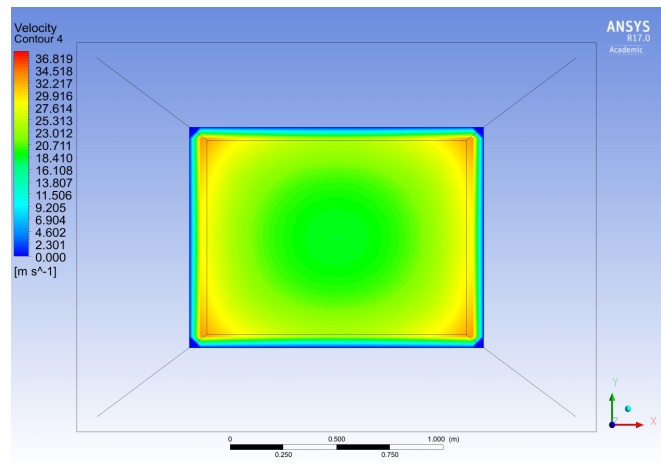

(c) 24 inches from inlet

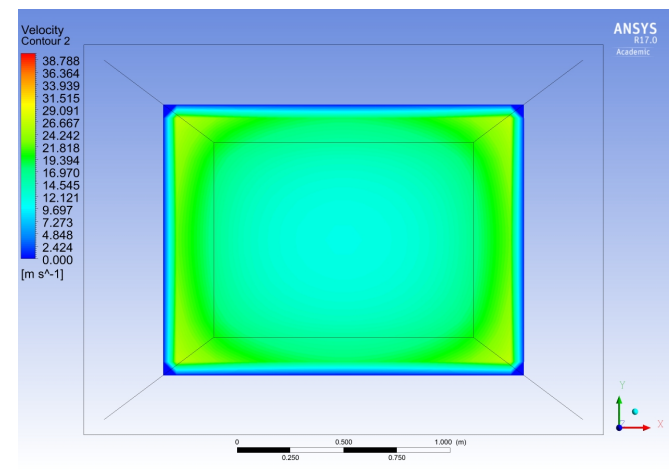

(b) 12 inches from inlet

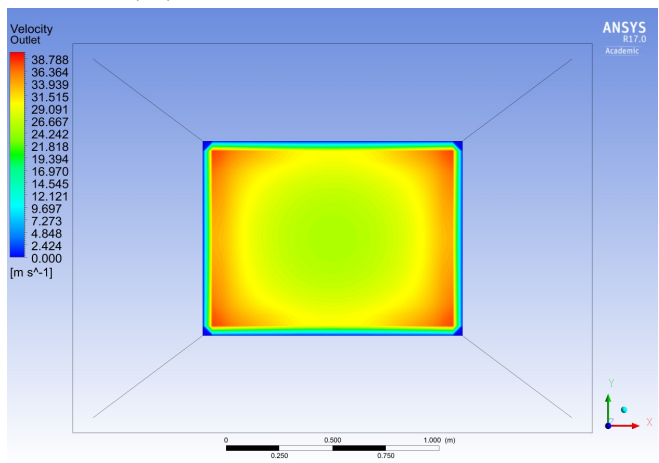

(d) Outlet of Cornell Contraction

Figure 3.8: Development of the velocity profile through Cornell contraction

example for behavior through a contraction nozzle. The Cornell's contraction is more pronounced, so it is easier to distinguish small changes in the general direction of the flow. The flow develops into a cup shape velocity through the contraction [24].

The WVU EWT, based on the simulations, used a "design by eye" S-Shape design for the shape of the contraction walls. Figure 3.9 is a rendering of the contraction after the S-Shape redesign. The shape is supported by a series of boards that reinforce the shape of the wall. Figures 3.10 and 3.11 show the shape of the walls from the top and side view, respectively. 


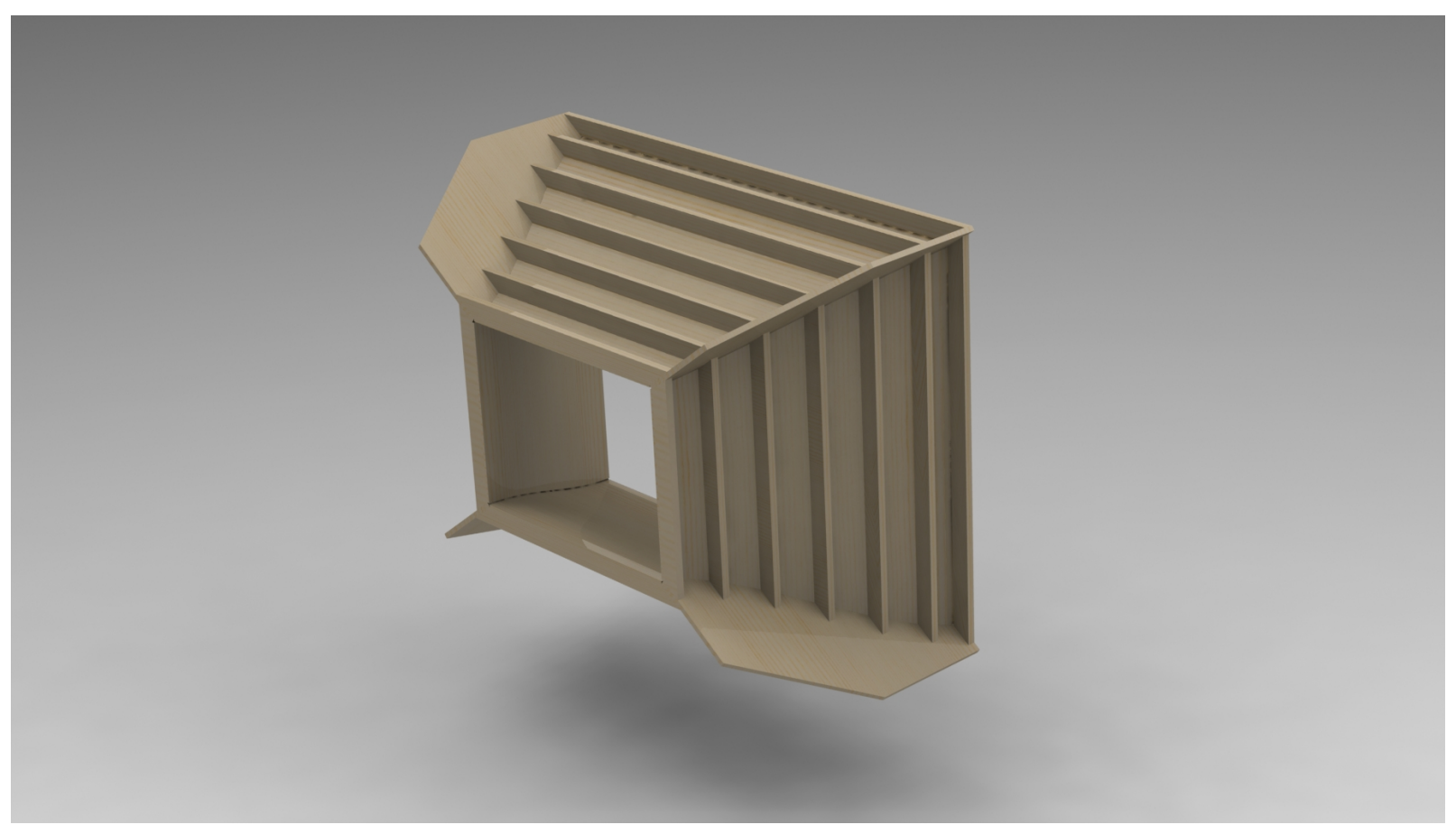

Figure 3.9: Isometric view of redesigned "S-shape" contraction

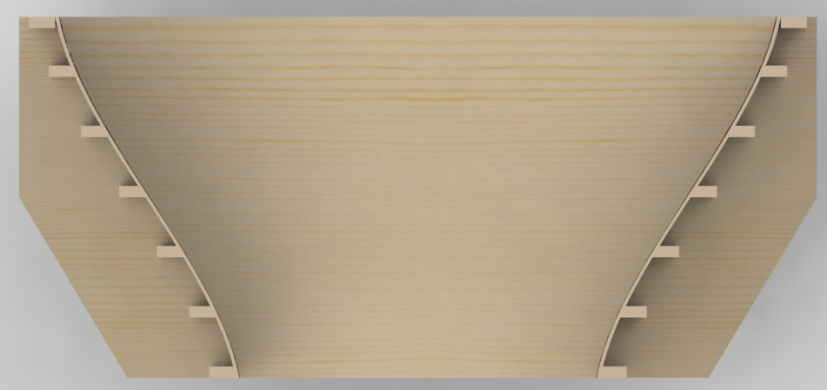

Figure 3.10: Top view of redesigned "S-shape" contraction 


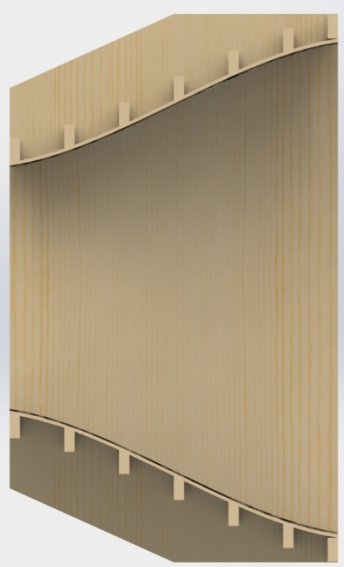

Figure 3.11: Side view of redesigned "S-shape" contraction

Finally, it is worth mentioning that the inlet of the contraction and settling chamber combination has rounded lips for intaking air smoothly. If the flow entering the setting chamber had an abrupt contraction from outside the wind tunnel could leading to separation near the corners. The smooth transitions of the rounded lips is used to avoid this separation from occurring.

\subsection{Fetch}

The fetch is the key section of this tunnel that sets it apart from other types of tunnels. This section is where the boundary layer is allowed to thicken in a desired fashion as the flow moves towards the test section. The fetch must be designed properly to allow for the boundary layer to reach the desired thickness. A number of factors must be considered while designing the fetch.

As stated in Chapter 2, the surface roughness and flow speed are two parameters that are used to describe the boundary layer. Two methods that are used to help create boundary layers in tunnels are surface roughness elements added to the floor of the tunnel, and spires at the inlet of the fetch section. The length of the EWT fetch is considered short so spires and 
roughness elements must both be used to create a boundary layer that can adhere closely to the power law approximation used for atmospheric simulations. Each has a design method to get the boundary layer profile to the requirements of the user.

\subsubsection{Spires}

The spires are placed at the beginning of the fetch section. They restrict the air based on the geometric dimensions of the spire. For example, a triangular base spire blocks more air near the floor, which allows for air flowing higher in the tunnel to move more quickly than at the bottom. This allows the flow to form a taller boundary layer. It is possible to calculate the geometry of the spires for ideal boundary layer growth.

For the EWT, the design goal is to have a boundary layer form a height of 24 inches tall halfway through the fetch, which is two-thirds of the neutral roof position. This will allow the second half of the fetch and testing chamber to be used for models and experiments.

In his paper, Irwin [30] presented equations that can be used to design spires and roughness elements to create desired boundary layers in short wind tunnels with rectangular working sections. These equations are based on the desired Hellman exponent and boundary layer height. Figure 3.12 shows the arrangement of the spires and the roughness elements.

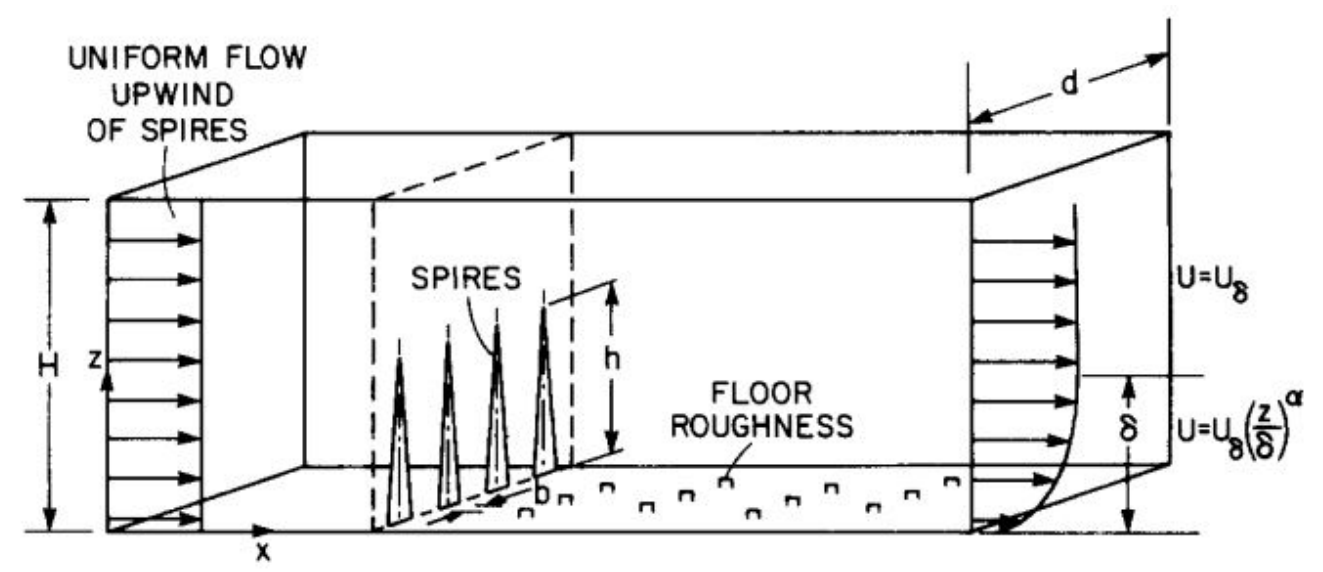

Figure 3.12: Spire and roughness element configuration [30]

Using Equation 3.1 [30] the height of the spire can be solved. 


$$
h=1.39 \frac{\delta}{1+\frac{\alpha}{2}}
$$

With $\delta$ being the desired boundary layer height (24 inches) and $\alpha$ being the Hellman exponent (0.2), h comes out to be about 30.325 inches. Using this result, the base width of the triangular spire may be solved using Equations 3.2, 3.3, and 3.4.

$$
\frac{b}{h}=0.5\left[\Psi \frac{\frac{h}{\delta}}{1+\Psi}\right]\left(1+\frac{\alpha}{2}\right)
$$

with $\Psi$ and $\beta$ given by:

$$
\begin{gathered}
\Psi=\frac{\beta\left(\left[\frac{2}{1+2 \alpha}\right]+\beta-\left[\frac{1.13 \alpha}{(1+\alpha)\left(1+\frac{\alpha}{2}\right)}\right]\right)}{1-\beta^{2}} \\
\beta=\frac{\frac{\delta}{h} \alpha}{1+\alpha}
\end{gathered}
$$

A graphical representation of Equations 3.1 and 3.2 can be seen in Figure 3.13 and 3.14, respectively.

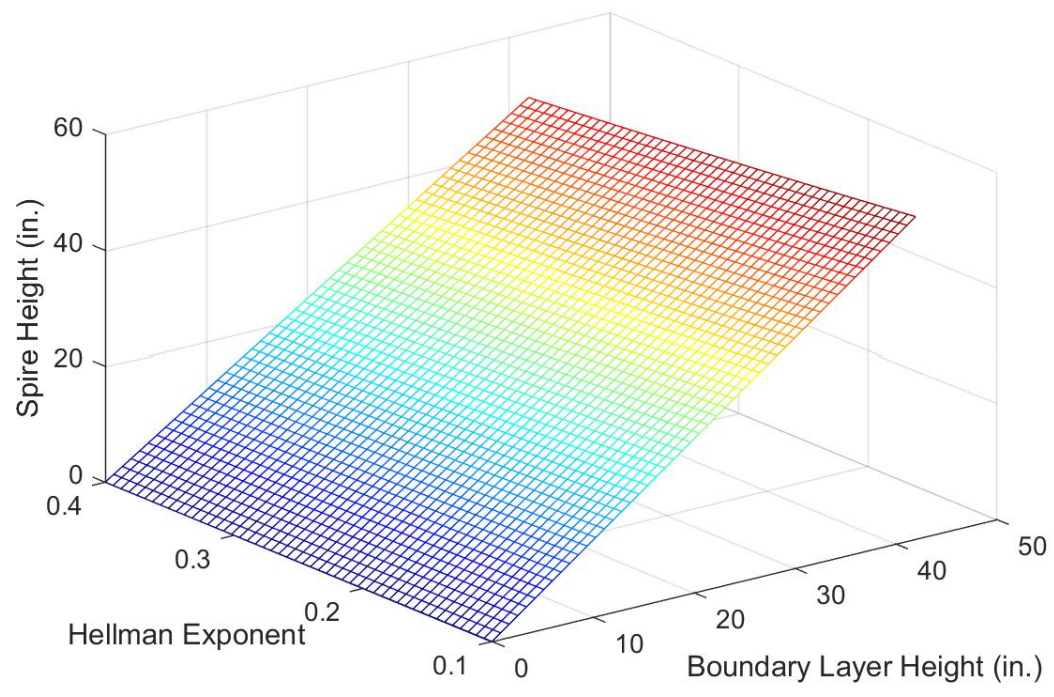

Figure 3.13: Graphical representation of estimated spire height (in inches) 


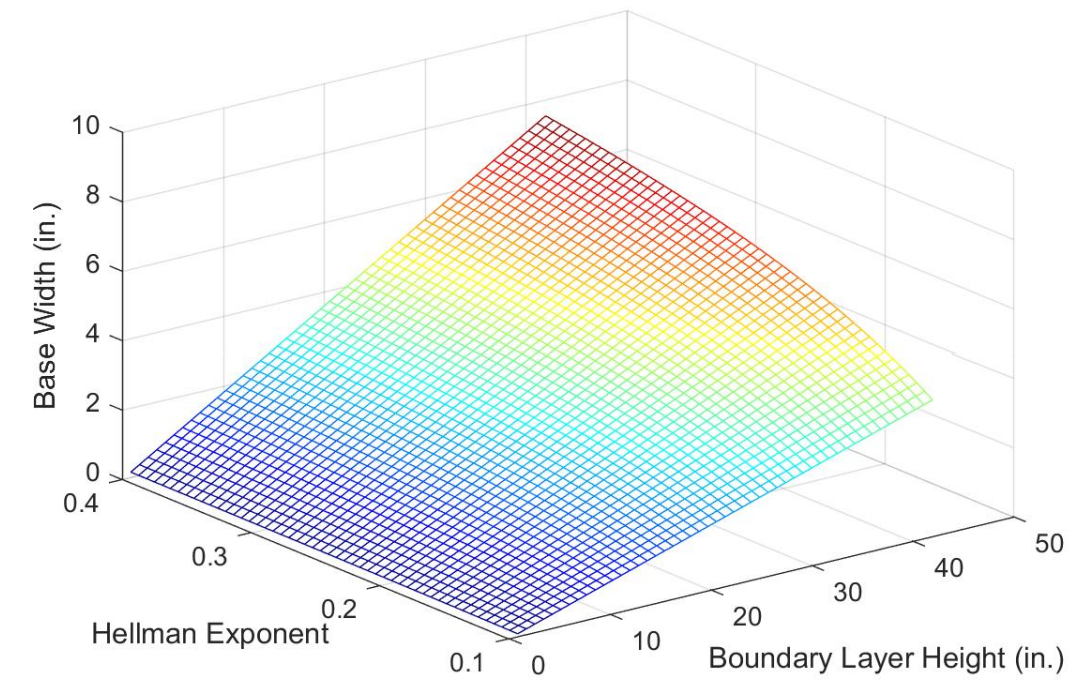

Figure 3.14: Graphical representation of estimated base width (in inches)

Solving for $b$, with the $h$ already found, the spire base width will be 3.33 inches. With the base and height calculated, the design of the spire can be found. A drawing with dimensions can be seen in Figure 3.15. The spires are spaced with a center to center distance of $\frac{h}{2}$. Irwin also observed that a non-triangular face had no obvious advantages over a simple triangle spire [30].

\subsubsection{Roughness Elements}

The spire design is only the first step in designing the fetch to create a boundary layer that is desired. Roughness elements must also be added to floor of the fetch to simulate roughness conditions of the planetary body. These could include urban or open country roughness. Continuing with Irwin's observations on boundary layer generation in tunnels, it is important to calculate the surface element's geometry needed for a boundary layer of 24 inches thick at a point 16 feet along the fetch.

Using the assumption that with the appropriate roughness, the boundary layer at $6 h$ distance down the fetch is close to equilibrium, allows the Gartshore's relationship, shown in Equation 3.5 [45], between the Hellman exponent, $\alpha$, and the skin friction, $C_{f}$, to be used. 

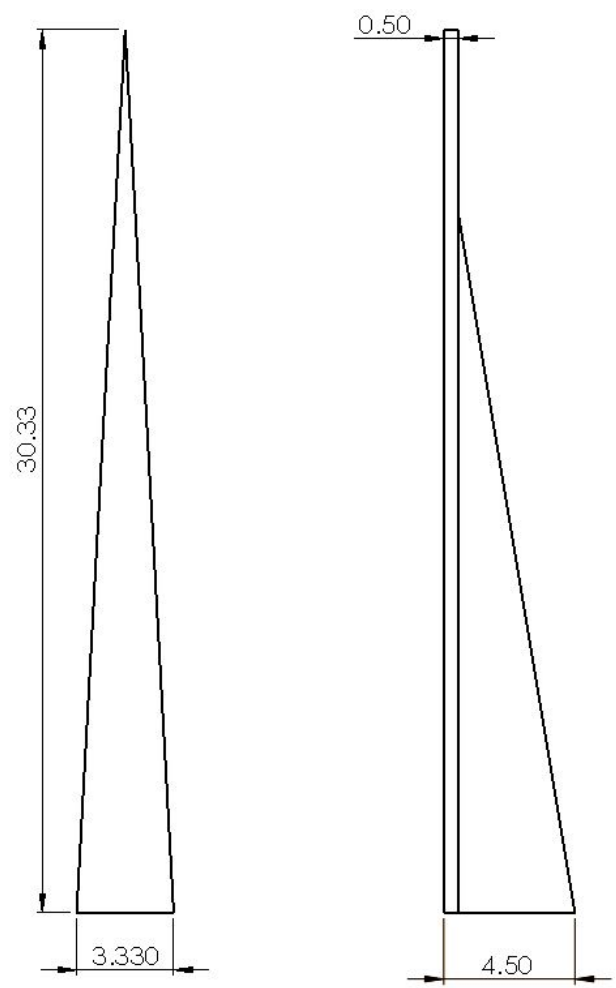

Figure 3.15: Spire Design (all dimensions in inches)

$$
C_{f}=0.136\left[\frac{\alpha}{1+\alpha}\right]^{2}
$$

This relationship to find the skin friction will allow for the height of the roughness elements to be calculated. Using seven elements as the first row after the designed spire, each block is spaced at center-to-center distance, $D$, of 6 inches.

The Wooding's empirical correlation, shown in Equation 3.6, [46] is used to calculate the ratio of cube height, $k$, to the boundary-layer height.

$$
\frac{k}{\delta}=\exp \left[\left(\frac{2}{3}\right) \ln \left(\frac{D}{\delta}\right)-0.1161 \sqrt{\left(\frac{2}{C_{f}}+2.05\right)}\right]
$$

Solving for the cube height, $k$, is found to be 0.625 inches, it must also be noted that the above equation is only valid in the range $30<\frac{\delta D^{2}}{k^{3}}<2000$. That condition is met with this geometry found. A graphical representation of the Wooding's formula for roughness 
elements 6 inches apart can be seen in Figure 3.16.

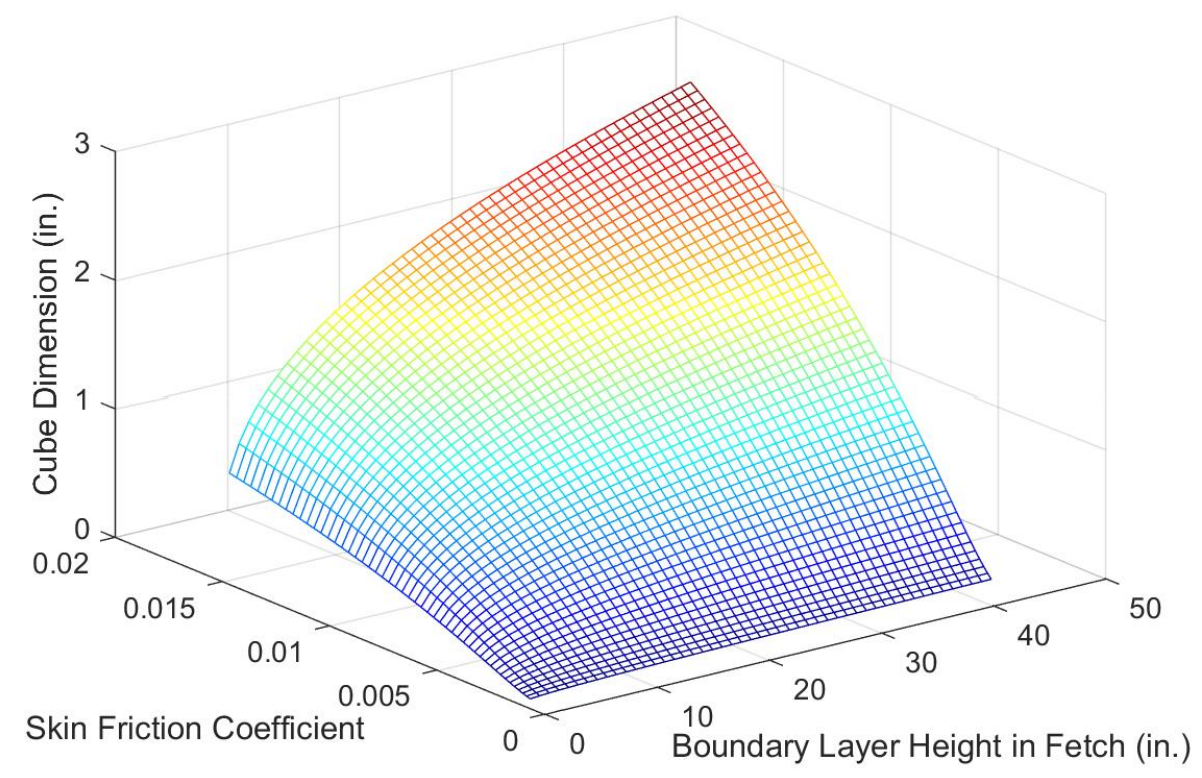

Figure 3.16: Graphical representation of the Wooding formula with elements 6 inches apart (all dimensions in inches)

The spire and roughness element dimensions have been solved so that a boundary layer height of 24 inches will be formed halfway through the fetch. Taking into account the calculated values and stated layout, Figure 3.17 illustrates the layout of the floor in the first half of the fetch section.

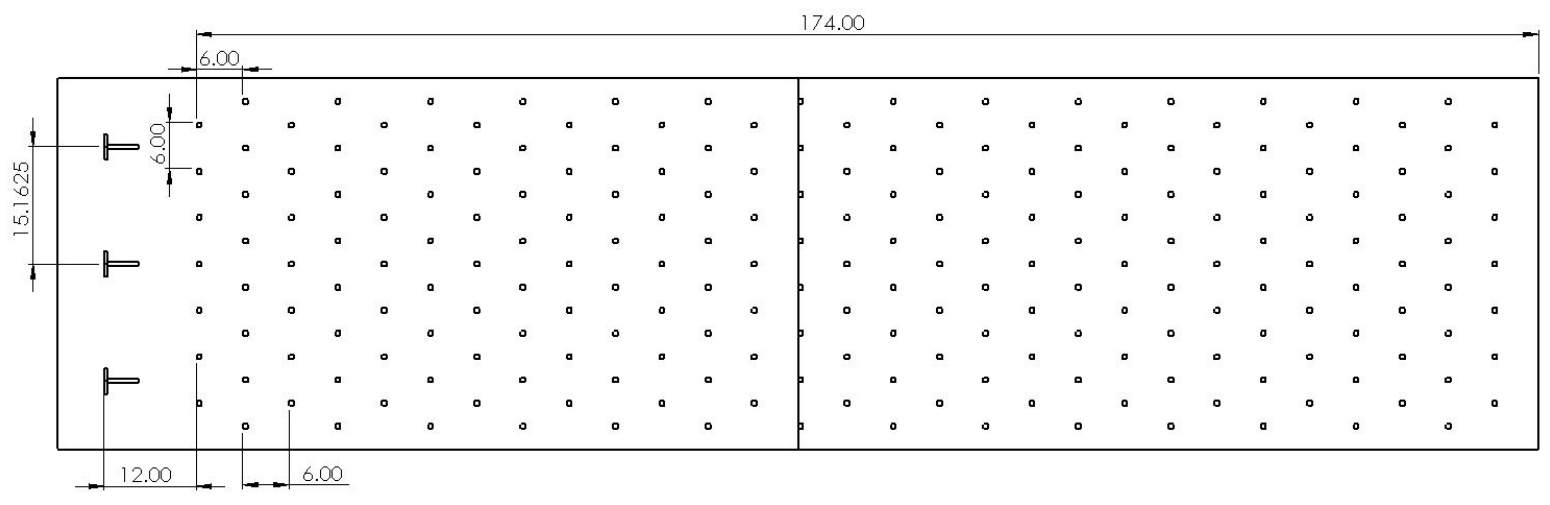

Figure 3.17: Fetch floor layout (all dimensions in inches) 


\subsubsection{Adjustable Roof}

When simulating an atmospheric boundary layer, a zero pressure gradient found in a natural boundary layer is ideal for testing. To achieve this zero gradient, the wind tunnel is equipped with an adjustable ceiling that may be raised to have a zero pressure gradient condition met. To calculate the needed displacement a weighted average of the displacement thickness of all four wall was used. The ceiling and side walls follow a simple 1/7th power law. The floor thickness was more complicated to calculate since it was not a smooth wall. Ribando graphically showed the ceiling displacement (Appendix A) needed for varying conditions of sand roughness, velocity, and power law exponent. The original design called for an adjustable range of $20 \mathrm{~cm}$ [1]. Since this is a user-adjustable feature of the tunnel, it can changed based on user's needs. Therefore, the original design of $20 \mathrm{~cm}$ will be used. Static pressure probes are placed along the length of the fetch for users to verify zero pressure gradient conditions are present in the fetch. A rendered view of the adjustable ceiling is shown in Figure 3.18.

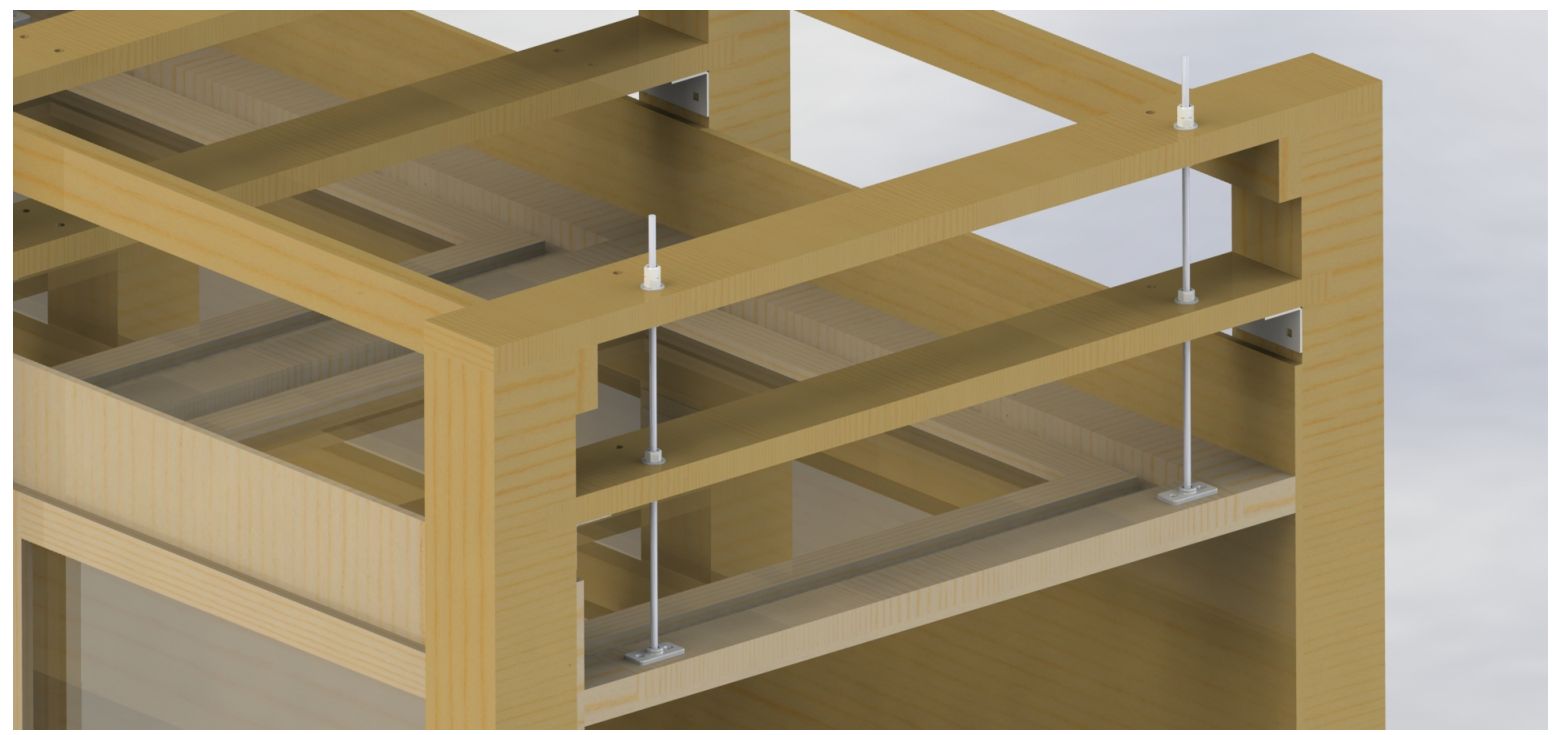

Figure 3.18: Adjustable ceiling render; the nuts on threaded rods can be tightened and loosened to raise and lower each section independently to achieve zero pressure gradient. The nuts are held in place by additional lock nuts above and below each cross-support

An example of the ceiling adjusted for zero pressure gradient through the fetch can be 
seen in Figure 3.19. Using Ribando's method [1] the conditions examined are $30 \mathrm{~m} / \mathrm{s}$ velocity in a suburban terrain $(N=4.5)$. The inlet is 36 inches in height, as the flow moves through the fetch the ceiling needs to be displaced a total of 4.72 inches to maintain the zero pressure gradient. Therefore, the outlet height is 40.72 inches. Note that the fetch height is not a linear relationship. The dashed line illustrates a constant 36 inches height through the entire fetch. A larger image of 3.19 can be found in Appendix B.

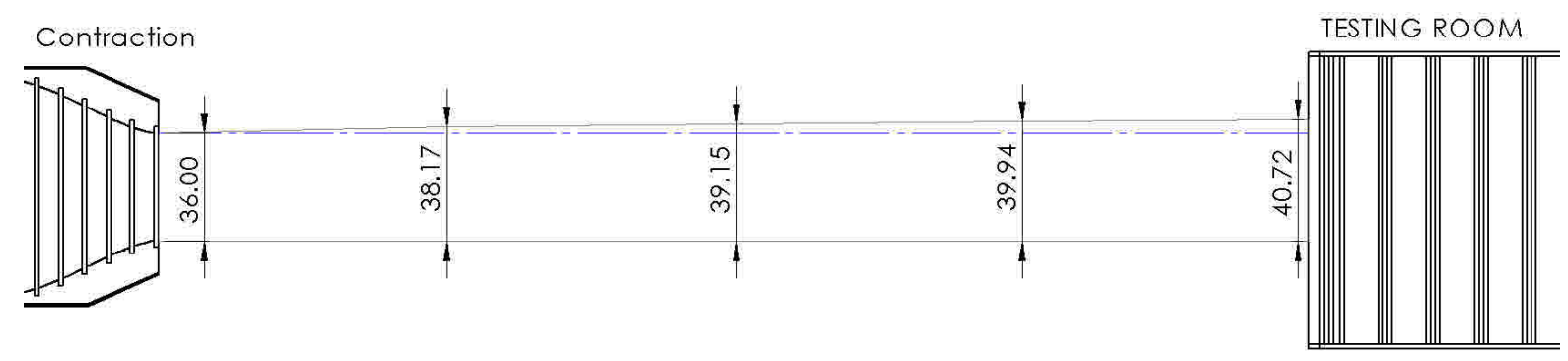

Figure 3.19: Example fetch ceiling adjustment

\subsubsection{Windows}

A new addition to the EWT is the installation of observation windows in the fetch. The windows are 3 feet by 3 feet transparent polycarbonate plastic. This modification allows users to observe an experiment that is set up in the end of the fetch. Photography and other flow visualization equipment such as Particle Image Velocimetry systems (PIV) can also be used with the addition of the transparent windows. Side view and isometric view rendering of the designed fetch are shown in Figure 3.20 and 3.21, respectively. 


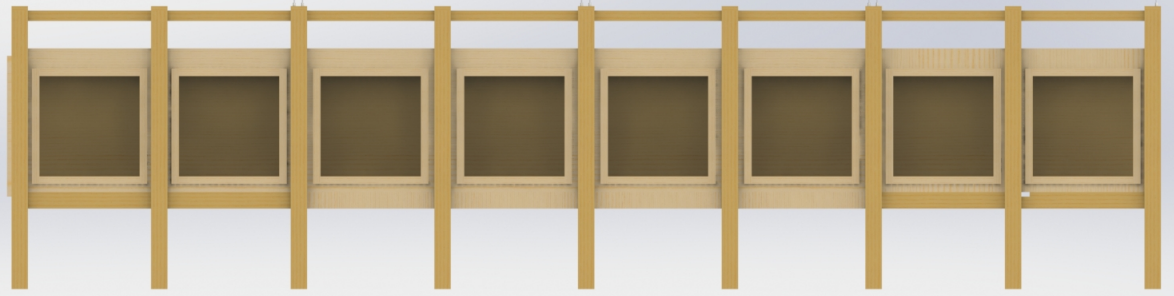

Figure 3.20: Side view of the fetch

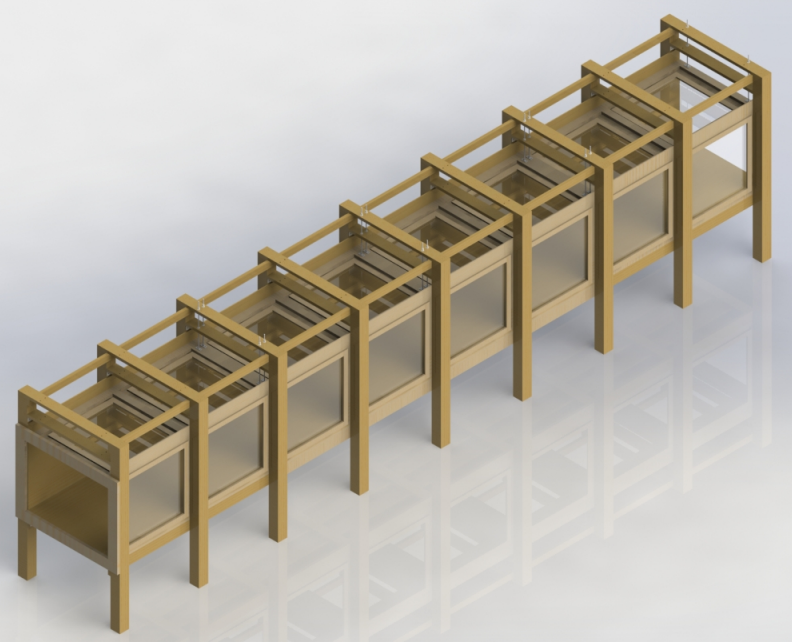

Figure 3.21: Isometric view of the fetch

\subsection{Diffuser}

The originally-designed wide angle diffuser, according to technicians at Cornell, suffered from performance issues. The technicians did not detail what exactly caused the performance issues. Looking at the wide angle diffuser design, the diffuser was designed to have screens installed. Screen are a common method of increasing diffuser performance. When the divergence angle is too great, it may lead to flow separation in the diffuser. Screens 
are placed at multiple locations along the diffuser. Each screens reduces the boundary layer thickness at that location. The flow then resumes its boundary layer growth. Eventually the flow will reach the end of the diffuser without any separation occurring due too the multiple flow "resets" [41].

Flow separation can cause issues in the upstream flow and can lead to unsteady flow fluctuations, but perhaps more importantly flow separation can lead to dramatic decreases in drive system efficiency as the flow separation negates any drive system pressure differentials directly downstream of the separation point (i.e., the drive system effectively stalls in the region of the flow separation). Due to the performance issues of the Cornell tunnel, the new EWT has been redesigned with a shallow angle divergence diffuser.

It is also worth noting that the original tunnel's diffuser inlet was close to the outside wall of the testing chamber. This caused recirculation and entrainment issues inside the testing room [47]. To combat this the outside wall of the testing section was moved away 4 feet so the expansion of the jet will not hit the wall and could expand evenly to reduce undesirable flow conditions inside the testing chamber.

\subsubsection{Diffuser Inlet}

A design feature of this tunnel is the open jet testing section, shown in Figure 3.22. The inlet of the diffuser must be larger than the exit of fetch section due to the expansion of the open jet. Abramovich [48] provides an excellent reference for calculating the open jet expansion, as well as other properties of a open jet. The test section is short enough that

a core of constant velocity exists along the entire length. This allows the use of the initial region in the estimation of the spread of the open jet. Abramovich gives the semi-empirical Equation 3.7 for the slope of the constant core velocity region.

$$
\tan \left(\alpha_{1}\right)=\frac{y_{1}}{x+x_{O H}}=0.112
$$




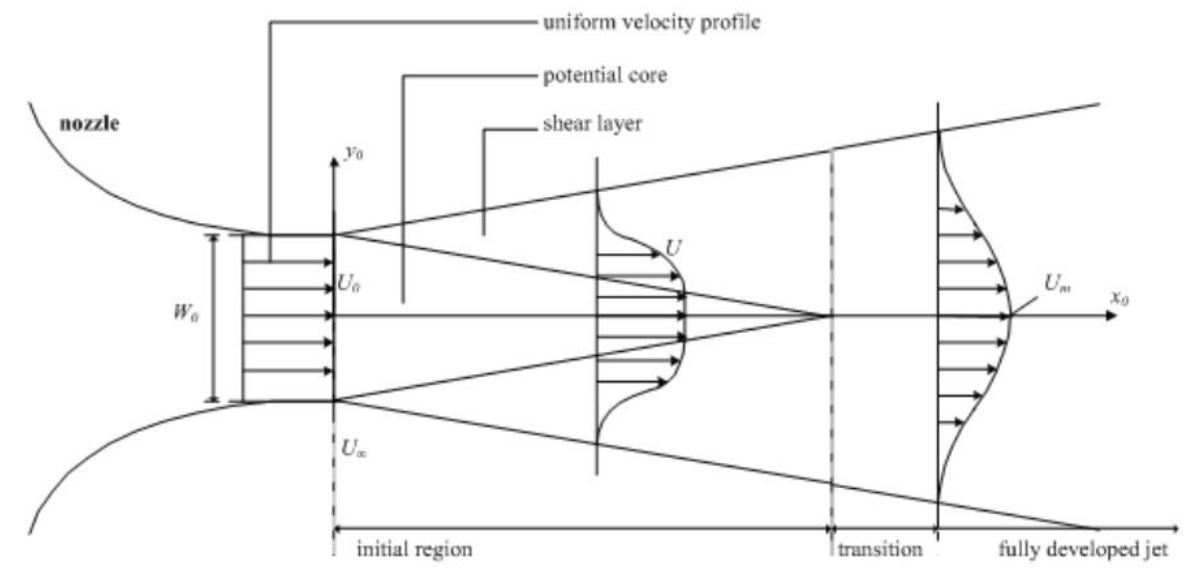

Figure 3.22: Open jet similar to the test section of the EWT [2]

With $\alpha$ is the angle of expansion, $\mathrm{y}$ is the distance of expansion perpendicular to the flow, $x_{O H}$ equal to 2.7 times the boundary layer height at the exit of the fetch. The outlet of the fetch section is not a uniform velocity profile. The jet will behave as if the expansion started upstream of the actual exit within the fetch section.

Abramovich also gives the slope of the outer edge of the open jet jet with Equation 3.8. Once again the exit flow of the fetch is not uniform and the jet starts upstream of the exit within the fetch.

$$
\tan \left(\alpha_{2}\right)=\frac{-y_{2}}{x+x_{O H}}=0.158
$$

For the constant mass core boundary, he gives Equation 3.9:

$$
y_{R}=y_{2}+0.515\left(y_{1}-y_{2}\right)=-0.019(x-2.7 \delta)
$$

When finding the dimensions of the diffuser inlet, the mass core expansion is what is used to calculate expansion. In Figure 3.23, the expansion is shown as a function of boundary layer height and distance from fetch outlet. The expansion shown is the expansion from one side of the fetch. Each side of the fetch will expand the distance shown. If a boundary layer 
is formed with the fetch the mass core starts to expand before it reaches the end of the fetch.

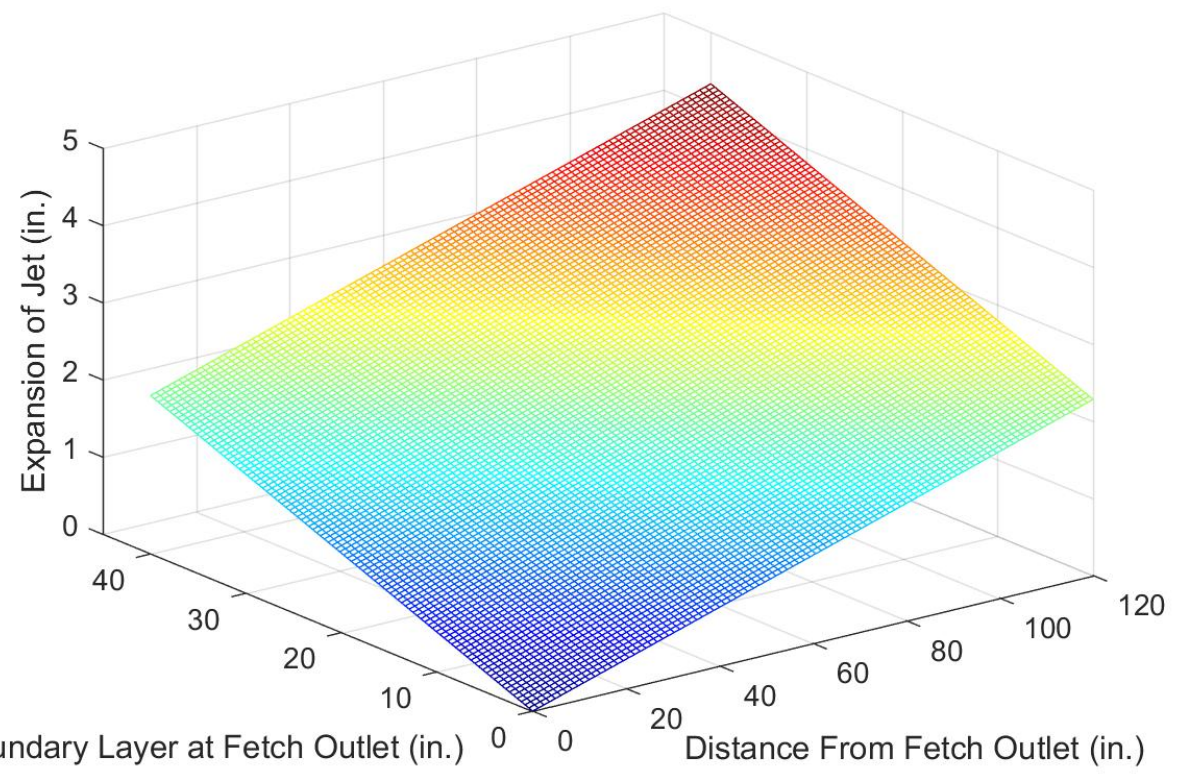

Figure 3.23: Open jet mass core expansion through the test section of the EWT (in inches)

Using Equation 3.9, the jet expands the greatest distance when the side wall boundary layer is increasing. At $\delta=15 \mathrm{~cm}$, the jet diverges $5.8 \mathrm{~cm}$, or 2.28 inches. At $\delta=30 \mathrm{~cm}$, it diverges $7.33 \mathrm{~cm}$, or 2.88 inches. Since it is desired to catch the entire mass core, the greater value of expansion will be used. With the fetch, exit constant laterally at 48in the divergence from both walls is added $48 \mathrm{in}+2 * 2.88=53.76 \mathrm{in}$.

The vertical expansion is trickier than the lateral expansion. Since the roof is adjustable, the height of the jet opening varies. The expansion distance added is the same as in the lateral case, 2.44 inches. However, since the roof can operate between a height of 36 inches and about 44 inches, the required inlet height is not a set value. The compromise is that the fetch outlet height will be set at 40 inches. This decision was based on the figure in Appendix A, where the average is around 4 inches for ceiling displacement. Adding the expansion distance at the floor and roof, $40 \mathrm{in}+2 * 2.88=45.76 \mathrm{in}$. The entrance will have rounded collectors on the edges, because the expansion is not a large value, and any changes in the expansion are absorbed by the collectors. . 


\subsubsection{Low Divergence Angle Diffuser}

The original diffuser, shown in Figure 3.24, was designed to be a wide angle diffuser with screens installed. The screens were supposed to be placed to stop separation from occurring within the diffuser. The separation can cause a drop in performance in the tunnel. However, the screens were not installed or were removed from the diffuser.

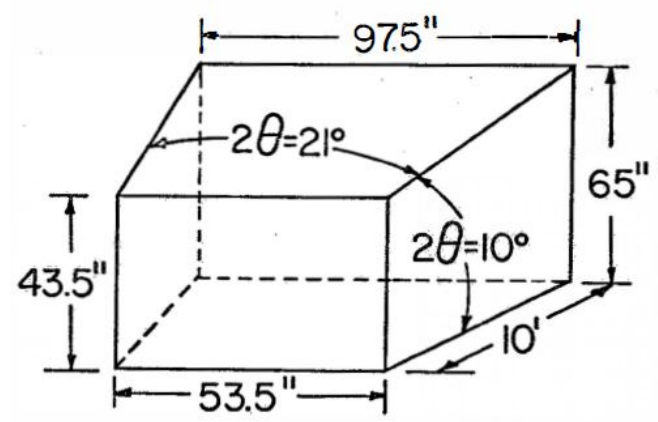

Figure 3.24: Original wide angle diffuser design [1]

A major reason why the original Cornell tunnel was fitted with a wide angle diffuser was the available space. The use of a low divergence angle diffuser requires more space, something that was not available at Cornell. The area in which the tunnel is to be installed at WVU has plenty of space to allow for the use of low angle diffuser.

Research recommends the diffuser angle not exceed more than 5 degrees for best flow steadiness. It is worth noting the best pressure recovery is achieved at about 10 degrees [41]. Since the EWT that is used at relatively low speeds, pressure loss is not a major concern. An EWT is trying to control chaos and any unsteadiness in the flow will cause unpredictability in controlling the growth of a boundary layer.

The new diffuser was designed so that the divergence angle is at 5 degrees. This is the recommended angle of divergence, and should not allow the flow to separate in the diffuser. The inlet dimensions have been already determined in the previous section. The dimensions of the fan assembly at the exit will determine how long the diffuser will have to be for the goal of 5 degrees' divergence angle is to be met. Since the original fans and frame are being 
used, the original dimensions can be reused, and based on the original design, the dimensions of the outlet of the diffuser are 97.5 inches by 65 inches. However, measurements taken from the actual tunnel during decommissioning show that the outlet of the diffuser has a cross section of 109 inches by 67.75 inches. Since the fans and frame are being reused, these measured dimensions will be used.

Using simple trigonometry, the length of the diffuser for a 5-degree angle of divergence is 312 inches, or about 26 feet. Figure 3.25 is a visualization of the diffuser's core. Figure $3.26,3.27$, and 3.28 are side, top, and isometric renderings of the new low divergence angle diffuser, respectively.
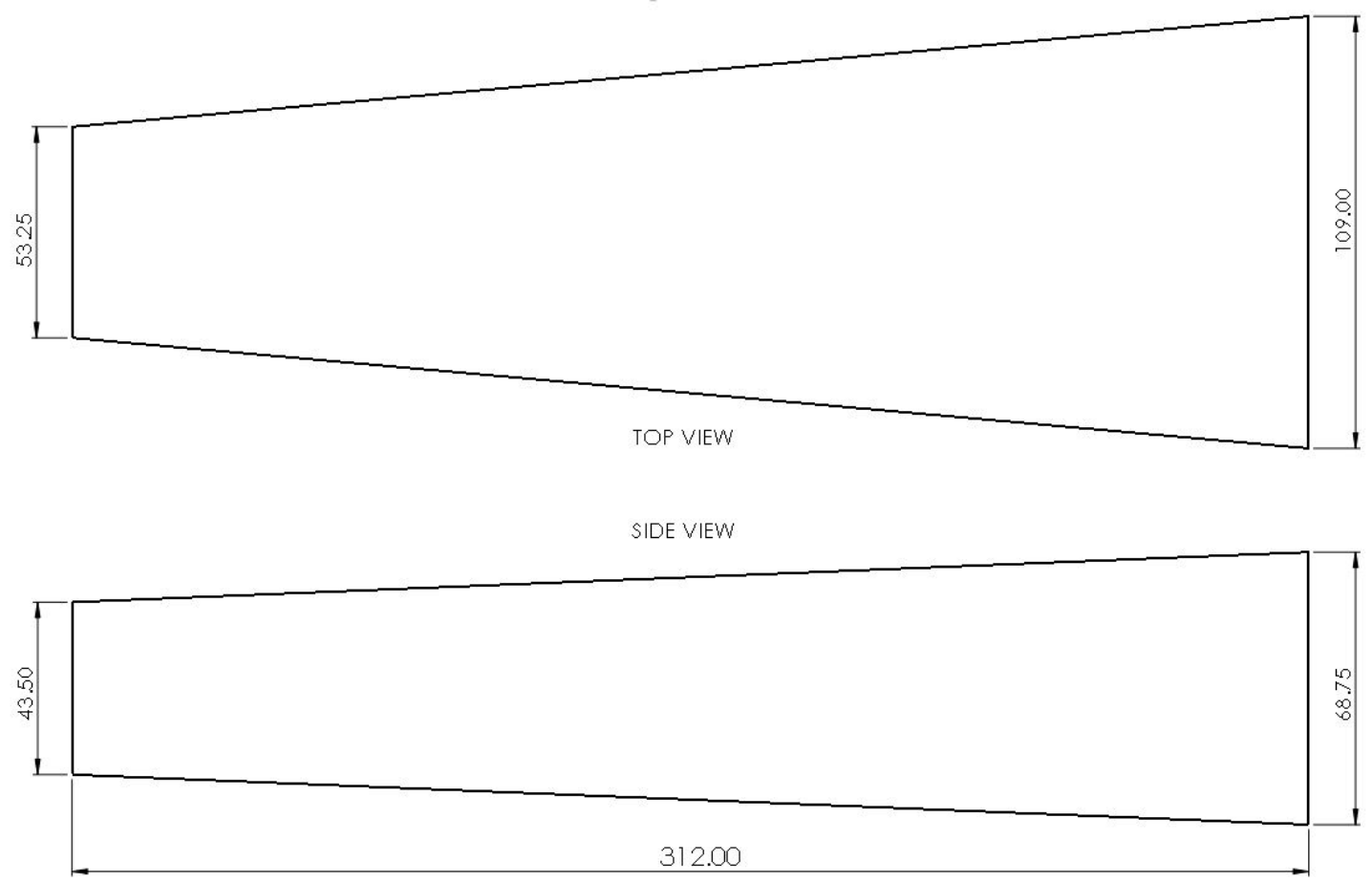

Figure 3.25: WVU low angle diffuser core 


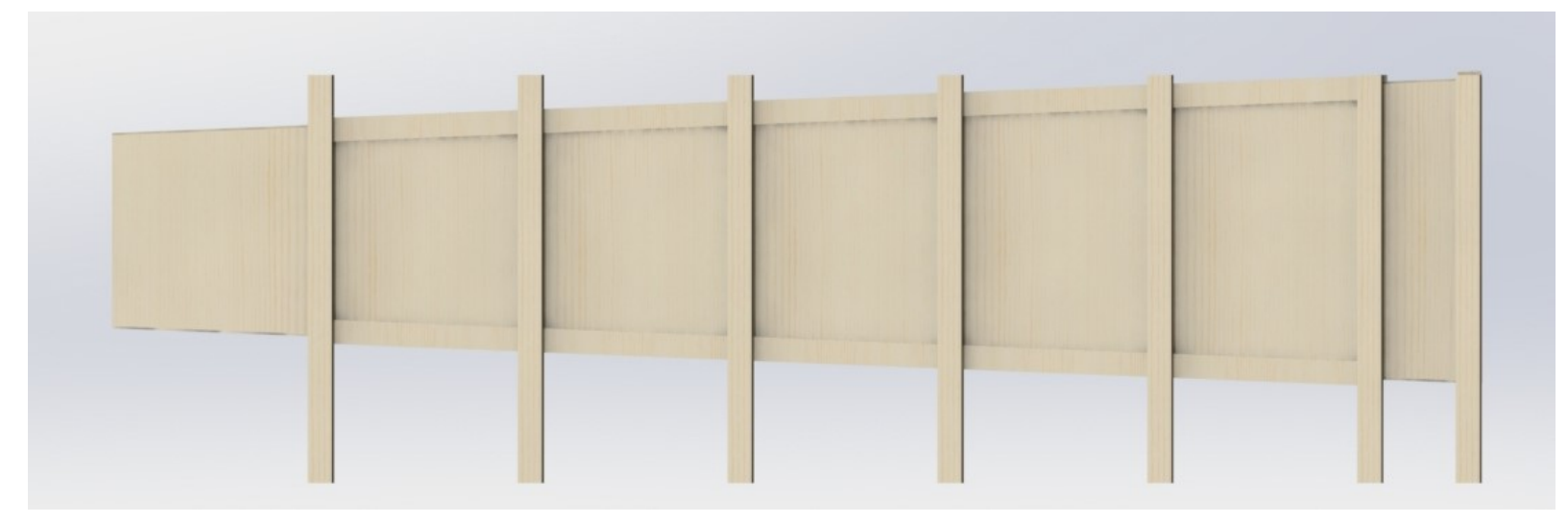

Figure 3.26: Side view rendering of WVU low angle diffuser

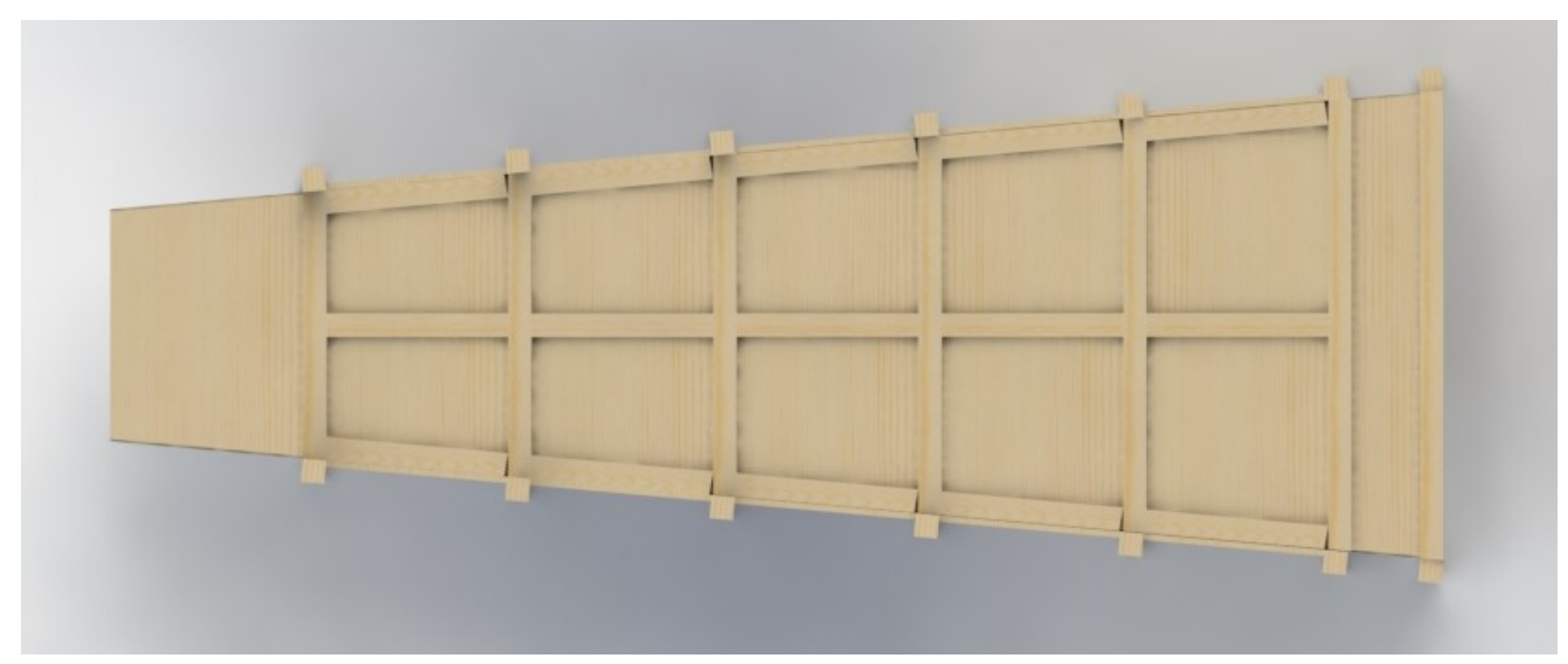

Figure 3.27: Top view rendering of WVU low angle diffuser

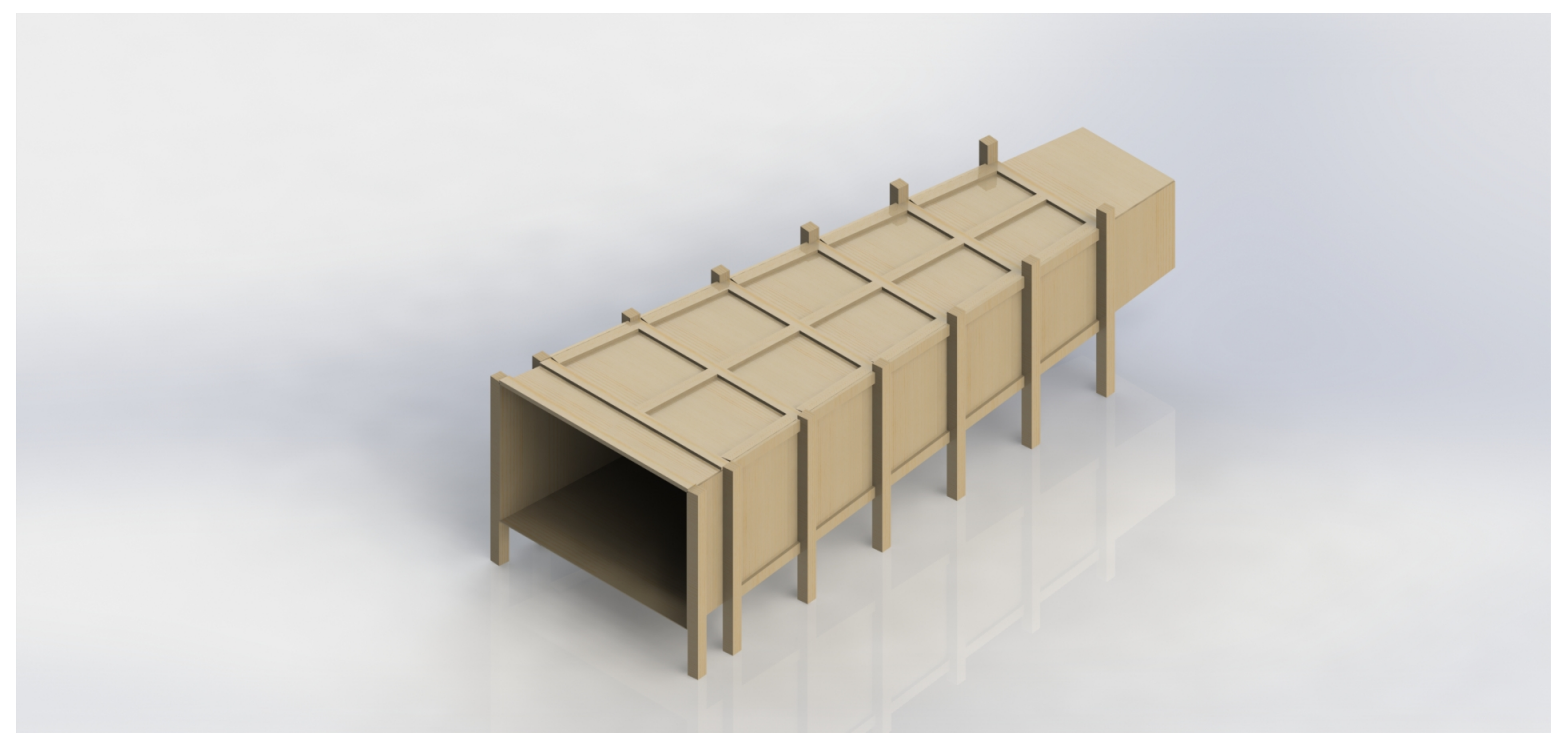

Figure 3.28: Isometric view rendering of WVU low angle diffuser, viewed from outlet 


\subsection{Drive System}

The fans are being reused from the original Cornell tunnel. This system includes 6 fans in a 3 by 2 matrix arrangement. The fans are Buffalo Forge Type "S" Adjustax, Arrangement 4, Vane Axial Fan, Size 25A5-3500 RPM, powered by a two-speed, single winding, variable torque motor. Literature on the fans is difficult to find, due to the age of the fans. In addition to the variable pitch of the fans, inlet guide vanes (IGVs) have been installed on the fans. The IGVs create a pre-swirl to adjust the angle of attack as air moves over the fan blades. The IGV system can be electronically opened and closed from the testing room to alter the angle of attack.

Each fan is attached to its own separate electric motor. The 6 motors are General Electric 3-Phase 15 HP 230V motors. These 2 speed motors have operating RPMs at 1780 and 3550. The tunnel has been wired for the higher of the speeds that were used at Cornell.

To allow the user to adjust speed without having to shut down the EWT and have an electrician rewire the motors, 6 Variable Frequency Drives (VFDs) have been added to each motor. VFDs allow the user to vary the frequency and voltage of the input to the motor in order to control the speed. In some cases, the VFDs are able to be interfaced and controlled via a computer. The VFDs that have been chosen are GS3-2015 15HP DURApulse models. This model was selected for its ability to be controlled by a computer remotely. The added flexibility of VFDs allows EWT users to create custom mappings of speed versus time, which may be able to create flow events that can be reproduced multiple times, such as gusts. All equipment has been wired in a way that will allow the user to control the drive system from inside the testing chamber.

\subsection{Complete Tunnel}

All the sections of the EWT have been review and design methodology have been presented. Using all the designs created in each section each can be combined to create the full 
tunnel design. Figures 3.29 and 3.30 are a full tunneling rendering from a isometric, and side view, respectively.

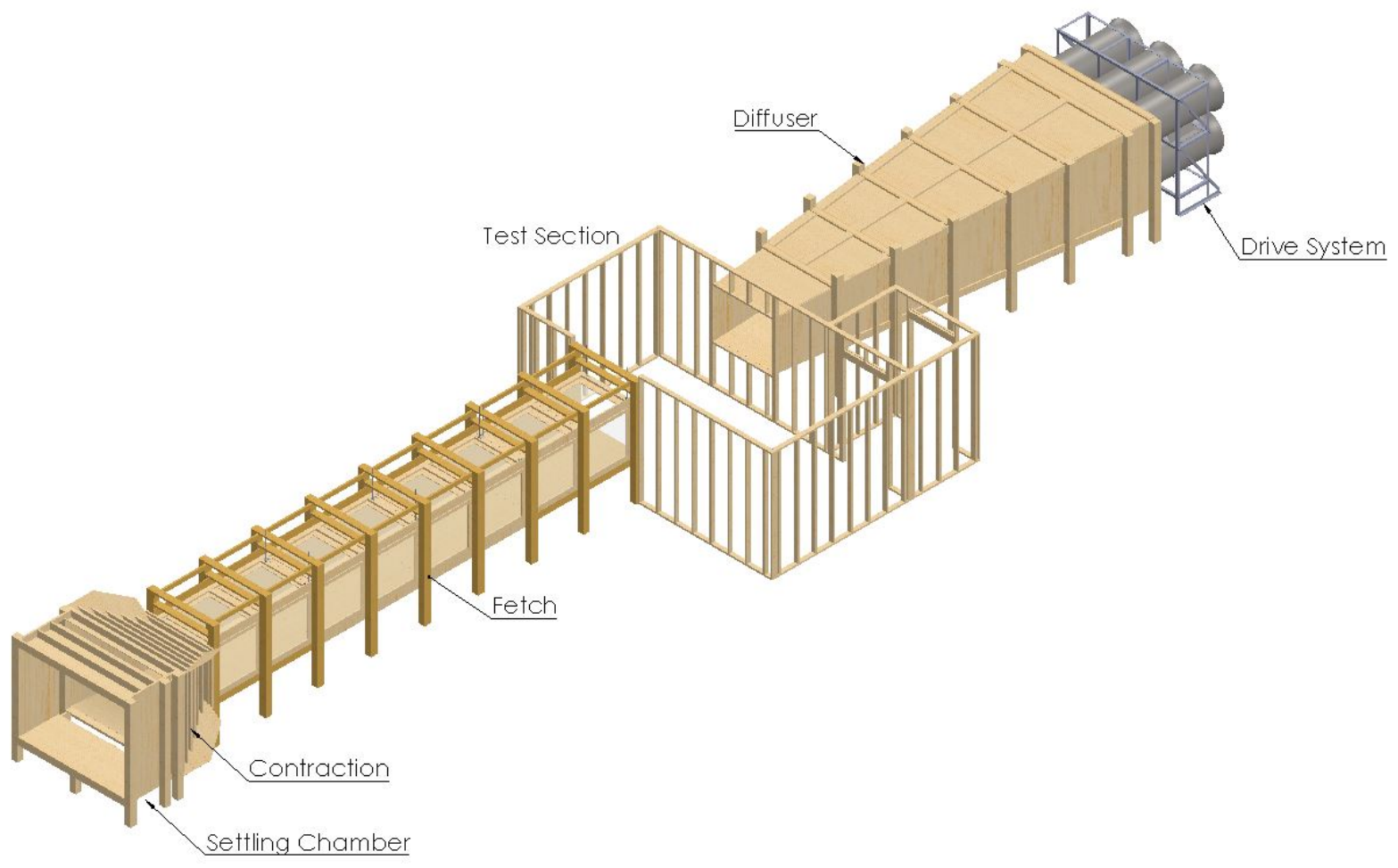

Figure 3.29: Isometric view rendering of complete EWT

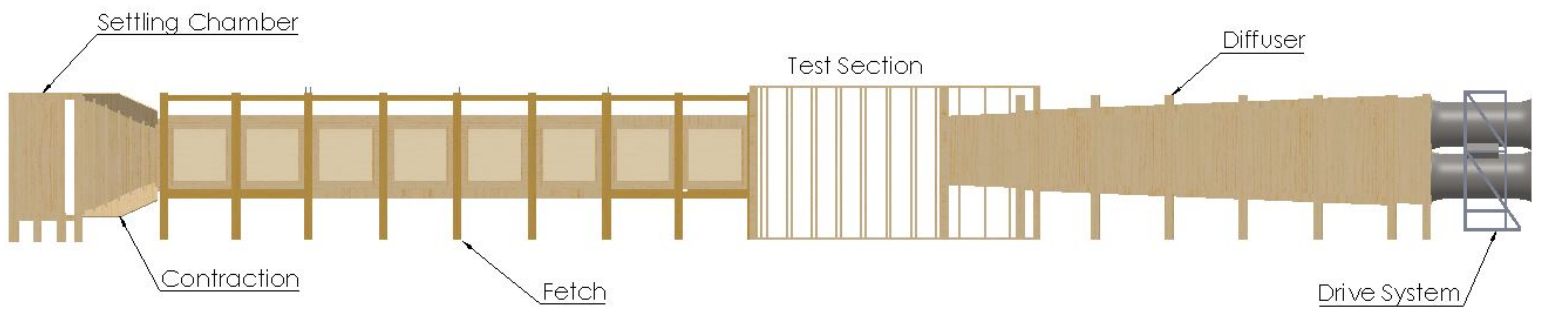

Figure 3.30: Side view rendering of complete EWT 


\section{Chapter 4}

\section{Performance Estimations}

The components of the West Virginia University's EWT have been redesigned for increased performance of the contraction and diffuser, and the power requirements for the fan drive system have been altered. In this section each component of the EWT will be examined and the theoretical performance will be calculated, which will provide a conclusion on whether the current power/fan system is capable of performing to the desired levels.

\subsection{Pressure Loss per Section}

Each section of the EWT has an associated pressure drop during operation. The loss in each section is defined as the mean loss of total pressure sustained by the stream in passing through the particular section. This pressure drop effects the performance of the tunnel by limiting the maximum speed the EWT can attain. The following information will detail the expected pressure drop based on theoretical performance values.

\subsubsection{Settling Chamber}

The settling chamber contains screens and honeycombs. Screens are the major source of pressure drop in a settling chamber and can in fact be the largest source of pressure drop for 
an entire tunnel (rivaled only by high speed turning sections in closed-loop type tunnels). The friction over the length of the settling chamber is considered negligible compared to the pressure loses that the screens create. Therefore, this friction loss will not be considered, only the screen pressure loss will be calculated.

The new tunnel is reusing the Cornell tunnel screen assembly thus the pressure loss coefficient will be the same as the one calculated by Ribando [1]. The change of pressure for a screen can be found using Perry's Chemical Engineering Handbook [49] for incompressible fluids, with constant densities:

$$
\Delta P=K \frac{\rho U^{2}}{2}
$$

where $\rho=$ fluid density, $U=$ superficial velocity based upon the gross area of the screen, $K=$ pressure loss coefficient.

The pressure loss coefficient for the screen installed in the orginal EWT is given by Ribando [1]:

$$
K_{S C} \approx 1.0
$$

\subsubsection{Contraction}

The first step in finding the pressure loss coefficient is finding the hydraulic diameter at the inlet and outlet of the contraction. Hydraulic diameter is given by the following:

$$
D_{H}=\frac{2 L w}{L+w}
$$

Substituting the inlet and outlet dimensions the hydraulic diameters for the inlet, outlet, and the average are: 


$$
D_{H}=6.86 \mathrm{ft} . \quad D_{O}=3.43 \mathrm{ft} . \quad D_{A V}=5.145 \mathrm{ft} .
$$

The contraction ratio is equal to 4 , therefore, the velocity at the outlet is 4 times the velocity at the inlet of the contraction. Using the change in pressure equation [50] to solve for the $K$ value for the contraction:

$$
\begin{gathered}
\Delta P=f \frac{L}{D} \frac{\rho U^{2}}{2 g_{c}} \\
\frac{\Delta P}{\frac{\rho U^{2}}{2 g_{c}}}=0.34 f=K_{c}
\end{gathered}
$$

Wattendorf [51] also gave a reasonable approximation for contraction loss in Equation 4.7. Since contraction loss coefficients are very low compared to other sections of the tunnel, the importance of the shape when considering pressure loss is less important than such things as contraction separation.

$$
K_{c}=0.32 f_{A V} \frac{L_{n}}{D_{H}}
$$

The friction factor is dependent on the Reynolds number at the outlet of the contraction. Based on the Reynolds number and the relative surface roughness, the Moody Chart can be used to find the friction factor. The Moody Chart can be found in Appendix C.

$$
R e=\frac{U D_{O, H}}{\nu}
$$

In Table 4.1, the pressure coefficient is small compared to other sections of the wind tunnel. A value of 0.01 is a good conservative estimate for the pressure loss coefficient for the contraction.

$$
K_{C} \approx 0.01
$$


Table 4.1: Pressure coefficient of the contraction at various velocities

\begin{tabular}{|c|c|c|c|}
\hline Velocity (ft/s) & Reynolds Number & Friction Factor & Pressure Coefficient \\
\hline 5 & $1.07 \mathrm{E}+05$ & 0.018 & 0.0061 \\
25 & $5.33 \mathrm{E}+05$ & 0.014 & 0.0048 \\
50 & $1.07 \mathrm{E}+06$ & 0.013 & 0.0044 \\
75 & $1.60 \mathrm{E}+06$ & 0.011 & 0.0037 \\
100 & $2.13 \mathrm{E}+06$ & 0.01 & 0.0034 \\
\hline
\end{tabular}

\subsubsection{Fetch}

The fetch section is considered to have zero pressure gradient, due to the adjustable roof that is installed.The pressure loss in the fetch is due to the friction of the roughness elements. Using techniques outlined by Gousseau [52] using the lifted ceiling for zero pressure gradient.

$$
\begin{gathered}
\Delta P_{\text {static }, \text { in }}=\Delta P_{\text {static }, \text { out }} \\
K_{F}=\frac{\Delta P_{t}}{q_{T S}}=\frac{v_{I}^{2}}{v_{T S}^{2}}-\frac{v_{O}^{2}}{v_{T S}^{2}}
\end{gathered}
$$

using continuity of mass

$$
K_{F}=\left(\frac{H_{T S}}{H_{I}}\right)^{2}-\left(\frac{H_{T S}}{H_{O}}\right)^{2}
$$

Using 40 inches as the ceiling displacement for the fetch at the exit and the designed test section height of 36 inches the maximum pressure coefficient can be calculated.

$$
K_{F} \approx 0.19
$$

\subsubsection{Test Section}

An open jet friction factor has a reasonable value of $f=0.08$ [14]. Using Equation 4.14, one can easily calculate the pressure coefficient for the open jet test section. 


$$
\begin{gathered}
K_{T S}=\frac{f L}{D_{F, H}} \\
K_{T S} \approx 0.23
\end{gathered}
$$

\subsubsection{Diffuser}

Originally the tunnel was designed with a wide angle diffuser. With the installation of a new low angle diffuser, the pressure loss will change. The loss coefficient is the sum of the friction loses and the expansion losses.

Assuming that the friction factor and the density are constant throughout the diffuser, the relationship between area ratio, friction factor and divergence angle is given as [24]:

$$
K_{f}=\left(1-\frac{1}{A_{R}^{2}}\right) \frac{f}{\sin (\theta)}
$$

With,

$$
A_{R}=\frac{A_{D, O}}{A_{D, I}}=\frac{7384.25}{2316.37}=3.188
$$

Once again using the Moody Chart from Appendix C, the friction factor can be found and used to determine the friction loss coefficient. For the Reynolds number the average hydraulic diameter is used as the characteristic length.

$$
\begin{gathered}
R e=\frac{V D_{D, H, A V}}{\nu} \\
D_{D, H, A V}=5.245 \mathrm{ft} .
\end{gathered}
$$

Based on the Moody chart and the equation that calculates the pressure coefficient, a conservative estimation of a loss coefficient. Using Table 4.2 the frictional $\mathrm{K}$ value is 
examined at various velocities a conservative $K_{f}$ of 0.20 can be determined.

Table 4.2: Pressure coefficient of the diffuser at various velocities

\begin{tabular}{|c|c|c|c|}
\hline Velocity $(\mathrm{ft} / \mathrm{s})$ & Reynolds Number & Friction Factor & Pressure Coefficient \\
\hline 5 & $1.63 \mathrm{E}+05$ & 0.015 & 0.1551 \\
25 & $8.14 \mathrm{E}+05$ & 0.0125 & 0.1293 \\
50 & $1.63 \mathrm{E}+06$ & 0.01 & 0.1034 \\
75 & $2.44 \mathrm{E}+06$ & 0.009 & 0.0931 \\
100 & $3.26 \mathrm{E}+06$ & 0.0075 & 0.0775 \\
\hline
\end{tabular}

$$
K_{f} \approx 0.20
$$

The expansion loses are a function of two variables, diffusion angle, and area ratio. Expansion loses can be found using the following equation:

$$
K_{e x}=K_{e}(\theta)\left(\frac{A_{R}-1}{A_{R}}\right)^{2}
$$

Eckert [53] experimentally found $K_{e}(\theta)$, based on geometry. For this tunnel, the divergence angle is 5 degrees. Therefore, their equation for square geometry between 1.5 and 5 degrees divergence can be used. Using $\theta$ equal to 5 degrees:

$$
\begin{gathered}
K_{e}(\theta)=0.1222-0.04590 \theta+0.02203 \theta^{2}+0.003269 \theta^{3} \\
-0.0006145 \theta^{4}-0.00002800 \theta^{5}+0.00002337 \theta^{6} \\
K_{e}(\theta)=0.7456
\end{gathered}
$$

With $K_{e}(\theta)$ found we can plug into the expansion loss equation to find $K_{e x}$ using Equation 4.21:

$$
K_{e x}=0.351
$$


Combining the friction loss coefficient and the expansion loss coefficient, the total pressure loss coefficient can be found for the diffuser section of the EWT

$$
\begin{gathered}
K_{D}=K_{f}+K_{e x} \\
K_{D} \approx 0.2+0.351=0.551
\end{gathered}
$$

Note that the dominant sources of pressure loss for the EWT would seem to be the screens and diffuser, based on $\mathrm{K}$ values.

\subsection{EWT Total Pressure Loss}

After finding all the pressure coefficients for each of the sections summing coefficients and multiplying by the EWT velocity would be the obvious method to find the total pressure loss for the entire EWT, shown in Equation 4.27. However, because the flow in the tunnel is not the same throughout and the shape changes they cannot be summed to get an accurate representation of total pressure loss.

$$
K_{T}=\sum\left(K_{1}+K_{2}+\ldots K_{n-1}+K_{n}\right)
$$

To find to total pressure loss for the EWT the pressure loss for each section is found individually and then summed, as seen in Equation 4.28

$$
\Delta P_{T}=\sum\left(\Delta P_{1}+\Delta P_{2}+\ldots \Delta P_{n-1}+\Delta P_{n}\right)
$$

where

$$
\Delta P_{i}=K_{i} q_{i}=K_{i} \frac{1}{2} \rho u_{i}^{2}
$$


with $q_{i}$ being dynamic pressure of the section

To compare the pressure loss among the different parts, the pressure loss coefficient relative to the test section $K_{T S}$ is introduced. Table 4.3 shows the pressure loss and $K_{T S}$ for each of the sections

$$
K_{T S, i}=K_{i} \frac{q_{i}}{q_{T S}}
$$

Table 4.3: Total Pressure coefficients and pressure losses for sections with test section velocity equal to $30 \frac{\mathrm{m}}{\mathrm{s}}$

\begin{tabular}{|c|c|c|c|c|c|}
\hline Section & $K_{i}$ & $q_{i}(\mathrm{~Pa})$ & $\Delta P_{i}(\mathrm{~Pa})$ & $K_{T S}$ & Percent \\
\hline Settling Chamber & 1.0 & 27.5 & 27.49 & 0.048 & 4.73 \\
Contraction & 0.01 & 27.5 & 0.2749 & 0.00048 & 0.047 \\
Fetch & 0.19 & 569.0 & 108.11 & 0.19 & 18.63 \\
Test Section & 0.23 & 569.0 & 130.87 & 0.23 & 22.55 \\
Diffuser & 0.551 & 569.0 & 313.5361 & 0.551 & 54.03 \\
\hline & & Total & 580.29 & 1.019 & 100 \\
\hline
\end{tabular}

\subsubsection{Fan Power Required for Steady Operation}

The power needed to operate a wind tunnel is calculated by multiplying the total pressure loss with the flow area [41][53]:

$$
\text { Power }=A_{T S} U_{T S} \Delta P_{T}
$$

To run at the goal of $30 \mathrm{~m} / \mathrm{s}$ the power required would be about $15,841.9 \mathrm{~W}$ or $15.8 \mathrm{~kW}$. The total available power using the existing six motors from the Cornell tunnel is $67.11 \mathrm{KW}$. However, that is the power required if the fans are running at 100 percent efficiency with no losses. Fan and motor efficiency must be taken into account. Using the following Equation the power required by the fan for steady flow is calculated:

$$
\text { Power }_{\text {fan }}=\text { Power } \frac{R F}{\eta}
$$


with $R F$ being reserve factor, and $\eta$ the combined fan and motor efficiency. The efficiency given by literature supplied by Buffalo Forge (Appendix D) is about 65\%, and the reserve factor is 1.1 to account for any unknown interactions with the fans. With those values the power required to be inputed by the fans is $26.73 \mathrm{~kW}$, this accounts for about half the available power from the combined six motors. Therefore, there is enough power for flow in the test section to reach $30 \frac{m}{s}$, with extra power available.

\subsubsection{Variation of Test Section Velocity}

With the installation of the VFD drives, the amount of power that can be inputted into system is infinitely variable. Combined with the IGVs that were originally installed, the wind speed can be fine-tuned. The original performance curves of the IGVs at the original two speeds was supplied by Buffalo Forge to Cornell in Appendix E. With the addition of the VFDs the new EWT can perform at more than these two speeds. With the modifications of the EWT these plots may not be exactly identical. Therefore, the maximum average velocity and data pertaining to fan and IGV performance has changed and will be found during qualification, but is expected to be over $30 \mathrm{~m} / \mathrm{s}$. 


\section{Chapter 5}

\section{WVU EWT Construction}

\subsection{Contraction}

The contraction is four individually constructed sides that when attached together form the contraction as a whole. The sides are made of wood and use two by fours to create cross bracing, shown in Figure 5.1. The sheeting was then attached to the cross bracing to form the wall shape that is required for optimal flow.

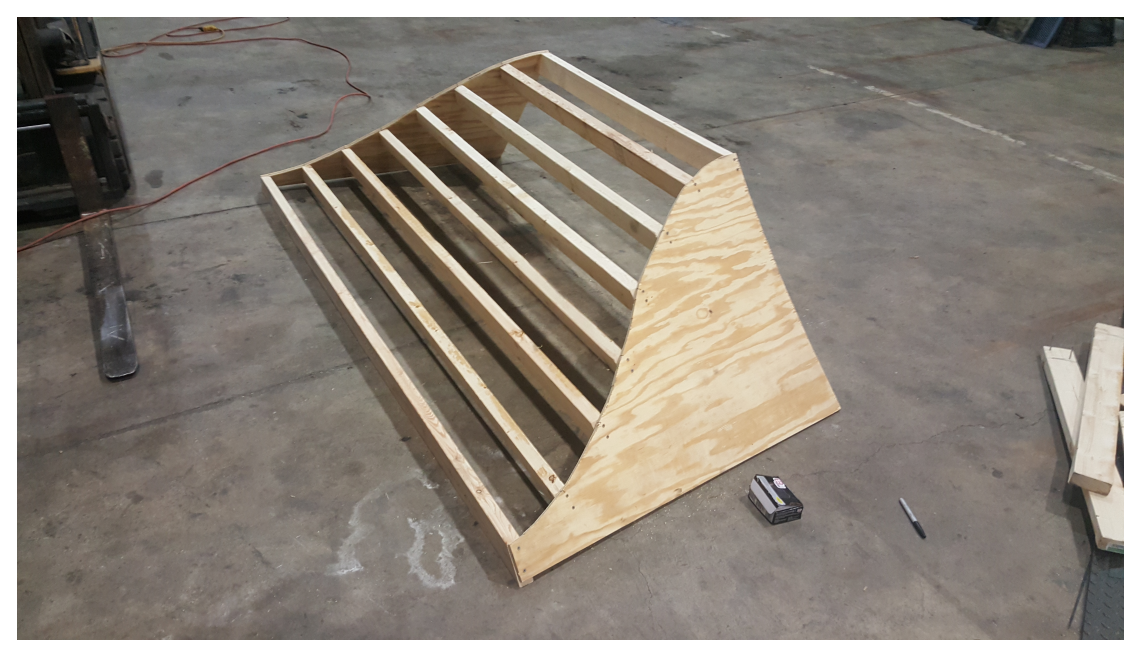

Figure 5.1: One side of the contraction; four were created and attached to each other to create the shape of the contraction

The contraction is then attached to the beginning of the fetch and the settling chamber, 
at the location in Figure 5.2. The contraction uses the fetch and settling chamber as its support, and does not require any support from the ground.

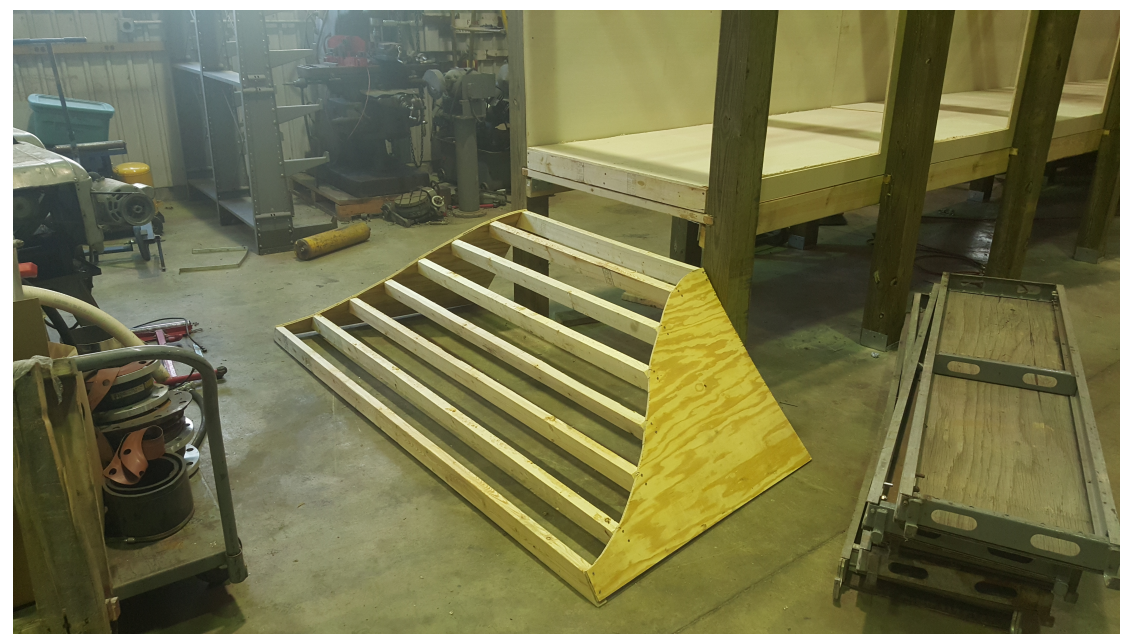

Figure 5.2: Contraction side placed at location on the EWT before installation

\subsection{Fetch}

The main supports of the fetch section are attached to the concrete floor. Each support is a self-contained unit that includes floor supports and adjustable ceiling support, along with a guide for the ceilings' threaded rods to reduce the degrees of freedom the ceiling has; see Figure 5.3.

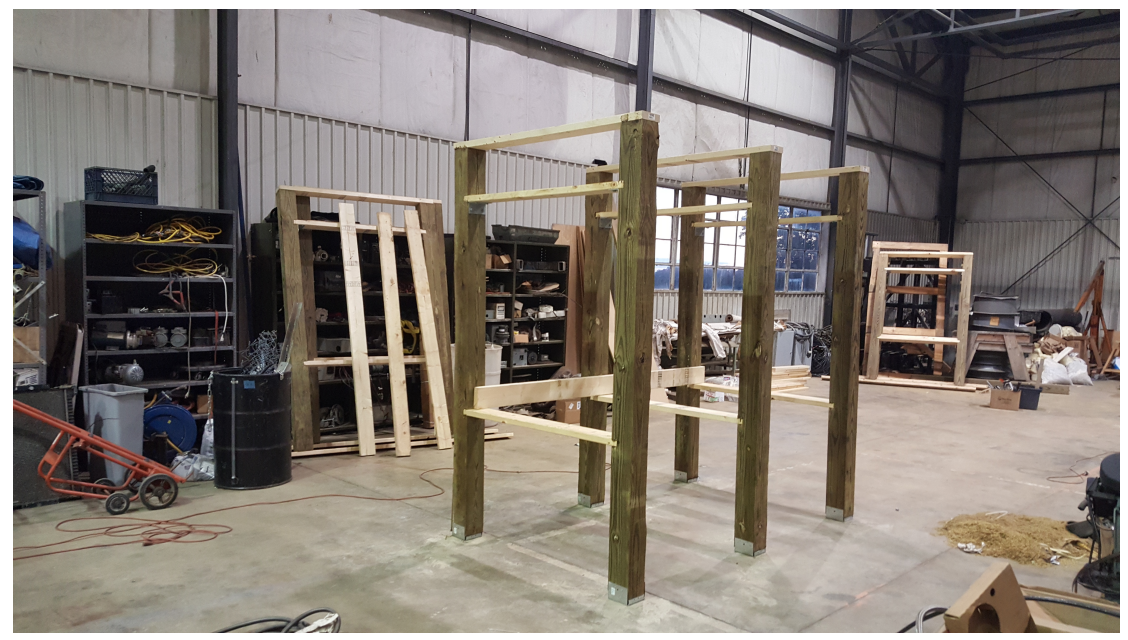

Figure 5.3: First three main supports for the fetch section of the nine total are placed 
The walls of the fetch are made of hardwood plywood, and run the entire length of the fetch. This wood was primed so that the wall could be painted to the desired color. One wall installed is shown in Figure 5.4.

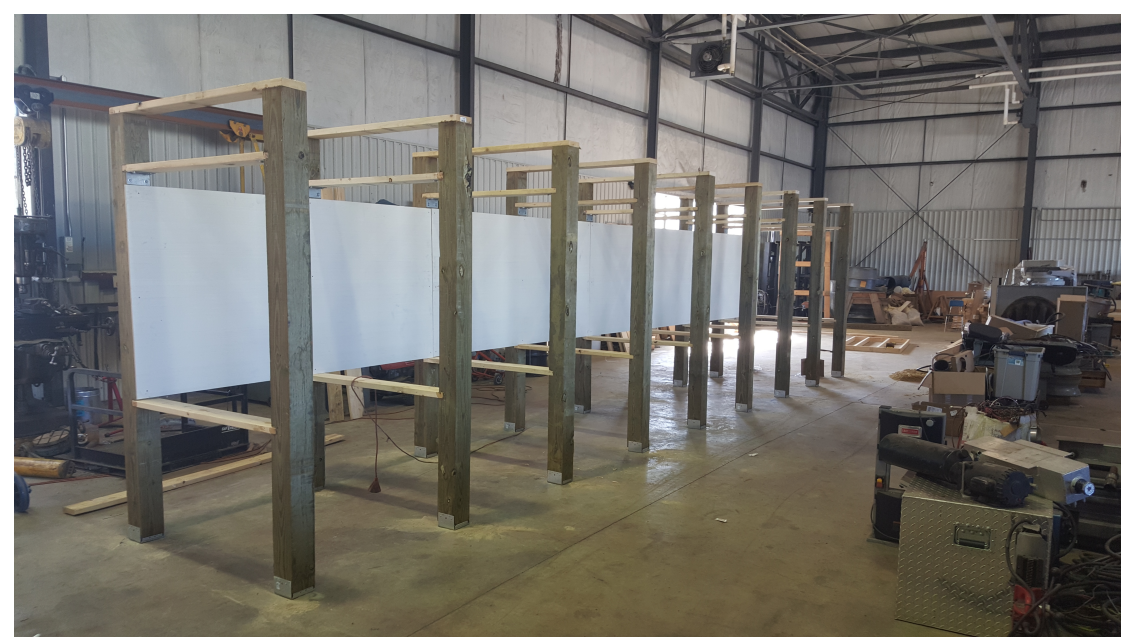

Figure 5.4: All main fetch supports in place, with one interior wall installed

The floor is removable inside the fetch. This allows for different floor designs to be created and swapped out for different roughness elements to be used to create various BL velocity profiles; see Figure 5.5.

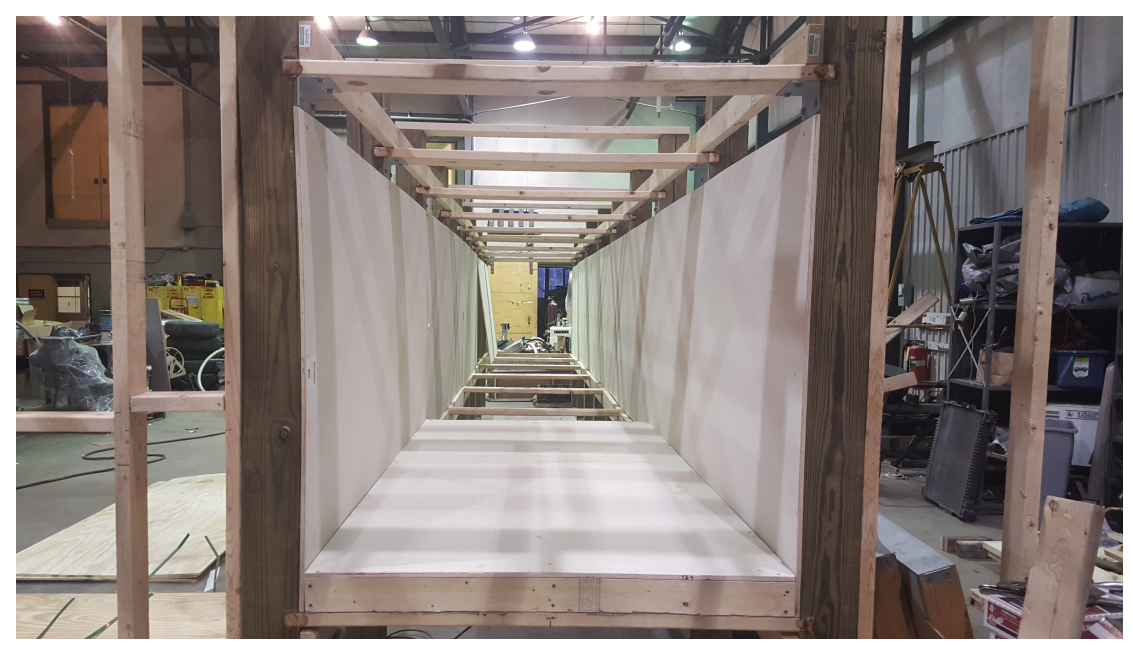

Figure 5.5: Both side walls were installed with the first removable floor section placed inside for sizing verification

Another reason for the installation of removable floor is the possibilities of installing 
water pans where the floor is. This allows testing that may require the study the effects of a boundary layer formed over water.

The windows are installed in the fetch to allow the user to observe flow inside the fetch. This may be useful for researchers who use the end of the fetch as an ad hoc test section. The windows are made of polycarbonate sheets that are transparent. Acrylic was not used due because it can chip more easily then polycarbonate can. The cutting out locations of the walls in the fetch are shown in Figure 5.6 and 5.7.

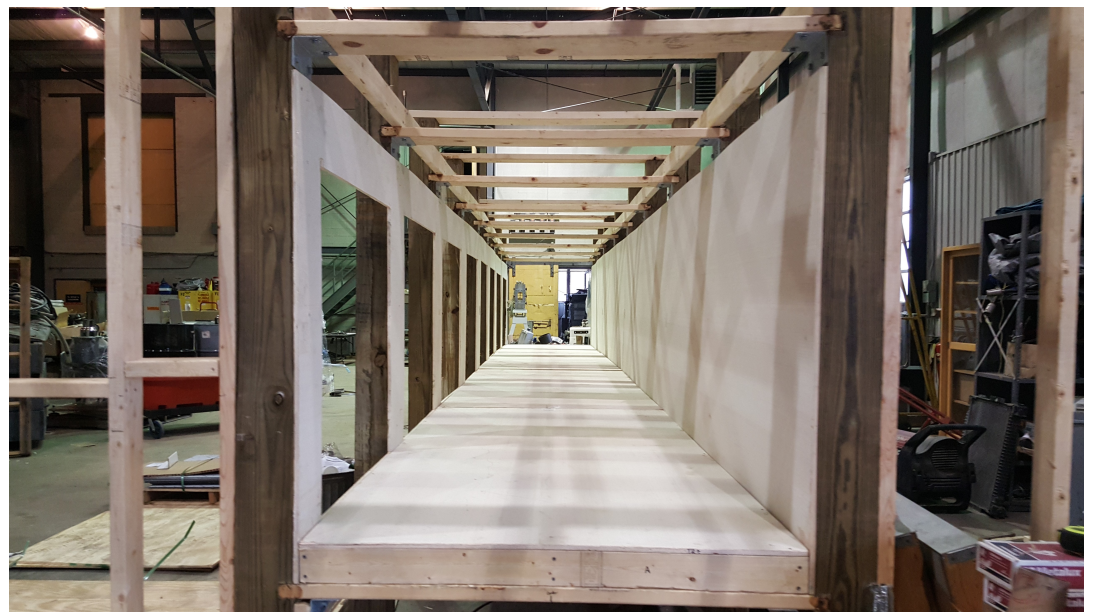

Figure 5.6: Areas where window assembly will be placed cut into wall. Removable floor completed and installed

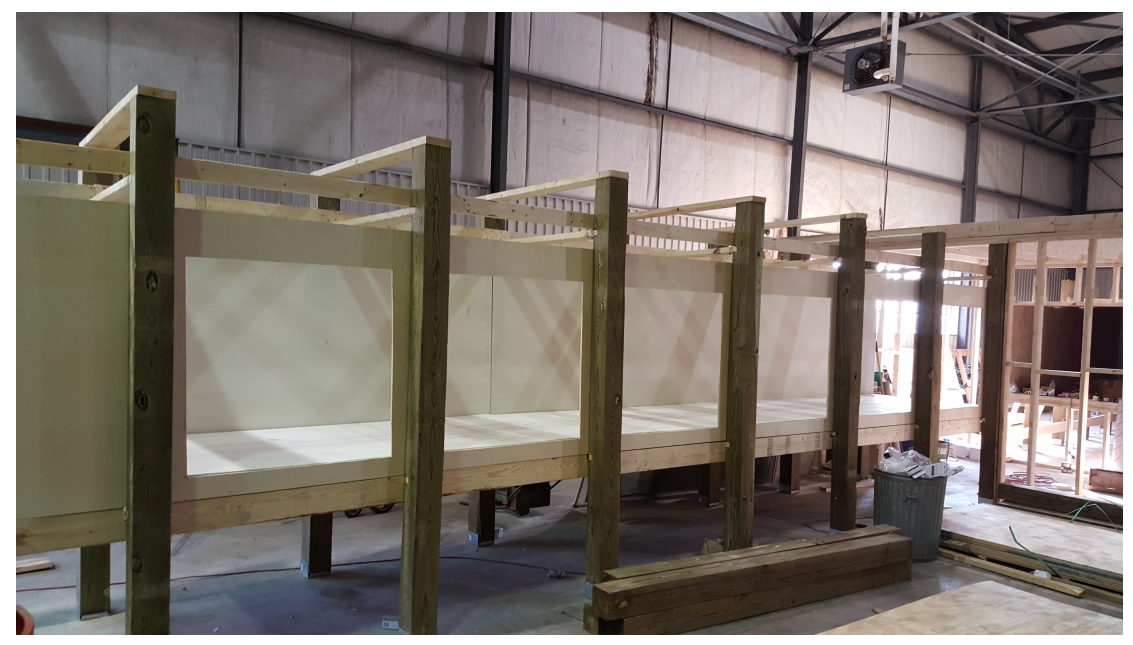

Figure 5.7: Areas where window assembly will be placed cut into wall. Removable floor completed and installed 


\subsection{Testing Room}

The testing room is a framed room constructed using basic carpentry techniques. Standard two by four studs on 16 inch centers are used for structural strength. Small studs were placed in between studs to to brace and increase the rigidity of the room. Double plates are used at the ceiling for support of the ceiling frame. The floor is attached to the concrete floor using masonry screws that are resistant to pull out and can keep the walls in place. Figure 5.8-5.11 show views of the construction of the testing room.

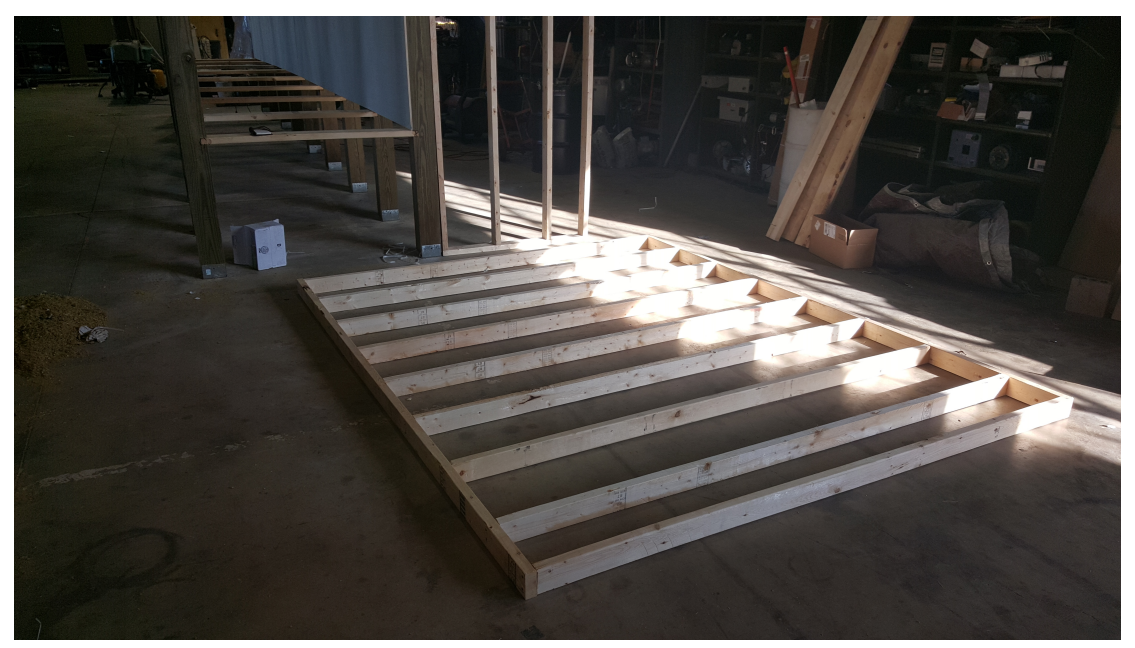

Figure 5.8: First short wall in testing room before being stood vertical

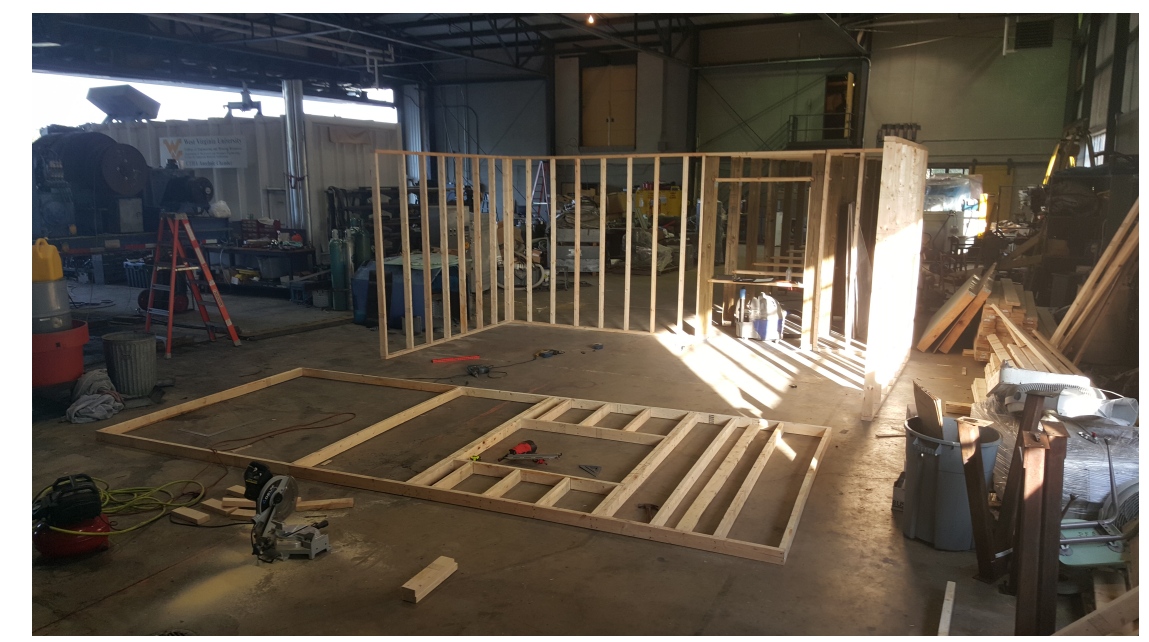

Figure 5.9: Long wall and location of diffuser inlet being constructed 


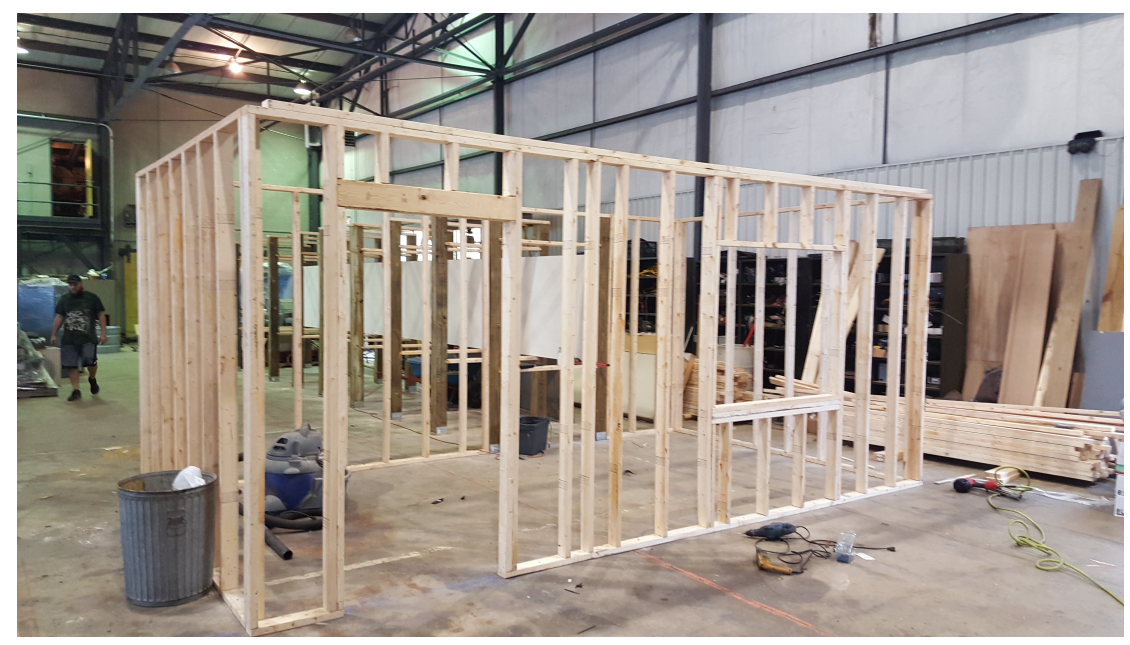

Figure 5.10: Main testing room walls complete

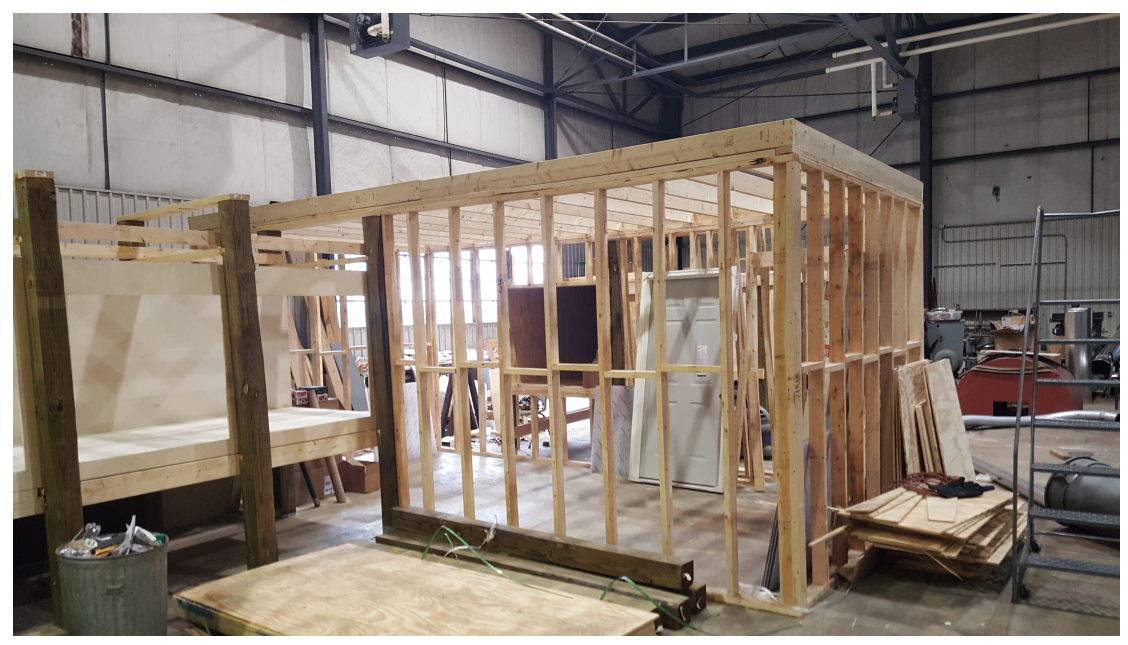

Figure 5.11: Completed main testing room, ceiling now constructed. Electrical and drywall were next step at this point

The inlet of the diffuser is created inside the wall of the testing room. The diffuser will then attach to the wall. This is done to reduce any leakage when transitioning from the testing room to the diffuser. The testing room also has a small airlock room (not pictured); the addition of the airlock room suppresses any secondary flows that may occur from the door opening and closing. The ceiling uses two by six boards on a 16 inch center to support the drywall that hangs on the ceiling. 


\subsection{Diffuser}

The diffuser supports are similar to the design of the fetch, with the exception that the ceiling guides are not needed; see Figure 5.12. Two cross braces are used to support the floor and the ceiling of the diffuser.

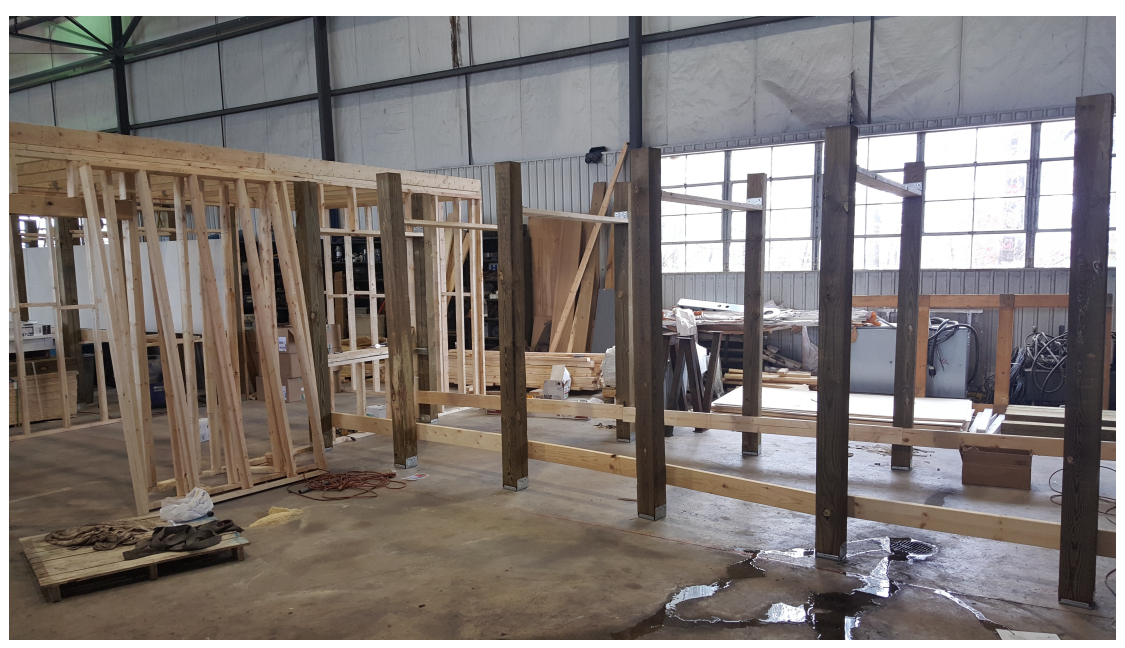

Figure 5.12: Main support for diffuser installed

The shell is a made of half inch thick plywood the entire length of the diffuser. Each 4 foot section is cut to shape of the expansions on all four walls. The smaller section allows for easier repair. If a model was to become lose and enter the diffuser and damage the walls instead of replacing a cumbersome 8 foot section the area that sustained the damage can be replaced easily, by one person if necessary. Figure 5.13 shows the diffuser shell being installed. 


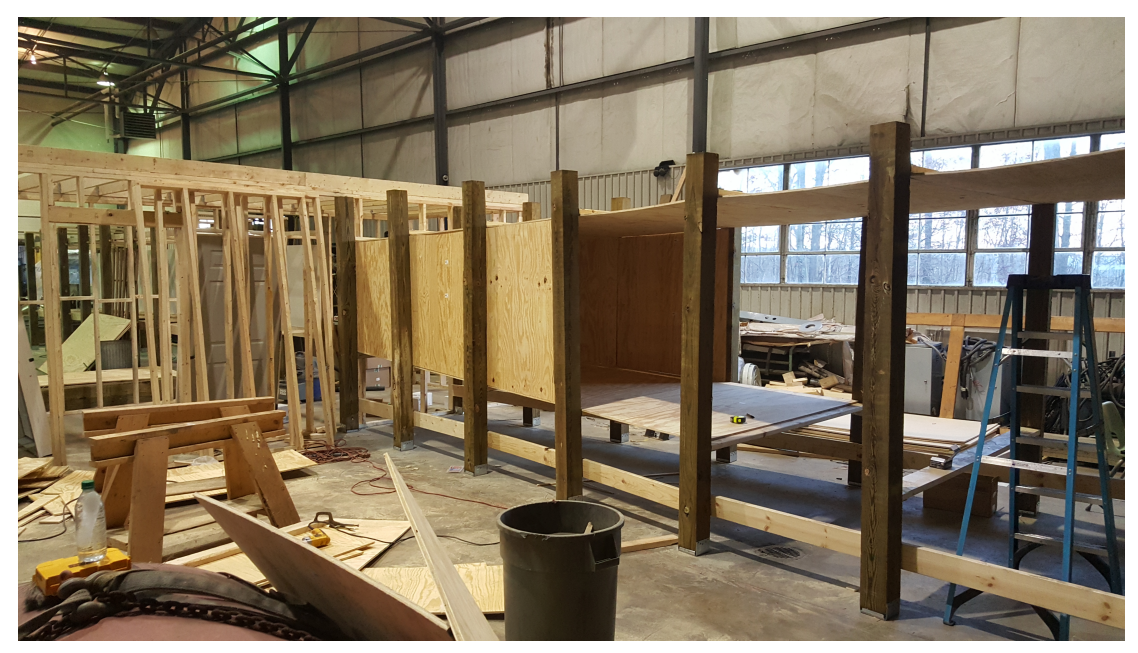

Figure 5.13: Diffuser shell being installed

Corner supports are added along the length of the fetch section; shown in Figure 5.14. This reinforces the corner while also sealing the diffuser and reduces the leakage from the section.

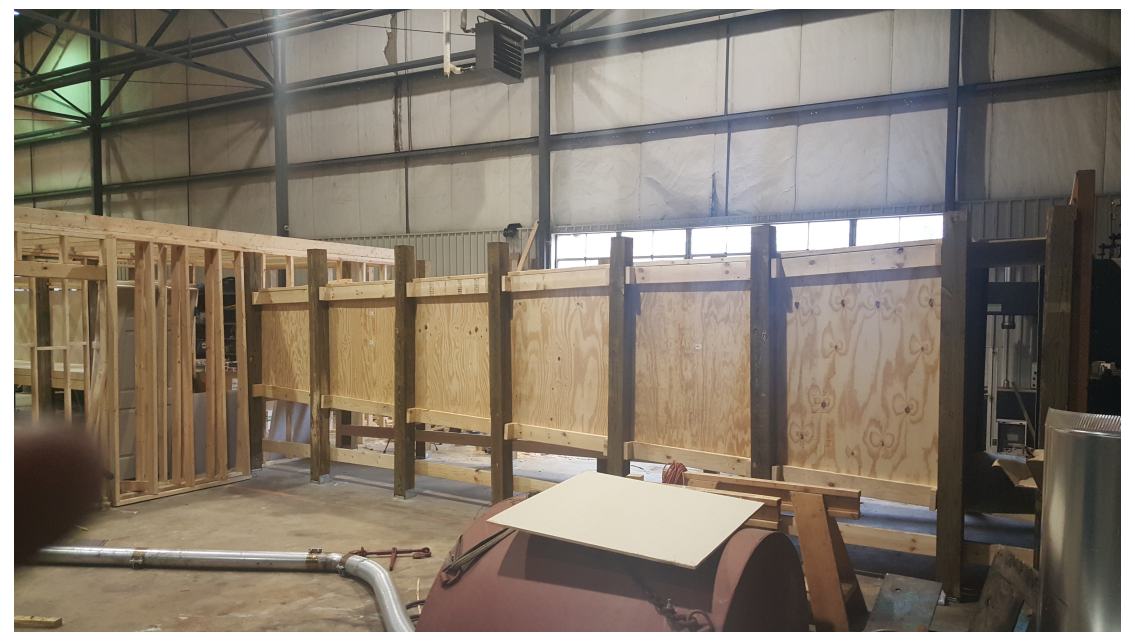

Figure 5.14: Diffuser walls installed and corners reinforced

\subsection{Drive System}

The original frame from Cornell was cut in half for transportation purposes. The frame then needed to be welded back together before then motors could be installed; see Figure 5.15. 


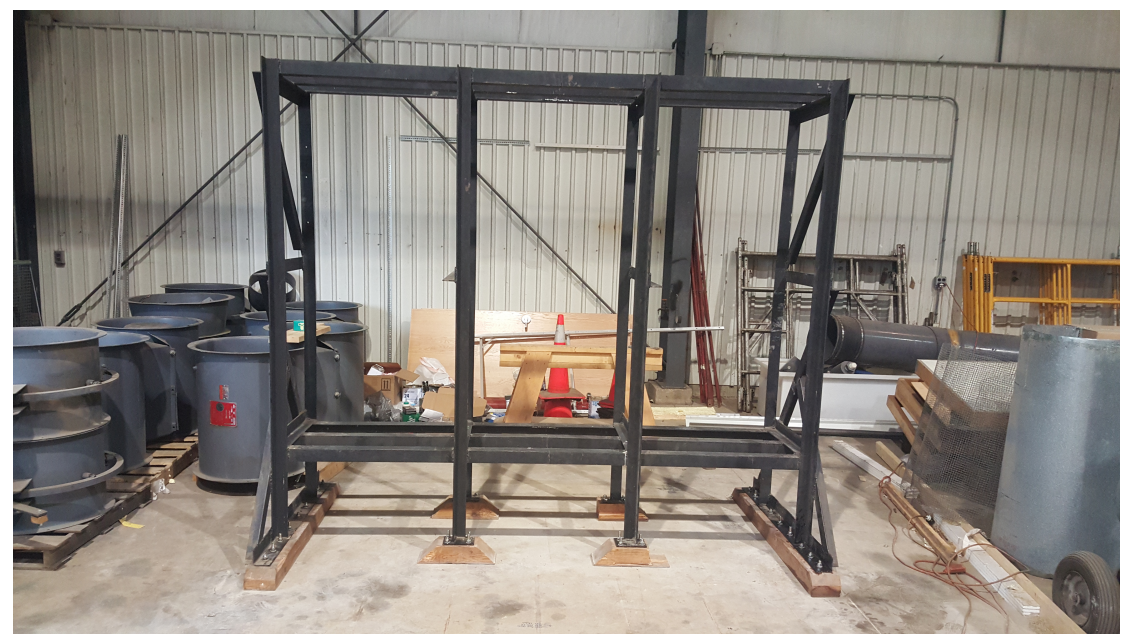

Figure 5.15: When the frame that hold the motors was transported it was cut in half. Welding the frame back together was required before motors could be placed back in it.

The drive system frame uses anchors embedded in the concrete floor. The large number of anchors distributes any forces generated by the drive system. The wood set between floor and frame acts as a vibration dampening; see Figure 5.16.

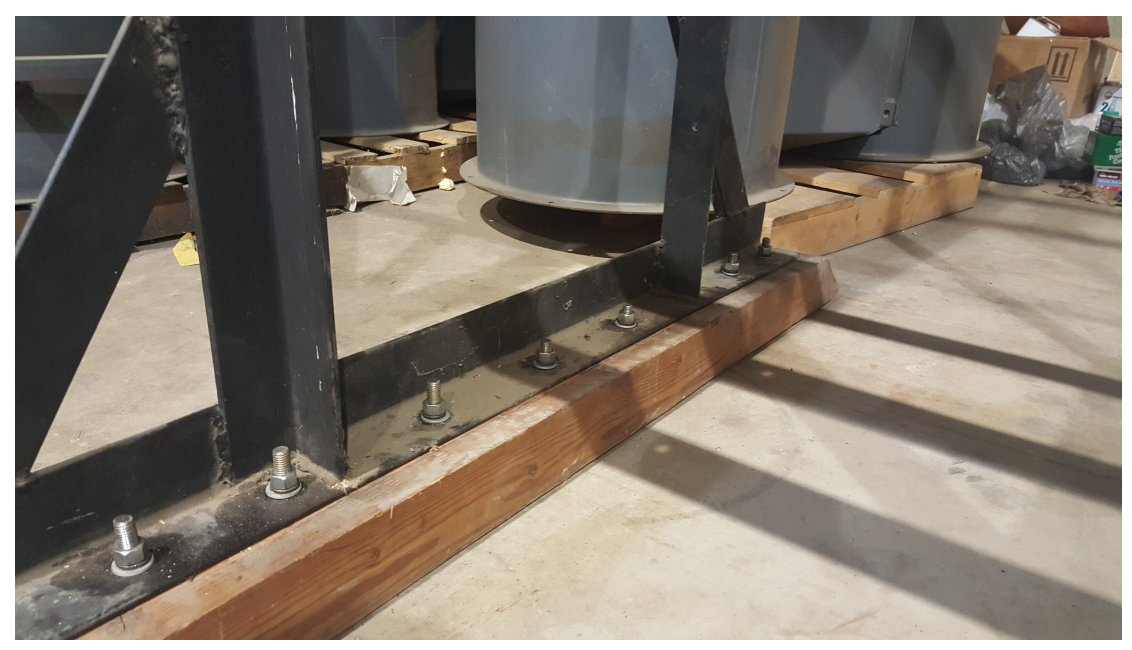

Figure 5.16: The frame as attached the floor using anchors that were implanted into the concrete

All six motors are individually attached to the frame using 6 half inch bolt and nut combinations. The top row hangs from the top supports, while the bottom motors are set on top of the bottom supports, shown in Figure 5.17 


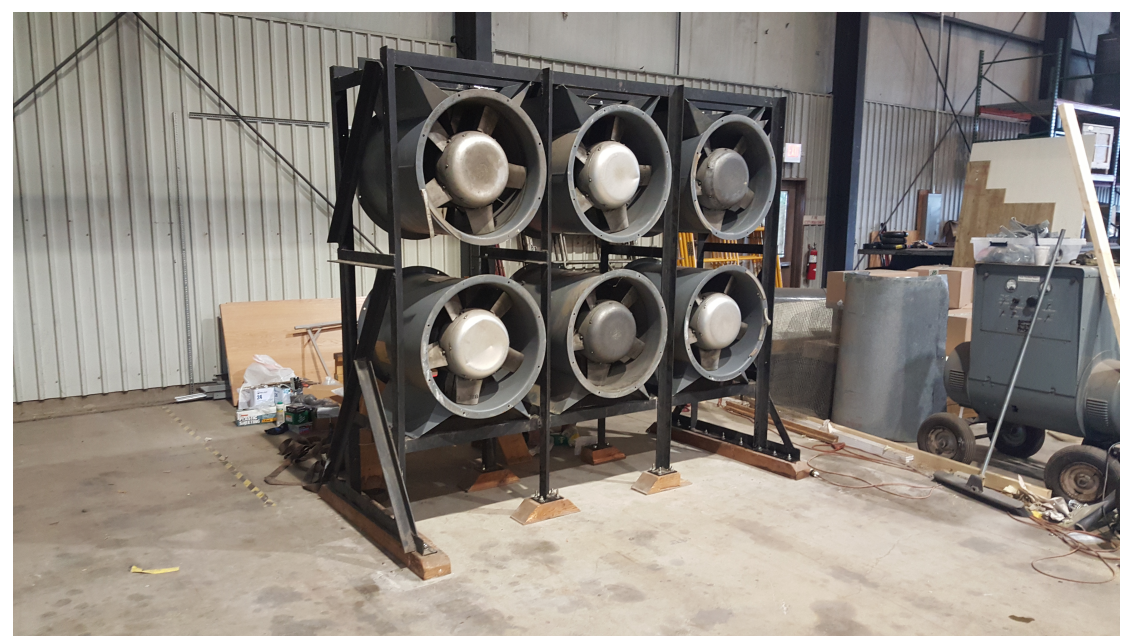

Figure 5.17: All motors installed and secured to the frame 


\section{Chapter 6}

\section{Qualification Methods}

The construction of any new tunnel or the redesign of a current in-service tunnel requires that certain parameters must be measured to give users the baseline characteristics of the wind tunnel's test section. The new West Virginia University EWT is no exception. After completion of construction, measurements of the characteristics will be needed. This section will discuss the types of measurements, and the methods needed to meet the requirements.

\subsection{Measured Parameters for Qualification}

\subsubsection{Velocity}

First, a setup must be developed to measure velocity over the complete cross-sectional area of the test section, because unlike a general use wind tunnel the velocity profile is not uniform. A common way to measure velocity is the use of a setup with anemometers. Multiple types of anemometers exist, but only a few can meet the design requirements needed for WVU's EWT. For example, a cup anemometer is unlikely to be used in the EWT due to its bulk size and limitations on an area velocity can be measured.

Two common anemometers used in wind tunnels are hot-wire anemometers and pitot static anemometers. A hot-wire anemometer uses a metal wire, whose resistance is sensitive 
to temperature. A relationship between the velocity and measured voltage can be established. The relationship is described by a calibration curve; an example is shown in Figure 6.1.

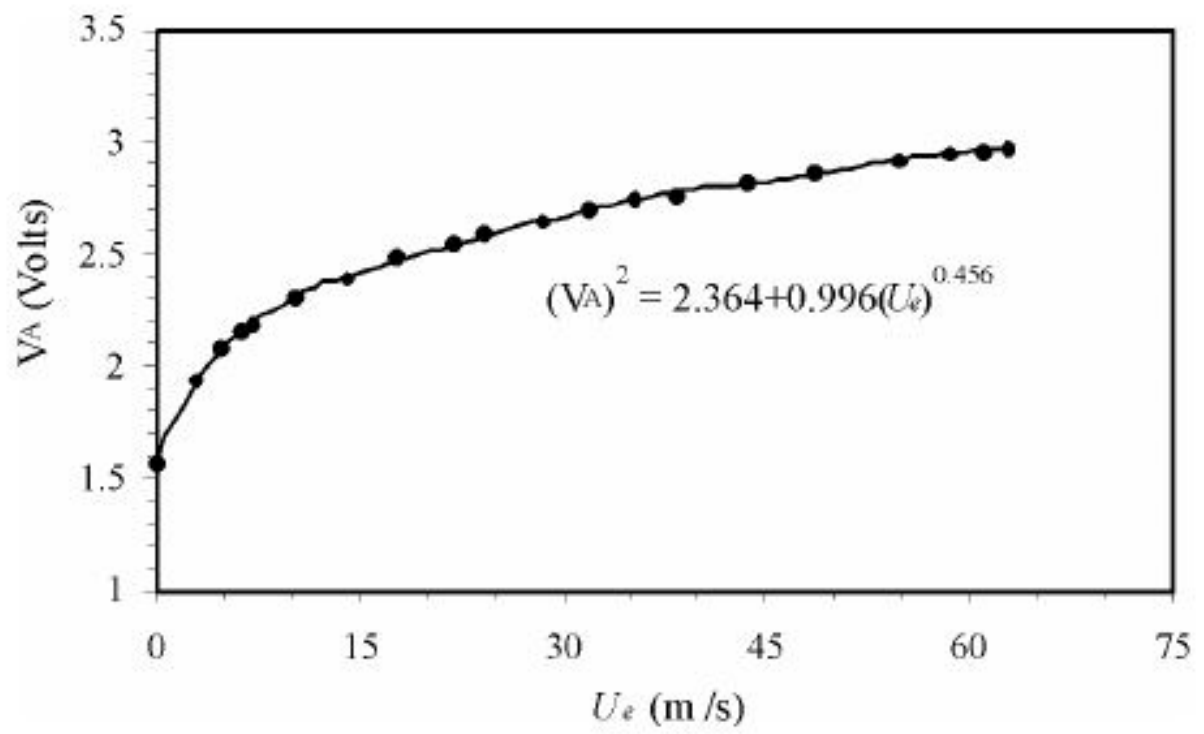

Figure 6.1: Example hot-wire anemometer calibration curve

A pitot static anemometer measures the total pressure of a flow when it is directly pointed into the flow direction, although it can accurately read up to 20 degrees off-angle [24], by measuring the pressure inside the pitot tube since there is no outlet for the flow to pass-through. This type of anemometer uses Bernoulli's equation:

$$
P_{t}=P_{s}+\frac{\rho U^{2}}{2}
$$

where $P_{t}$ is the total pressure and $P_{s}$ is the static pressure. By solving for the velocity, you can find the velocity at the pitot static tube:

$$
U=\sqrt{\frac{2\left(P_{t}-P_{s}\right)}{\rho}}
$$

Hot-wire anemometry (HWA), sometimes called constant temperature anemometry (CTA), is often used to accurately measure test section velocity. Due to the high response rate (often greater than $100 \mathrm{kHz}$ ) of HWAs to changes in velocity, it is ideal for use in an environment 
where turbulence must be measured accurately. The primary disadvantage for any HWA system is the relative fragility of the thin wires themselves. For EWT applications, or any other application where the flow has a high potential for aerosols (e.g., small grains of sand or even large dust particles) the wires can suffer foreign object damage (FOD). In such cases, CTA can still be used, but the sensors employed are somewhat larger film-based probe tips.

\subsubsection{Turbulence}

There are multiple ways to measure turbulence. A past common way to measure turbulence is by using a turbulence sphere. These spheres are used because when the flow trips to turbulent in the wake there is a dramatic drop in drag, making it easy to find critical Re. The critical Reynolds number for a sphere in a free atmosphere to trip to turbulent flow in the wake has been found through flight data to be $3.85 * 10^{5}$ [54].

The critical Reynolds number can be measured for a sphere in two ways. The first method is by plotting measured $C_{D}$ based on cross-sectional area versus the diameter-based Reynolds Number. The second method is by taking the average of the four pressures on the back of the sphere and subtract the average from the total pressure at the leading edge of the sphere. A plot of $\Delta P / q$ versus the Reynolds number is created.

Using a force or pressure measurement, the critical Reynolds number is found, and then comparing the free atmosphere Reynolds number, the turbulence factor is calculated below:

$$
T F=\frac{3.85 \times 10^{5}}{\operatorname{Re}_{T S}}
$$

From the turbulence factor the effective Reynolds number can be found for the tunnel through multiplying the turbulence factor by the Reynolds Number in the test section, shown in Equation 6.4.

$$
R e_{e f f}=T F * R e_{T S}
$$


The main drawback of the using a turbulence sphere is that it gives an overall averaged picture of how the test section turbulence is behaving. Inside a EWT the turbulence behavior is very sensitive inside the test section. Therefore, a turbulence sphere is not ideal for measuring turbulence levels in an EWT.

Another method of measuring turbulence inside a tunnel is the use of a hot-wire anemometer. Since the hot-wire anemometer is small in size and has a fast response rate to changes in velocity, it is ideal for measuring turbulence in an EWT. It can easily be attached to a mechanism and can be moved to take data at various points in the test section.

Turbulence intensity is a percentage based parameter that hot film anemometers can determine. Unlike a turbulence sphere, which relies on force and pressure measurements, a hot-wire is able to use velocity directly to determine turbulence. Turbulence intensity is the ratio of standard deviation of the change in local wind velocity and the main wind velocity, shown in Equations 6.5 and 6.6.

$$
\begin{gathered}
\sigma=\overline{u^{\prime}(t)^{2}} \\
T I=\frac{\sigma}{U_{\infty}}
\end{gathered}
$$

A rough relationship between turbulence intensity and turbulence factor is:

$$
T I=1.255(T F-1.0)
$$

\subsection{Recommendations for Qualification of WVU EWT}

For the EWT, a system that is capable of measuring the velocity profile and turbulence intensity needs to be constructed. This system must be able to accurately measure the boundary layer that is present when the flow is at the desired position in the tunnel. In 
this section, recommendations for a system will be outlined for use in the West Virginia University EWT qualification.

\subsubsection{Measuring Velocity}

For velocity profile measurements, a thermal anemometry system is recommended to be used. A hot wire anemometer fast response to changes in velocity is the ideal type of measurement device. However, due to the types of test that are conducted inside an environment wind tunnel, such as aerosol testing, a hot wire probe is not rugged enough to withstand such conditions. A hot film probe works on the same principle as hot wire probe but with increased resistance to damage. The sensor is maintained at a constant temperature by use of a bridge and amplifier circuit, shown in Figure 6.2. The amplifier senses when the bridge is off balance and will adjust the voltage to rebalance the bridge. The voltage supplied can be related to the flow velocity.

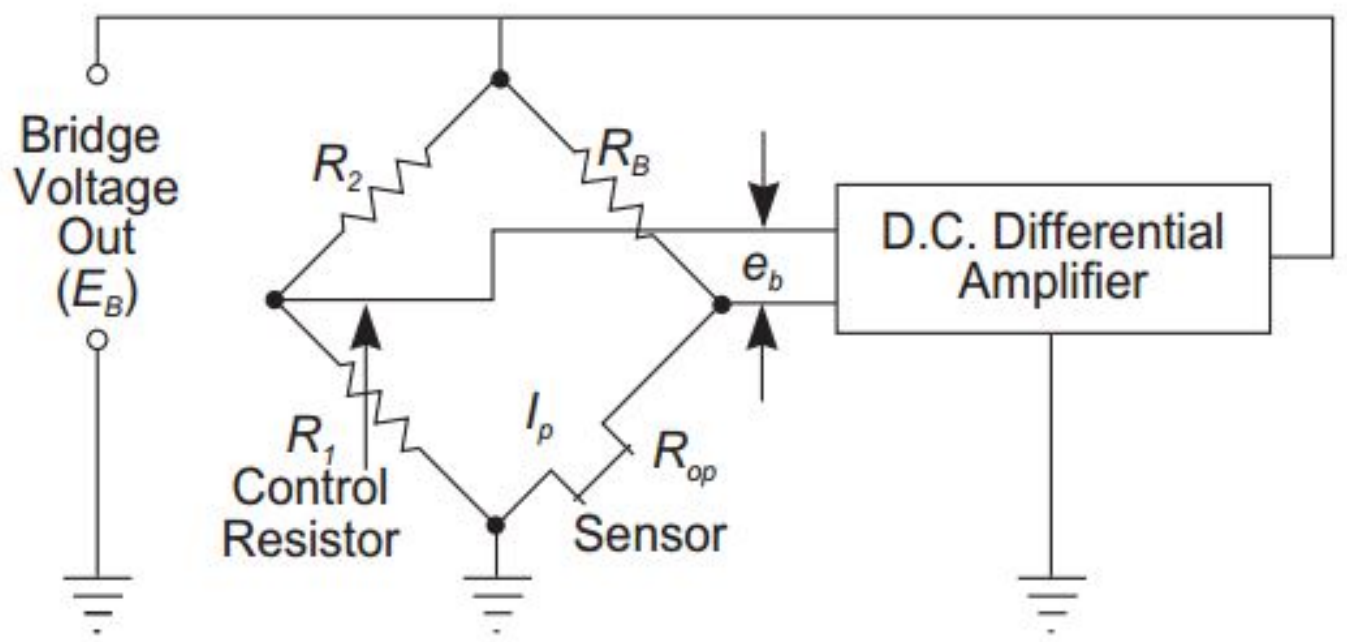

Figure 6.2: Bridge and amplifier circuit used in CTA systems to measure velocity [55]

The probe being used can only give one point of data in the cross-section. This could be considered acceptable in a general wind tunnel because in theory the flow is uniform. However, in this EWT, the flow is not uniform. A boundary layer is formed in the fetch, 
in which flow near the ceiling is quicker than near the floor. When qualifying a tunnel, the velocity profile in the entire cross section of the testing section is required.

The next design consideration is the method of accurately collecting velocity data in the test section. One way to obtain this data is to create a grid of anemometers that can simultaneously collect data. The first problem with the design is the number of channels that are required for data acquisition. Each probe will have to be within less than an inch of each other to understand the behavior of the flow in the test section. The lateral dimension of the test section is 48 inches so one row of anemometers will number more than 48 channels to collect data simultaneously.

Second, there will be a concern about the amount of blockage that will be created by an array of probes. The blockage may have an effect on all the probes in the array, and by extension, will give inaccurate readings of tunnel characteristics when empty.

Third, the cost of 48 separate probes and a data acquisition system, that can take 48 channels of data simultaneously, is not economical, costing tens of thousands of dollars. It is possible to collect more data by interlacing data collection so that channels will collect data by cycling through a different probe in a loop. This method will reduce the collection rate of the data and produce less accurate data. Using a grid of probes is not ideal for qualifying a EWT wind tunnel.

The next solution to consider is a single probe in which the position can be adjusted manually by the user to collect data. This method will solve the problem of the number of channels needed to collect data. Cost will be greatly reduced, and instead of hundreds of probes, only one is needed. The amount of blockage the probe will generate is greatly reduced. However, the extended amount of time that would be required to collect a full set of data points would be a drawback. The increased likelihood of temporally-induced data post processing required will also present a problem. Therefore, the design method could call for a single probe that the user can move around in the test section, but in a way that data can be taken at an increased rate. 
The repeatability of the position will create another problem to be solved. A human, without special equipment to relocate the probe, may not be able to replace a probe in the exact required position. The data taken from this new point will vary from data taken the first time because of the inaccurate location of the probe. A solution to this problem is to use a single probe on an automated platform. This platform will allow the user to repeat positions accurately and have the ability to take multiple data points quickly and efficiently. The cost will be greater than a single probe that is manually positioned, but much less then hundreds of probes. The use of a traversing mechanism is recommended for qualification of the EWT.

\subsubsection{Measuring Turbulence}

For the EWT, the hot film anemometers should to be used to measure the velocity profile of the flow, and they can also be used to find turbulence intensity. The flow velocity fluctuations can be measured with the probe and divided by the average flow velocity. There is no need for any additional probes or devices to measure the turbulence beyond the equipment for measuring the velocity profile.

\subsubsection{Interpreting Hot-Film Probe Signal}

A system that can acquire and interpret the outputs of probes is required. Many companies create these types of systems, such as, Dantec Dynamics and TSI. TSI's system the IFA 300 thermal anemometry system contains basic bridge circuits, amplifiers and signal conditioning devices which are required to operate the anemometer probes. The IFA 300 produces an analog voltage for each probe that goes through a digitizer. That signal is sampled by a data acquisition board mounted in a computer paired with software similar to TSI's ThermalPro. This type of software allows for data analysis and presentation of results. West Virginia University currently have two IFA 300 systems in its possession.

The required data acquisition hardware (DAQ) for the EWT's system does not need to 
be very extravagant for qualifications. A single digital channel is needed for one dimensional data sampling. The new VFDs can also be controlled by analog voltage inputs to the drives. Each VFD can be set individually by assigning it an address in the system and the speed changed through a single channel. A simple USB DAQ system such as National Instruments USB-6003 could be used. This system supports 13 channel digital I/O for probe data sampling, along with having analog output channels that can be used for VFD control.

It may also be desirable to have a DAQ system that is protected inside a computer case that is permanently paired with the wind tunnel. A PCI-E type card could be used and set up to control VFDs and other control systems. Like the USB type, the card does not need to be top of the line an example of such a card is the National Instruments model PCIe-6320. It has all the required channels for the system, while being cost effective.

\subsubsection{Calibration of Probes}

The system is not a simple plug and play apparatus that can output data without any calibration. To calibrate a hot film system, a known velocity of air must be measured by the hot film, and the corresponding analog voltage output is recorded at that corresponding point. A series of collection points and calibration curve (Figure 6.1) can be created.

A problem that is present when using CTA systems is contamination of the probe and altering the calibration curve. In an open wind tunnel, foreign particles (i.e. dust, pollen, and dirt) can be drawn into the tunnel. These particles can contaminate the HWA probe altering the voltage characteristics of the probe.

The probe can be fully recalibrated before each use to get accurate results. This however can be time consuming. Another method would be measuring the voltage at a single velocity and adjusting the entire calibration curve up or down to fit that point, since the calibration curve shape should be similar. This method is far less time consuming then having to recalibrate the probe before each use, and would be good for use when quick throughput of data runs is necessary. 
The final method that may be used would instead of using a CTA system for velocity measurements using a pitot-static probe to measure velocity, and a HWA for turbulence intensity measurements. Turbulence does not need to be measured at certain velocity, the variation in velocity is what is measured, and is relative to any velocity. Also, pitot-static probes are less vulnerable to contamination from particles entering the tunnel.

\subsubsection{Traverse System}

Given set points, the traversing mechanism can automatically move through the points collecting data and reducing time for data collection. These sorts of mechanisms can be either built using T-slots extrusions with stepper motors, or can be purchased off the shelf from an assorted number of vendors. An example T-slot extrusion traverse system, that uses stepper motors to adjust the position in both the vertical and horizontal direction, is modeled in Figure 6.3. This system would be attached to the floor and would be placed with a turntable located near the end of the fetch. A arm would be attached to the vertical extrusion that would have the probe holder in place. This arm would extend so that the probe would lineup with the center of the turntable. Ideally the system would also have a cover so the mechanism when not in use would not interfere with flow or any models placed in the testing chamber. A drawback of the example system is shed vortex-induced oscillations. The oscillation could cause sensor errors and inaccurate data collection. A way that may avoid these oscillation is to secure the other end of the arm to another structure that moves in sync with the bottom.

\subsubsection{Method of Qualification}

The goal of qualification is to find baseline conditions found in the EWT. This includes velocity profiles and turbulence data. This section will detail recommendations for the process of collecting and processing the data.

Baseline performance velocity and turbulence profiles should be found at multiple settings 


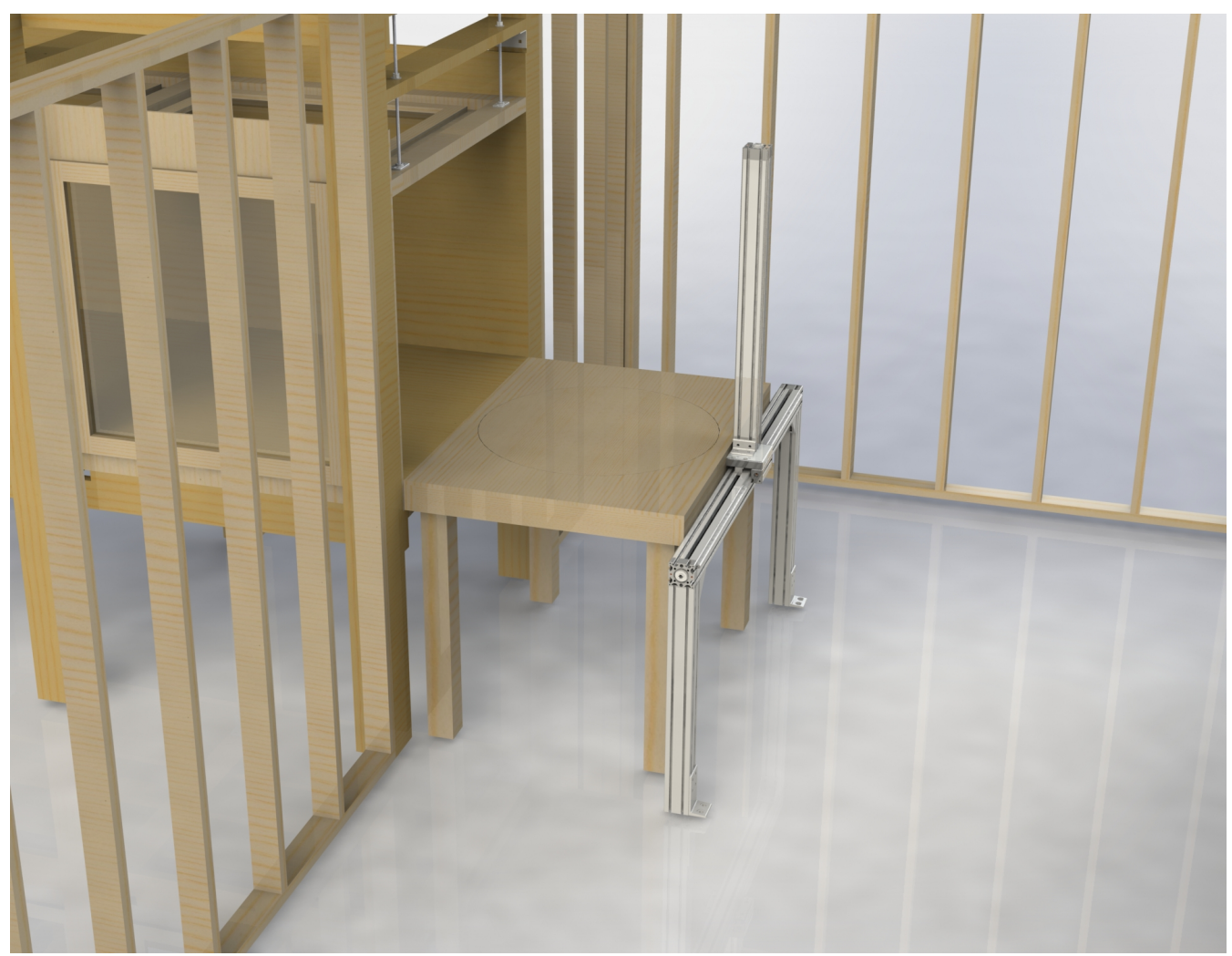

Figure 6.3: Example traverse system setup, the vertical arm can be removed when not in use

to give a baseline for users to use to create profiles they desire. Each collection ought to also investigate any problems with irregular flow in the tunnel's cross section. That data can be used to discuss ways to correct these irregularities. The settings that will be varied will be the motor speed and the percent IGV open to change the effective angle of attack on the fan blades, as shown in Table 6.1. Baseline performance of the IGV as reported by Buffalo Forge appears in Appendix D.

Table 6.1: Recommended settings used for qualification

\begin{tabular}{|c|c|c|}
\hline Setting & Motor Speed (RPM) & IGV Open (\%) \\
\hline 1 & 3500 & 100 \\
2 & 3500 & 50 \\
3 & 2675 & 100 \\
4 & 2675 & 50 \\
5 & 1750 & 100 \\
6 & 1750 & 50 \\
7 & 875 & 25 \\
\hline
\end{tabular}


Each setting tested should have a corresponding contour plot with velocity profile and turbulence intensity across the two dimensional cross-section measured at the center of the recommended turntable in the test section. These plots will be used to identify any kind of flow irregularities. Plotting the velocity at these seven recommended settings will illustrate the velocity profile over a large range of operating conditions. With the wide range of settings tested flow problems at any speed should be detected, and if needed can be corrected. Two plots will be reported for each direction. These plots with be filled with velocity and turbulence contour plots, so they will make any sorts of flow abnormalities apparent.

The velocity will be the average over a time interval. Using the points collected, the fluctuations can be measured and the standard deviation calculated to give the root mean square velocity. The root mean square can be then divided by the measured average velocity. The resulting answer will be the turbulence intensity at that collection point.

After any irregularities are found, a velocity profile at the center of the fetch from the floor to the ceiling will be reported. This information will provide baseline profiles for users of the tunnel to fine tune and to find the profile of the boundary layer they wish to test. Figure 6.4 is a typical example of the plot that shows the boundary layer profile at the center of the test section at one of the setting to be tested. 


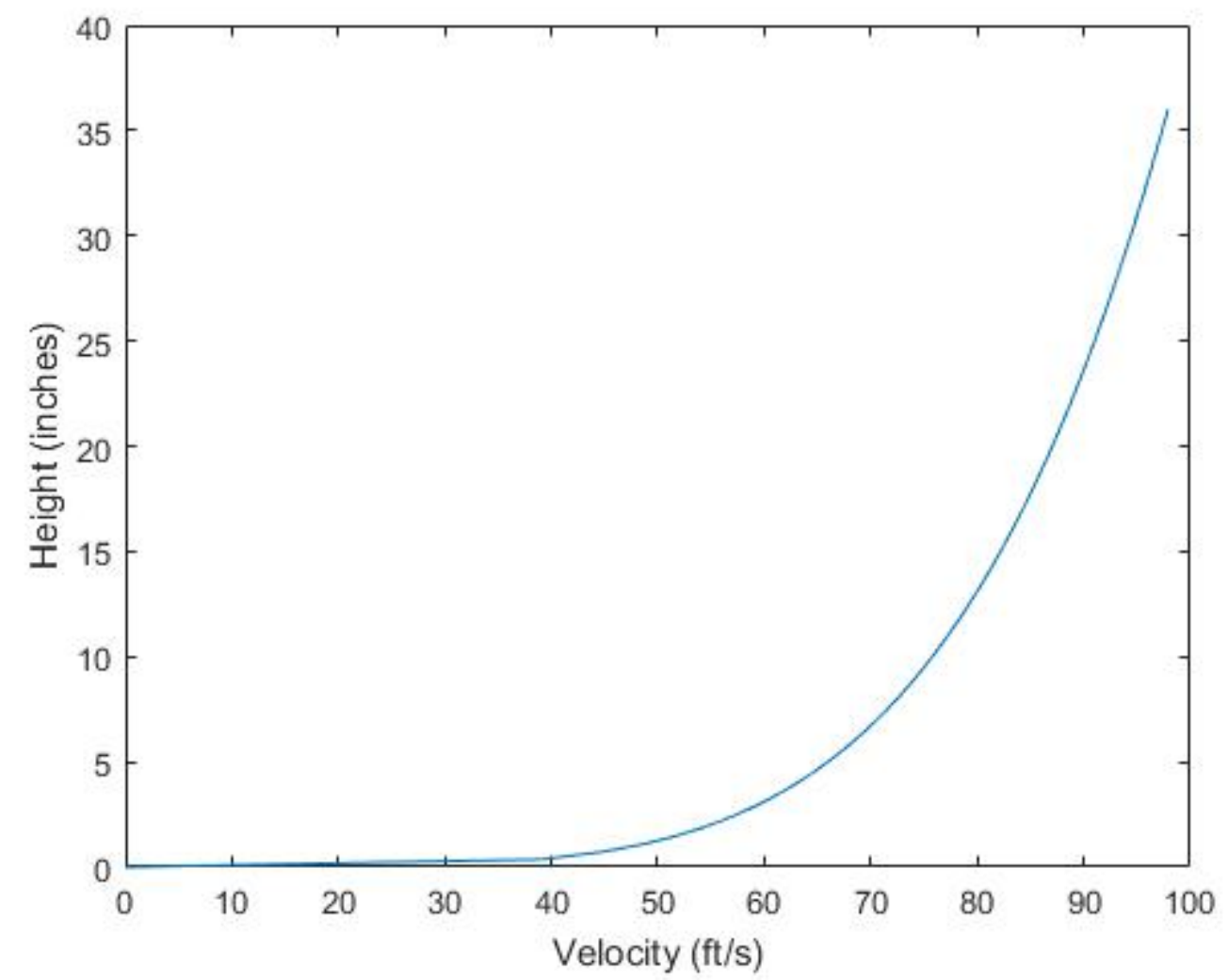

Figure 6.4: Example average center line profile reported for suburban setting 


\section{Chapter 7}

\section{Conclusions and Recommendations}

The original tunnel at Cornell had design inadequacies at the time of decommissioning. Using techniques outlined in this thesis, those problems areas have been addressed and redesigned to increase performance of the new Environmental Wind Tunnel installed at West Virginia University. The additions included the redesign of the contraction for better flow uniformity entering the fetch, as well as the lengthening of the diffuser for better performance and reduced chance of flow separation in the diffuser.

In addition to redesigning of certain sections of the original EWT, new features were added to the tunnel to increase the diversity of available testing conditions. The installation of variable frequency drives allowed for a more varied range of wind speeds. The windows installed allowed for better flow visualization techniques that included the ability to determine flow development within the fetch, or even to enable the fetch to be used as an ad hoc test section. Also, added to the new EWT are spires and roughness elements for increased boundary layer growth along the fetch. These elements are able to be removed and replaced

with different spire and roughness design via a removable floor. Depending on the design of the floor, the boundary layer will have different properties.

After redesign was completed, the EWT tunnel's theoretical performance was calculated and the results verified that the equipment will contain more than enough power for the 
EWT to perform up to expectations. The tunnel is calculated to surpass the desired $30 \mathrm{~m} / \mathrm{s}$, or about $70 \mathrm{mph}$ wind speed. This value matched the speed that the original tunnel was calculated to obtain. With the new additions, the performance has not been effected and can still work up to the required speeds.

\subsection{Future of EWT}

There are many ways to enhance the EWT from its original form that were not included due to lack of time or budgetary reasons. However, the EWT had windows installed throughout the fetch to allow for visual inspection of anything inside the fetch. The inclusion of these windows will allow for the future installation of flow visualization devices, from basic camera riggings to a particle image velocimetry system. A traversing system could be added to the EWT to allow for systems, such as, the PIV system to be easily moved along the fetch without having to refocus on a plane in the fetch each time.

A future consideration for the tunnel may include a heated floor, which will have an effect on the flow of the tunnel. Temperature has a direct correlation on the boundary layer profile by altering the shear stress. This change in shear stress exhibited can affect the velocity profile and BL height. The temperature would also induce buoyancy of the flow. This could come in handy when doing studies on areas where surface temperature is higher than normal, such as deserts and tropical regions. With the installation of a temperature controlled floor, the users will have an additional source of customization for their research.

Finally, a cold air intake may also be a future addition to the EWT. The climate in Morgantown in the winter can reach subfreezing temperatures. A cold air intake from outside the building will allow for icing studies to be conducted inside the tunnel during the winter months.

These recommendations are only the current considerations for upgrades. New developments in flow measurement and visualization are researched and developed continuously. 
The current design should be able to accommodate a diverse range of new technologies. Any of these techniques could be included into the EWT wind tunnel for more flexibility for researchers using the EWT. 


\section{Bibliography}

[1] R. Ribando, "The cornell environmental wind tunnel," M.S. Thesis, Cornell University, 1974.

[2] T. Tibbe, "Effect of open-jet shear layers on aeroacoustic wind tunnel measurements," National Aerospace Laboratory NLR, Technical NLR-TR-2010-138, 2010.

[3] T. Whitlow and L. Mudrak, "Effect of pot lip shape on soil surface evaporative losses," Journal of Environmental Horticulture, vol. 5, 1988.

[4] T. Morreale, P. Gergeley, and M. Grigoriu, "Wind-tunnel study of wind loading on a compliant offshore platform," Cornell University, Technical NBS-GCR-84-465, 1984.

[5] L. Prandtl, "ber flssigkeitsbewegung bei sehr kleiner reibung (motion of fluids with very little viscosity)," in Verhandlungen des III Internationalen Mathematiker-Kongresses, B. Teubner, Ed., Heidelberg, 1904, pp. 484-491.

[6] R. Stull, An introduction to boundary layer meteorology. Springer Science and Business Media, 1988.

[7] Z. Sorbjan, Structure of the atmospheric boundary layer. Boston: Kluwer Academic Publishers, 1989.

[8] J. Garratt, The atmospheric boundary layer. Cambridge University Press, 1994.

[9] C. Kaimal and J. Finnigan, Atmospheric boundary layer flows: Their structure and measurement. Oxford University Press, 1994. 
[10] V. Ekman, "On the influence of the earth's rotation on ocean currents," Arkiv for matematik, astronomi och fysik, vol. 2, no. 11, 1905.

[11] O. Sutton, Micrometeorology: A study of physical processes in the lowest layers of the earth's atmosphere. McGraw-Hill, 1953.

[12] E. Simiu and R. Scalan, Winds effects on structures: Fundamentals and applications to design. Wiley, 1996.

[13] T. Wei and W. W. Willmarth, "Reynolds-number effects on the structure of a turbulent channel flow," Journal of Fluid Mechanics, pp. 57-95, 1989.

[14] S. Pope, Turbulent flows. Cambridge University Press, 2000.

[15] D. Coles, "The law of the wake in the turbulent boundary layer," Journal of Fluid Mechanics, pp. 191-226, 1956.

[16] U. Hogstorm, "Review of some basic characteristics of the atmospheric surface layer," Boundary-Layer Meteorology, pp. 215-246, 1996.

[17] J. Wieringa, "Updating the davenport roughness classification," Journal of Wind Engineering and Industrial Aerodynamics, vol. 41, pp. 357-368, 1992.

[18] A. Obukhov, "Turbulence in an atmosphere with a non-uniform temperature," BoundaryLayer Meteorology, vol. 2, pp. 7-29, 1.

[19] A. Monin and A. Obukhov, "Basic laws of turbulent mixing in the surface layer of the atmosphere," Tr. Akad. Nauk SSSR Geophiz., vol. 24, pp. 163-187, 1954.

[20] A. Davenport, "The relationship of wind structure to wind loading," in Wind Effects on Buildings and Structures, Teddington, England, 1963.

[21] G. Taylor, "The spectrum of turbulence," in Proceeding of the Royal Society, vol. 164, 1938, pp. 476-491. 
[22] A. Kolmogorov, "The local structure of turbulence in incompressible viscous fluid for very large reynolds numbers," in Proceedings of the USSR Academy of Sciences, vol. 30, 1941.

[23] J. Counihan, "Adiabatic atmospheric boundary layers: A review and analysis of data from the period 1880-1972," Atmospheric Environment, vol. 9, pp. 871-905, 101975.

[24] J. Barlow, W. Rae, and A. Pope, Low-speed wind tunnel testing. John Wiley and Sons, 1999.

[25] J. Cermak, "Wind-tunnel testing of structures," Journal of the Engineering Mechanics Division, vol. 103, no. 6, pp. 1125-1140, 1977.

[26] J. E. Cermak, "Wind tunnel design for physical modeling of atmospheric boundary layers," American Society of Civil Engineers, Engineering Mechanics Division, Journal, vol. 107, pp. 623-642, 1981.

[27] E. Plate and J. Cermak, "Micrometeorological wind tunnel facility: Description and characteristics," Colorado State University, Tech. Rep. CER63EJP-JEC9, 1963.

[28] J. Counihan, "An improved method of simulating an atmospheric boundary layer in a wind tunnel," Atmospheric Environment, vol. 3, pp. 201-214, 21969.

[29] J. Counihan, "Simulation of an adiabatic urban boundary layer in the wind tunnel," Atmospheric Environment, vol. 7, pp. 673-689, 71973.

[30] H. Irwin, "The design of spires for wind simulation," Journal of Wind Engineering and Industrial Aerodynamics, vol. 7, no. 3, pp. 361-366, 1981.

[31] K. Rasmussen, "Laboratory studies of aeolian sediment transport processes on planetary surfaces," Geomorphology, vol. 244, pp. 74-94, 2015.

[32] H. Cheng, J. He, X. Zou, J Li, C. Liu, B. Liu, C. Zhang, Y. Wu, and L. Kang, "Characteristics of particle size for creeping and saltating sand grains in aeolian transport," Sedimentology, vol. 62, no. 5, pp. 1497-1577, 2015. 
[33] J Hodgkinson, Q. Shan, and R. Pride, "Detection of a simulated gas leak in a wind tunnel," Measurement Science and Technology, vol. 17, no. 6, pp. 1586-1593, 2006.

[34] F. Pascheke, J. Barlow, and A. Robins, "Wind-tunnel modeling of dispersion from a scalar area source in urban-like roughness.," Boundary-Layer Meteorology, vol. 126, pp. 103-124, 2008.

[35] A. Vieira de Melo, J. Santos, I. Mavroidis, and N. Reis, "Modelling of odour dispersion around a pig farm building complex using aermod and calpuff. comparison with wind tunnel results," Building and Environment, vol. 56, 2012.

[36] J. Yi and Q. Li, "Wind tunnel and full-scale study of wind effects on a super-tall building," Journal of Fluids and Structures, vol. 58, pp. 236-253, 2015.

[37] S. Liang, L. Zou, D. Wang, and H. Cao, "Investigation on wind tunnel tests of a full aeroelastic model of electrical transmission tower-line system," Engineering Structures, vol. 85, pp. 63-72, 2015.

[38] S. Stenabaugh, Y. Iida, and G. Kopp, "Wind loads on photovoltaic arrays mounted parallel to sloped roofs on low-rise buildings," Journal of Wind Engineering and Industrial Aerodynamics, vol. 139, pp. 16-26, 2015.

[39] K. Blackman, L. Perret, and E. Savory, "Effect of upstream flow regime on street canyon flow mean turbulence statistics," Environmental Fluid Mechanics, vol. 15, no. 4, pp. 823-849, 2014.

[40] P. Hancock and S. Zhang, "A wind-tunnel simulation of the wake of a large wind turbine in a weakly unstable boundary layer," Boundary-Layer Meteorology, vol. 156, no. 3, pp. 395-413, 2015.

[41] R. Mehta and P. Bradshaw, "Design rules for small low speed wind tunnels," The Aeronautical Journal of the Royal Aeronautical Society, pp. 443-449, 1979.

[42] J. Bell and R. Mehta, "Contraction design for small low-speed wind tunnels," Stanford University, Tech. Rep. JIAA TR-84, 1988. 
[43] R. Mehta, "Aspects of the design and performance of blower tunnel components," $\mathrm{PhD}$ thesis, Imperial College, 1978.

[44] M Hernandez, A. Lopez, A. Jarzabek, J. Perales, Y. Wu, and X. S., "Wind tunnel designs and their diverse engineering applications," in. Intech, 2013, ch. Design Methodology for a Quick and Low-Cost Wind Tunnel.

[45] L. Gartshore, "A relationship between roughness geometry and velocity profile shape," National Research Council of Canada, NAE Report LTR-LA-140, 1973.

[46] R. Wooding, E. Bradley, and J. Marshall, "Drag due to regular arrays of roughness of varying geometry," Boundary Layer Meteorology, vol. 5, pp. 285-308, 31973.

[47] C. Carrano, "Investigation and assessment of the environmental wind tunnel facility," Cornell University.

[48] G. Abramovich, The theory of turbulent jets, L. Schindel, Ed. MIT Press, 1963.

[49] D. Green and R. Perry, Perry's chemical engineers' handbook, 8th. McGraw-Hill Education, 2007.

[50] D. Shepherd, Elements of fluid mechanics. Harcourt, 1965.

[51] F. Wattendorf, "Factors influencing the energy ratio of return flow wind tunnels," in Fifth International Congress for Applied Mechanics, Cambridge, 1939.

[52] P. Gousseau, "The tu/e atmospheric boundary layer wind tunnel - computation of the pressure losses," PhD thesis, Eindhoven University of Technology, 2010.

[53] W. Eckert, J. Jope, and K. Mort, "Aerodynamic design guidelines and computer program for estimation of subsonic wind tunnel performance," National Aeronautics and Space Administration, Washington, Tech. Rep. NASA TN D-8243, 1976.

[54] C. Millikan and A. Kline, "The effect of turbulence:an investigation of maximum lift coefficient and turbulence in wind tunnels and in flight," Aircraft Eng., vol. 5, pp. 169174, 81933. 
[55] TSI, Tsi thermal anemometry probes catalog, 2012.

[56] (). Moody chart, [Online]. Available: http://www .dept . aoe.vt.edu/ jschetz / fluidnature/unit07/unit7f.html. 
Appendix A:

Ceiling Displacement for Zero Pressure Gradient

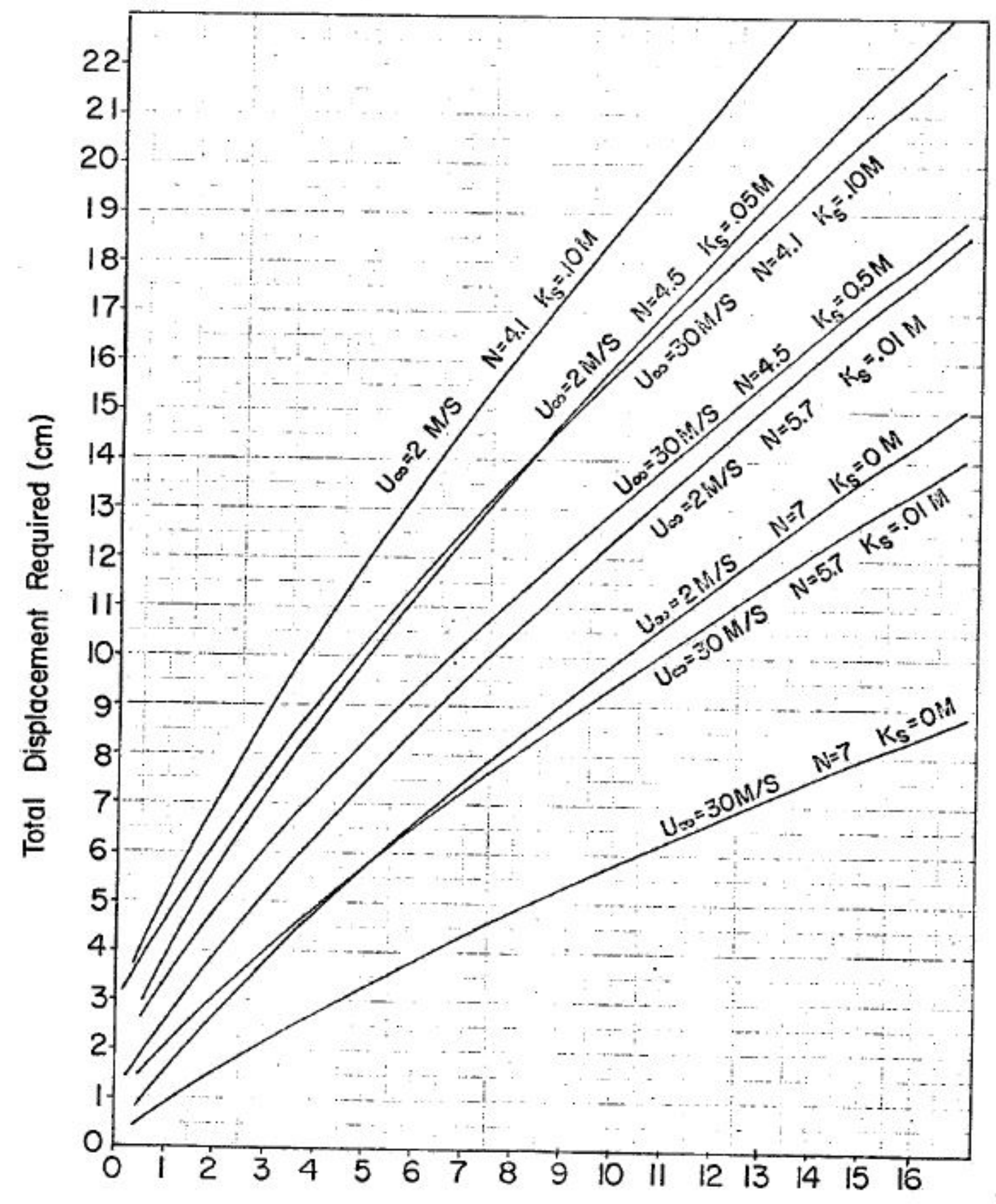

.. $\quad-\quad x \rightarrow$ meters 
Appendix B: Example Ceiling Displacement

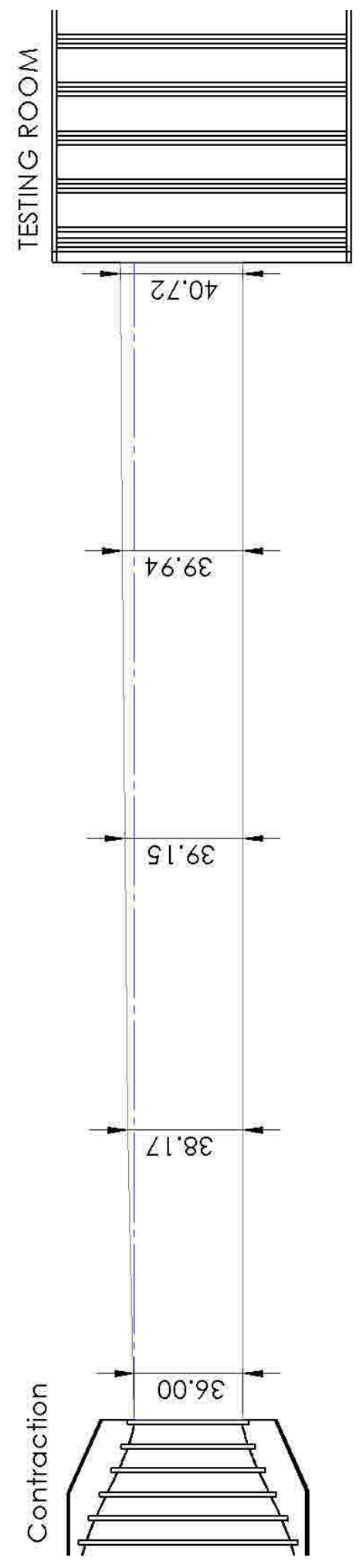




\section{Appendix C: Moody Chart}

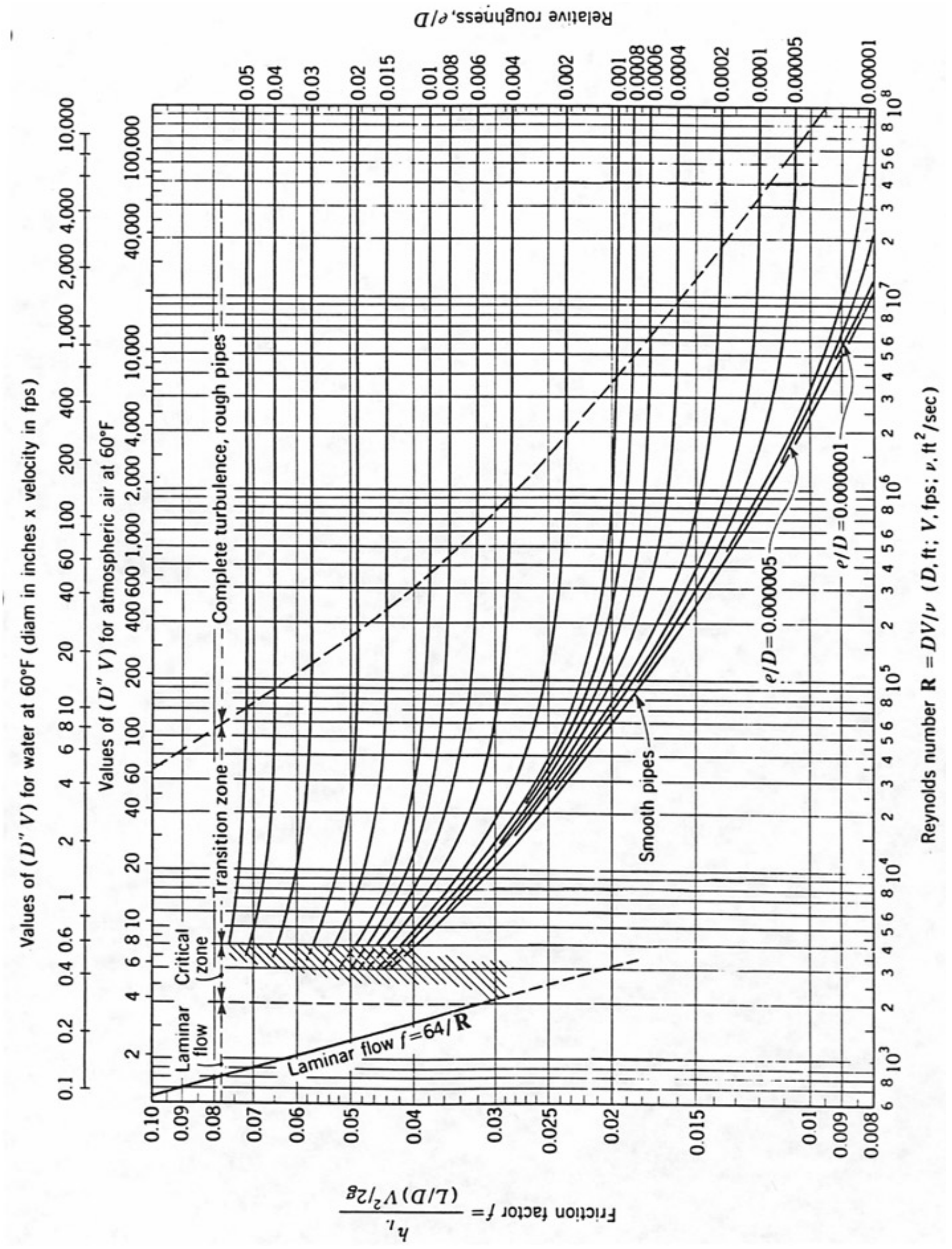

Figure 1: Moody Chart [56] 


\section{Appendix D: Buffalo Forge Fan Performance Curves}

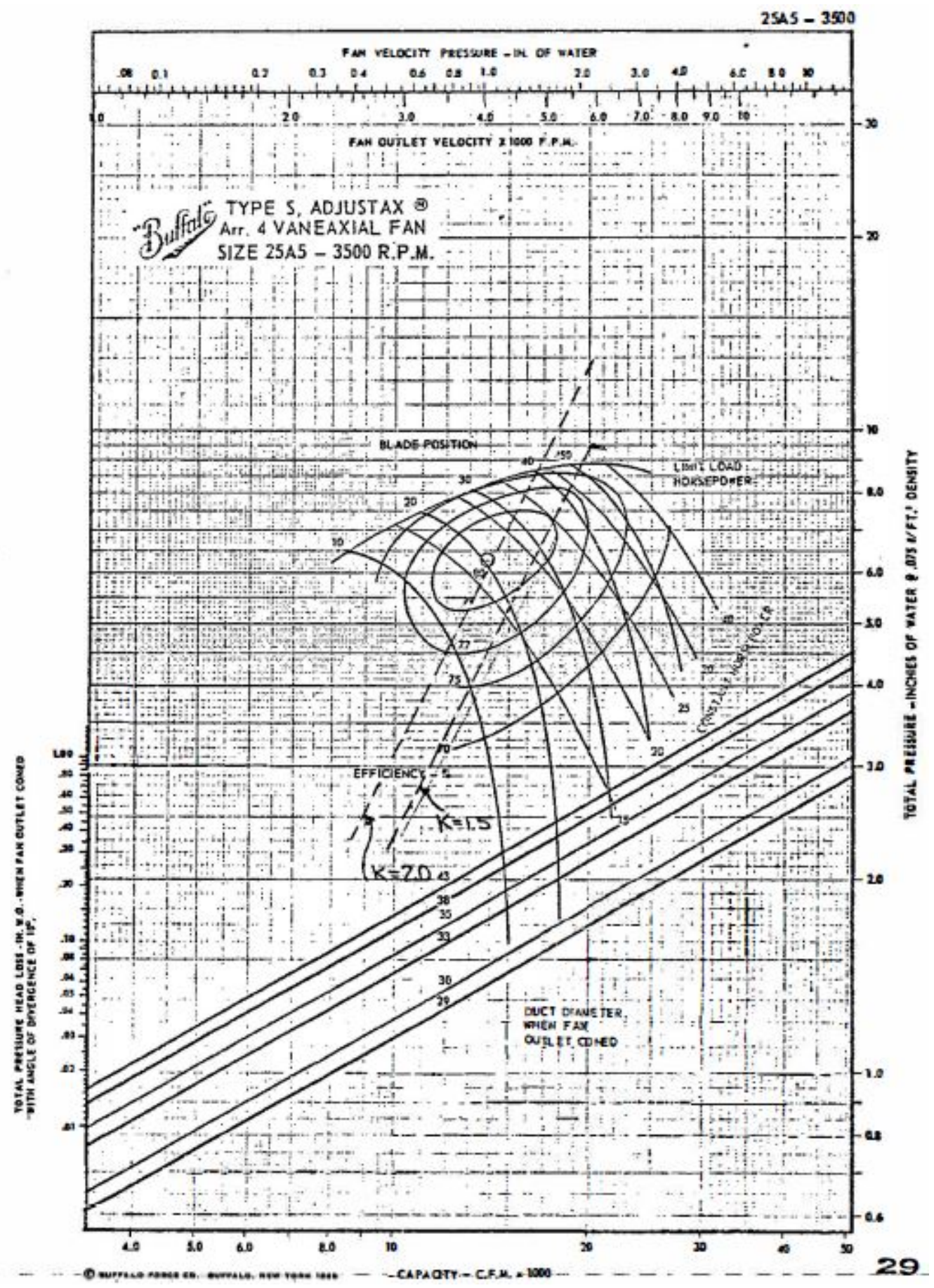




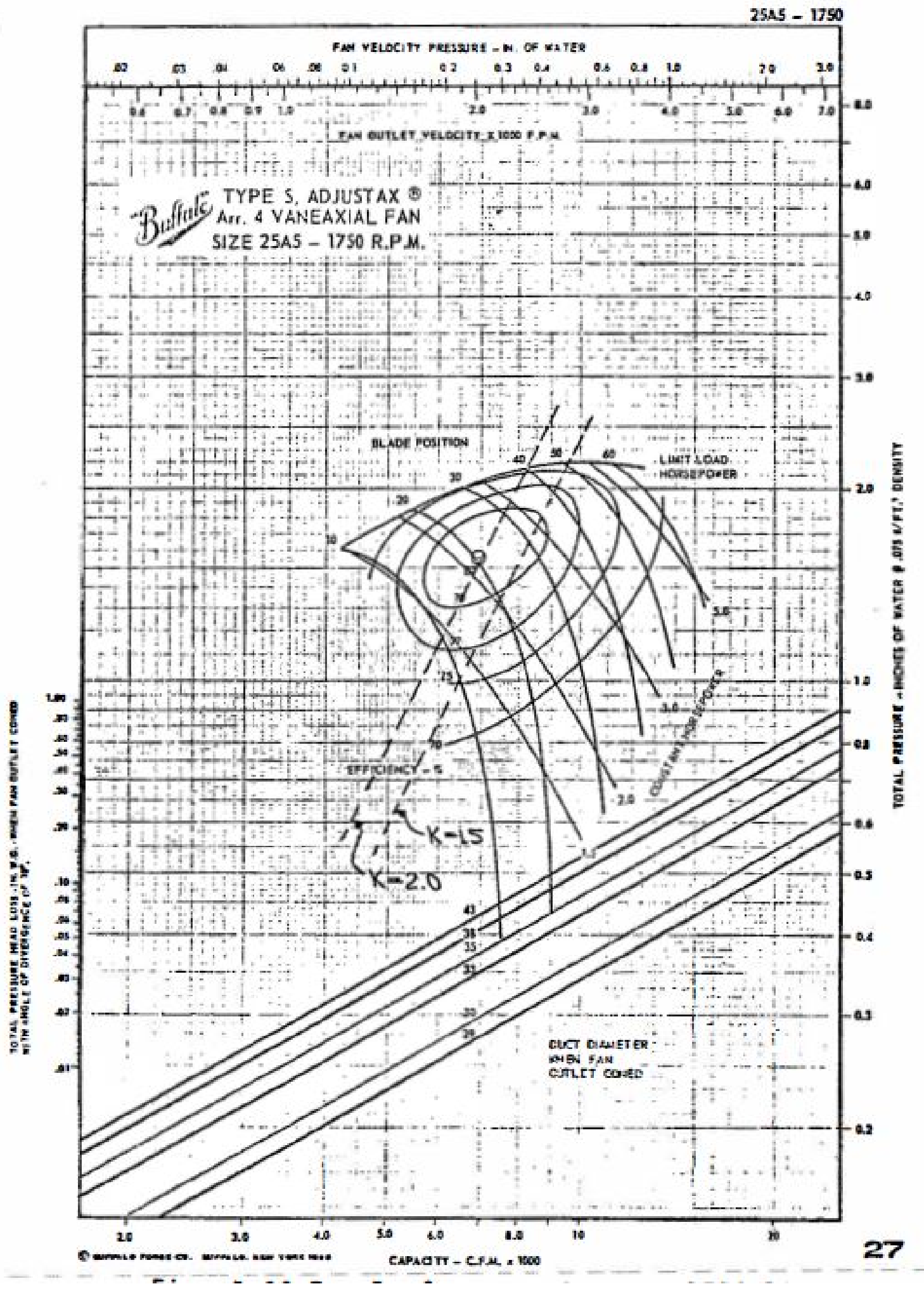




\section{Appendix E: IGV Data Reported by Buffalo Forge}

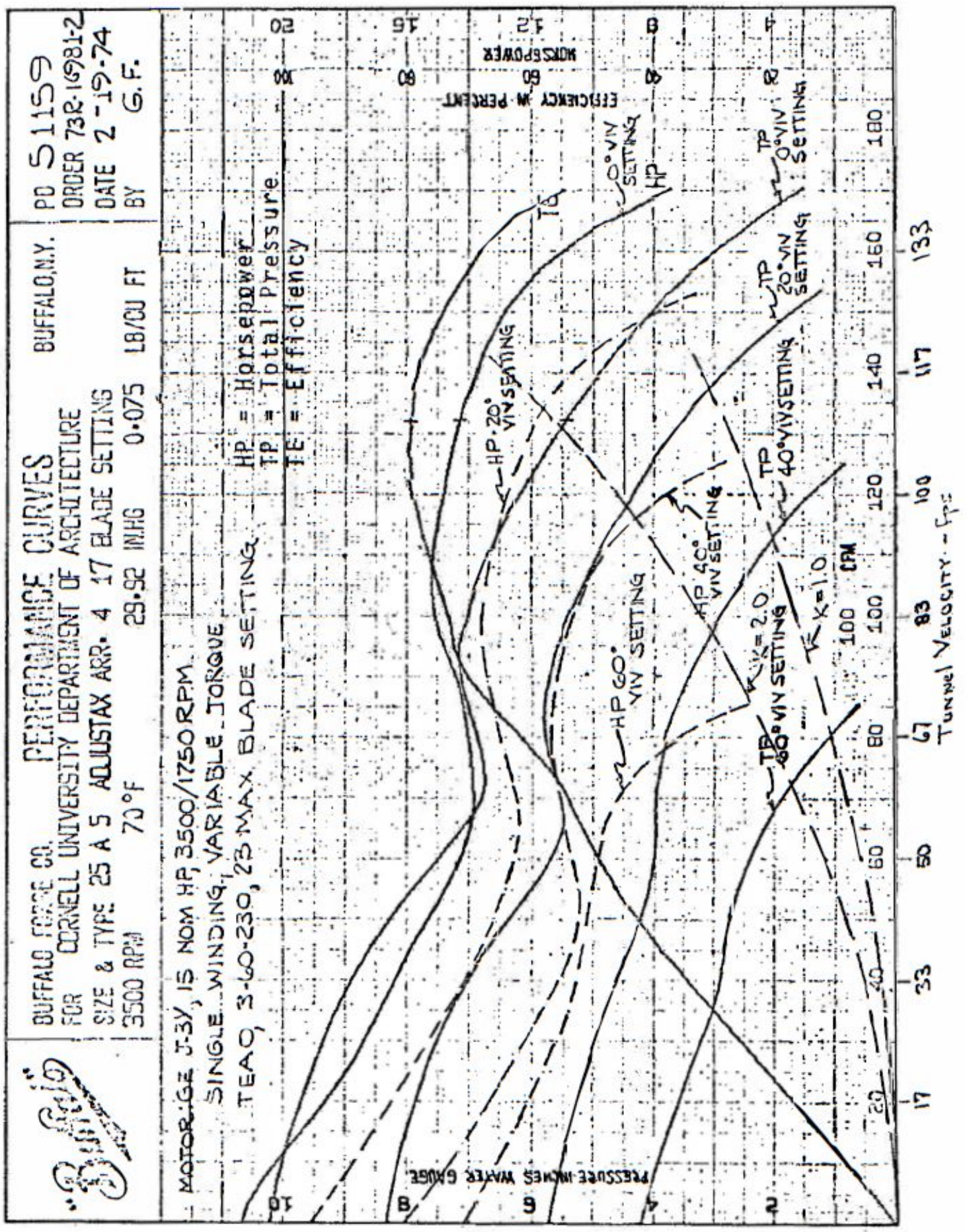




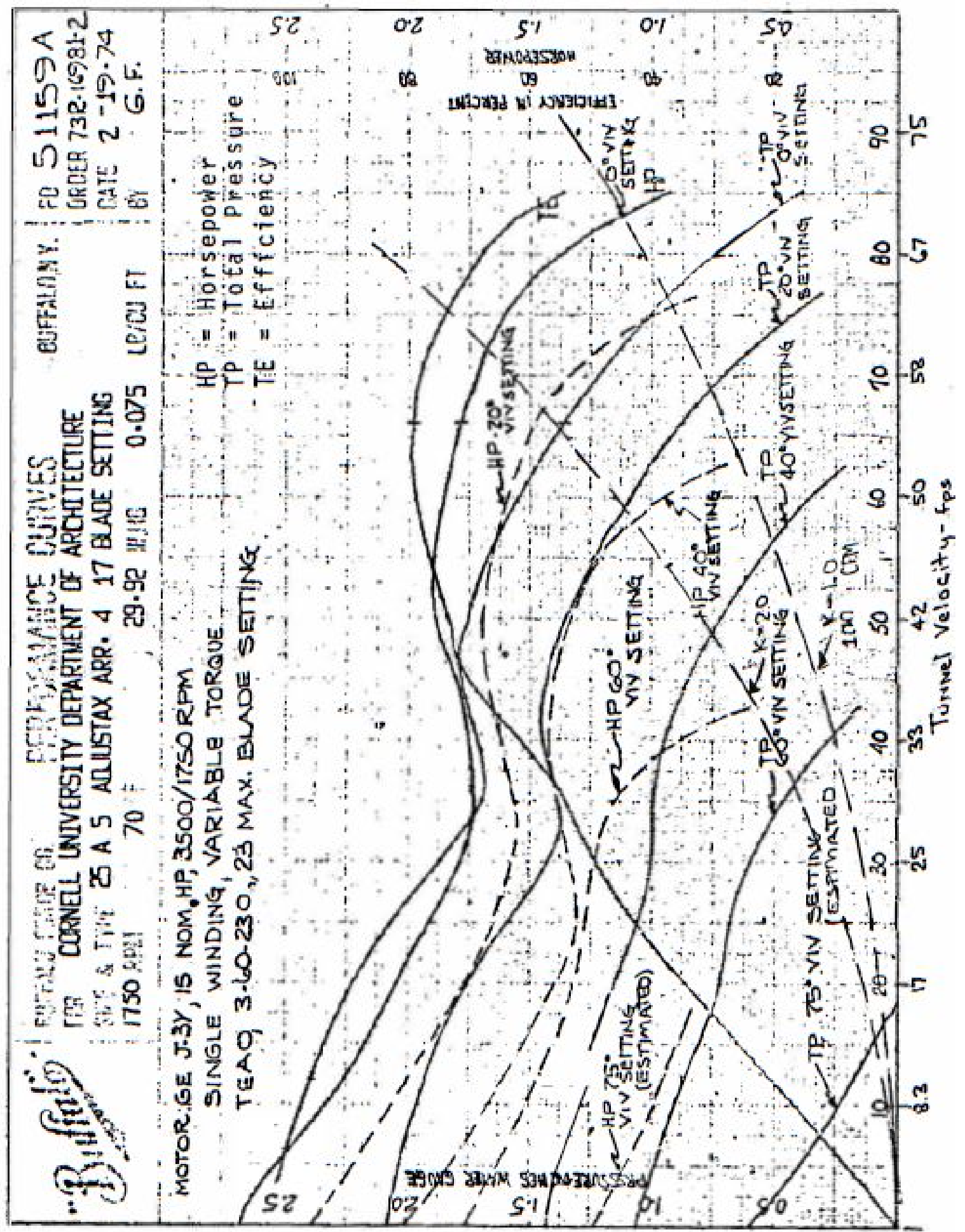

